Portland State University

PDXScholar

Summer 2012

\title{
Narrative Processes in Urban Planning: A Case Study of Swamp Gravy in Colquitt, Georgia
}

Ronald David Pate

Portland State University

Follow this and additional works at: https://pdxscholar.library.pdx.edu/open_access_etds

Part of the Civic and Community Engagement Commons, Urban, Community and Regional Planning Commons, and the Urban Studies and Planning Commons Let us know how access to this document benefits you.

\section{Recommended Citation}

Pate, Ronald David, "Narrative Processes in Urban Planning: A Case Study of Swamp Gravy in Colquitt, Georgia" (2012). Dissertations and Theses. Paper 469.

https://doi.org/10.15760/etd.469

This Dissertation is brought to you for free and open access. It has been accepted for inclusion in Dissertations and Theses by an authorized administrator of PDXScholar. Please contact us if we can make this document more accessible: pdxscholar@pdx.edu. 


\begin{abstract}
Narrative Processes in Urban Planning:
A Case Study of Swamp Gravy in Colquitt, Georgia
\end{abstract}

by

Ronald David Pate

A dissertation submitted in partial fulfillment of the requirements for the degree of

Doctor of Philosophy

in

Urban Studies

\author{
Dissertation Committee: \\ Carl Abbott, Chair \\ Sy Adler \\ Katrine Barber \\ Connie P. Ozawa \\ Richard Wattenberg \\ Christopher Zinn
}

Portland State University

(C)2012 


\begin{abstract}
In 1990 many in Colquitt, Georgia considered themselves to be a dying town due to the loss of jobs and outmigration that occurred when labor intensive farming transitioned to the machine. In response citizens brought in a theater director from Chicago who helped them launch a performance series of inclusive stories that were acted by local volunteers. The resulting series called Swamp Gravy has run from 1992 to present (2012), and has led to purported claims of community revitalization. The purpose of this study was to discover what this ongoing narrative community engagement meant to the people of Colquitt in regards to: community experiences that produced new relationships (including those between Blacks and Whites); personal empowerment; the coproduction of an emerging and diverse community identity; and institutional and economic development. Methods for this case study included narrative interviews of participants, attendees and local citizens, as well as observation of the town and the performances, and document analysis.

Many participant volunteers and attendees became Swamp Gravy enthusiasts, and describe their experiences as coming out into a meaningful experience of community, which included forming relationships with diverse others (including those of a different race). The enthusiasts speak of growing into
\end{abstract}


larger community responsibilities with others for the common good, and feel that ongoing and inclusive storytelling is very important to coproducing a diverse heritage that informs the future of their city. Other attendees (predominantly the business community) describe the benefits of Swamp Gravy as instrumental to having given the town recognition (identity) as an entertaining tourist attraction that exposed individual talent, boosted individual confidence, and enhanced social connectivity. Others in Colquitt were indifferent or resistive to the coming out that the performances invite. Most everyone recognizes that Swamp Gravy has attracted outside tourists which has boosted economic development, occasioned the renovation of downtown Colquitt square and the formation of institutions to continue to attract and accommodate visitors from afar. This case is theorized in terms of the emerging communicative turn in planning that juxtaposes the planner as mediator or facilitator, and stakeholders as co-producers. The findings in this case study support that the Swamp Gravy form of narrative process has some potential for guiding stakeholders to a just diversity in cities, neighborhoods and towns, and as such should be studied further. Urban planning in situations of urban renewal may be one place where utilizing this form of meaningful engagement could lead to discovery of new identities, which may both inform and motivate a just plan to be coproduced. 


\section{ACKNOWLEDGEMENTS}

There are dozens of people to whom I am indebted to for their time, contributions, and support of this research case study. I am deeply grateful to Joy Jinks, CMAC and the many citizens of Colquitt who accommodated this study in so many ways. I am grateful to Richard Geer and CPI for making themselves available, including their invitations to observe their work in other places. I have benefited greatly from the input and guidance of my dissertation chair, Dr. Carl Abbott, as well as Dr. Charles Heying, Dr. Connie Ozawa, Dr. Sy Adler, and my distinguished committee members. I am appreciative of the conversations that I have had about this case study with Dr. James Throgmorton and Dr. Leonie Sandercock - both inspirations to development of narrative processes in urban planning. I owe much to fellow student Jane Waddel, who was an encouraging sounding board throughout the research process.

To my wife Mary, I am most grateful for the support and encouragement that was instrumental in helping keep me moving forward on this project to completion. And lastly, to my father Robert M. Pate, who lived in endless pursuit of deliberation across boundaries of interests, I owe most of what has motivated me to study the potential for narrative processes to discover what is good for a diverse set of stakeholders. 


\section{TABLE OF CONTENTS}

ABSTRACT

ACKNOWLEDGEMENTS iii

LIST OF TABLES vi

LIST OF FIGURES vii

PREFACE viii

CHAPTER 1: COLQUITT, GEORGIA AND SWAMP GRAVY 1

Map 4

Colquitt-Miller Arts Council (CMAC) 10

Community Performance: Theater of the People,

By the People and For the People 15

CHAPTER 2: NARRATIVE PROCESSES IN URBAN PLANNING 21

The Narrative Turn in the Social Sciences 33

The Narrative Path to Active Communities 38

Story and Critical Race Theory 43

Communicative Agency and Storytelling in Community 44

Common Challenges to Narrative Theory and Praxis 46

CHAPTER 3: METHODS 50

Data Collection 51

CHAPTER 4: COMMUNITY PERFORMANCE: PROCESS \& PRAXIS 56

Historical Parallelism: Beyond Confrontation 60

Proleptic Stories: Playing Forward Lessons for Today 63

Community Storytelling as Responsive Self-Regulation 67

The Holographic Story 69

Multiple Stories Equals Multiple Perspectives $\quad 71$

Activating a Community of Communicative Agents 73

Community: Performance and Mimicry 76

Gathering Stories and Co-creating the Plays $\quad 80$

The Ebb and Flow of Community Buy-in 93

Designing a Theater with Community in Mind 111

$\begin{array}{ll}\text { Collaborative Place Making } & 119\end{array}$

Experiencing Cotton Hall 125

Swamp Gravy's Sacred Structures 130 
CHAPTER 5: BEING A PERSON IN COMMUNITY 138

Community as Experience 138

Community Experience Tracks 143

Swamp Gravy and Race: Mixing It All Up 179

Empowerment: Can Do Spirit 197

Empowerment: Confidence 200

Empowerment: Communicative Agency 203

Empowerment: Political 212

Empowerment: Making Connections 216

CHAPTER 6: BUILDING ON SUCCESS 225

Identity 225

Community and Economics 235

CHAPTER 7: CONCLUSION 256

Findings 258

Recommendations for Future Research 286

REFERENCES 288 


\section{LIST OF TABLES}

Table $1 \quad$ US Census Bureau, 2010 Census Data 8

Table $2 \quad$ Estimated Economic Impact of Swamp Gravy 251 


\section{LIST OF FIGURES}

Figure 1 Map Colquitt, Georgia 4

$\begin{array}{lll}\text { Figure } 2 & \text { Peace Mural } & 106\end{array}$

Figure 3 Cotton Hall Home Base 114

$\begin{array}{lll}\text { Figure } 4 \quad \text { Cotton Hall Early Sketch } & 115\end{array}$

Figure 5 Veronica Haire 154

Figure $6 \quad$ Volunteer Fire Department 169

$\begin{array}{lll}\text { Figure } 7 & 169\end{array}$

Figure $8 \quad$ CMAC Circle of Services $\quad 237$

Figure 9 Saturday Morning on the Square Mural 241

Figure $10 \quad$ Spirit of All Farmers Mural 243

$\begin{array}{lll}\text { Figure } 11 & \text { Sound Stage } & 246\end{array}$

Figure 12 CMAC Income Pie Chart 248 


\section{NARRATIVE PROCESSES IN URBAN PLANNING: A CASE STUDY OF SWAMP GRAVY IN COLQUITT, GEORGIA}

\section{Preface}

There are many who fail to recognize the potential value of an urban planning process such as community storytelling. The development balance in this country, especially in the past thirty years has tipped in further favor of a more hierarchical process -- from an advancing trickle-down economics, to the financial advantages given to business interests. Neo-liberal economic policies value and trust the controlling interests of the business elite when it comes to charting a successful future for everyone. Recent research on megaprojects has demonstrated that often, planning processes pose as a process of technical and economic engagement while avoiding the deeper story, which allows the economic rationalizations of development actors to marginalize the narratives of other stakeholders. It is not surprising that the consequences benefit by plotted design the narrow agendas of the economic actors, while commonly proving devastating to others (Flyvbjerg 2004).

Over the past fifteen years there have been a number of planning theorists who have suggested that the business of the planner is to listen to all the stories of the stakeholders (Forester 2001; Sandercock 2003b; Throgmorton 2003b; 
Mandelbaum 2003; Healey 1992). If narrative processes in urban planning can produce better plans in terms of being socially just, economically viable, and environmentally sustainable, then it is important that planners acquire competency at understanding and facilitating a process of listening to, telling, and responding to stories about what has been (via personal stories), in order to inform and guide what could be regarding a given planning situation.

Without meaningful communication storyteller to storyteller, the planning table can become a battleground where the agendas of seemingly rational development actors clash with what is often cast as the emotional outcries of marginalized stakeholders. In this scenario, the common sense of progress might seem to be on the side of what is constructed as the rational plan that is provided by development actors. However, the rational frame can be misleading and thereby bias the planning process about what direction leads to a progress that includes the common good of all stakeholders. It is thus important to give adequate consideration to understanding and developing alternative planning approaches such as narrative processes. However, one problem is that without active and dialogical storytellers in communities, there can be no significant narrative engagement that might inform and enable the co-production of plans for communities that are meaningful and thus more livable for all. Activating 
community storytellers is necessary if narrative processes are going to advance as a viable planning option.

In an attempt to address conditions of decline and in order to celebrate their heritage, citizens in the city of Colquitt, Georgia decided to gather their stories from all racial and socio-economic representations in their town for production in a community performance called, Swamp Gravy. The leader of the storytelling charge was Joy Jinks, a local social worker along with the Colquitt Miller County Arts Council (CMAC). Jinks' concern was that her town had low self esteem, which she felt was speeding up outmigration and hurting the town's chances of attracting outside business interests. She believed that discovering and staging the heritage of Colquitt would restore community pride. In 1992 Jinks along with her allies at CMAC brought in an experienced producer from Chicago who helped craft a community performance from their collected stories. Many now point to the ongoing storytelling event that began in 1992, Swamp Gravy, as being the catalyst that stimulated various forms of new life in this small rural town. The purpose of this research project is to discover and analyze the story that the people of Colquitt have to tell about these storytelling events that have taken place in Colquitt, Georgia since 1992. 
The central question in this research is to find out from the performers as well as general citizens: What does Swamp Gravy mean to the community of Colquitt, Georgia? Five sub-questions will be utilized in answering the primary research question:

1. Did Swamp Gravy change people's perceptions about other persons, including persons of a differing race from their own?

2. $\quad$ Did the Swamp Gravy plays make people feel empowered?

3. What effects on the identity of Colquitt did Swamp Gravy create?

4. What community serving institutions were started as a result of $\underline{\text { Swamp Gravy? }}$

5. $\quad$ And, what are the perceptions about how Swamp Gravy enhanced the economic growth in the community of Colquitt, GA?

It has been twenty years since the initial one-year production run of Swamp Gravy came to an end. However, the community performances have continued on, thereby providing a significant window through which to view the ongoing results of the community performance and its narrative processes. By listening to the personal stories that people tell about the Swamp Gravy plays from 1992 to 2012, critical insights might be gained that further support storytelling as a community activating process which can produce a number of 
results, including: building a sense of community; reconciling deep differences that exist between differing races; empowering persons to take on responsibilities in their community; and producing economic and institutional growth. Thus, listening to the citizens of Colquitt tell their stories about this storytelling event could help further advance storytelling processes as a viable process for planning and development.

In Chapter 1 this study provides an historical overview of Colquitt that describes the conditions of decline that existed at the time of the meeting between theater director Richard Geer and social worker Joy Jinks in 1991. The historical context of Colquitt that is common in the rural South was primarily the story of labor intensive farming being overtaken by industrial agriculture methods, which results in concentrating wealth to both larger and fewer farmowners, which at the same time significantly decreases the demand for human labor. Chapter 2 provides the various theoretical considerations in the study that pertain to: narrative processes in urban planning; the narrative turn in the social sciences; activating community in the small town; critical race theory and stories; responsive storytelling as communicative agency; and potential challenges to narrative theory and praxis. In keeping with the case of Swamp Gravy, Chapter 3 describes the narrative form of methodology that was used to carry out this 
study. Understanding what the director Richard Geer actually had in mind when he helped create Swamp Gravy in Colquitt is detailed in Chapter 4. Following the experiences of Swamp Gravy volunteers and citizens in Chapter 5 begins to reveal some of the play's effects on personal lives and relationships that also rippled out into the surrounding town of Colquitt. Swamp Gravy's effects on the identity of the town along with how it prompted the formation of community serving institutions and economic growth are discussed in Chapter 6. The conclusion in Chapter 7 identifies significant findings which enables theoretical discussion and the formulation of recommendations for future research. 


\section{Chapter 1: Colquitt, Georgia and Swamp Gravy}

The City of Colquitt, Georgia in Miller County is the home of Georgia's

official folk life play, Swamp Gravy. Colquitt is a small rural town that had

transitioned from labor intensive agriculture to mechanized industrial

agriculture between 1960 and 1980. In the ten years that followed the transition,

Colquitt lost 10.8 percent of its population to outmigration. Most didn't believe

they had a community heritage. By 1990, the downtown square was in an

advanced stage of decline. Most residents had opted to shop in larger adjacent

cities of Bainbridge, Georgia or Dothan, Alabama, where the arrival of big box

retail stores in 1980s siphoned off buyers from downtown Colquitt businesses.

The dominant question in 1990 was whether to stay or go. Local social worker

Joy Jinks diagnosed that Colquitt suffered from low self esteem, and believed

that residents needed to find a way to celebrate their heritage. In 1990, Jinks met

theater director Richard Geer at a conference in New York about how the arts

could be used to build community. Within the year, the two agreed that Geer

would help Colquitt gather local stories to use in a community performance that

was later given the name Swamp Gravy. Geer believed that the performance could

revitalize the town. Jinks desired that her fellow citizens might find something

they could celebrate about themselves. 
Dot Wainwright, the president of the Colquitt Miller Arts Council

(CMAC) came up with the name for the play. Swamp Gravy, while not previously existing as a local dish, would depict what people did to create a meal - take what was within arm's reach, tomatoes, fish drippings, potatoes, and whatever else was left over, put it in a pot on the stove and mysteriously a feast would soon emerge. The name and the process became the moniker for the ongoing community performance of the local community stories. The play started in 1992 and has continued non-stop. The play is produced every weekend in March and October. And each year features new set of stories gathered from local people and compiled into a script for the play. What is unique is that the play not only features a new set of collected local stories each year, but is also acted by a cast of local volunteers. The play has been purported to have been responsible for building bridges of relationships across multiple boundaries, while also being the catalyst for the revitalization of a town that was in serious decline. All of this started when Colquitt resident Joy Jinks met theater director Richard Geer, who had a dream that theater of the people, by the people, and for the people could activate community - which would be demonstrated by actors acting together for the common good of their community. Jinks desired for her declining home town to have something that it could celebrate. 
The city of Collquitt is located in the southwest corner of Georgia and is the only incorporated city in Miller County (Map Figure 1). People from outside the city limits that reside in Miller County commonly identify themselves as being from Colquitt. The land of Miller County lies between the Chattahoochee, Flint, and Apalachicola Rivers. Running underneath this land is the "Floridan Aquifer, considered to be the most abundant in the world, covering a 100,000 square mile area which has been the mainstay for supporting life and industry throughout the region" (Davis 1980, 1). An average of 50 feet of land separates the prolific Floridan aquifer from the land surface, which accounts for the abundance of springs and swamp land (Jinks 2008, interview).

Prior to white settlement, this part of southwestern Georgia was inhabited by Native American Indians. However, “after a bitter interracial warfare involving Andrew Jackson, southwest Georgia was officially opened for [white] settlement in 1816" (Davis 19080, 4). Between 1859 and 1874 the boundary between Miller and Early County was finalized. Miller County was "named after Andrew Jackson Miller, a lawyer who had been twice elected as the president of the state senate..., [and] was best known for introducing a bill to give property rights to married women." The city of Colquitt was formed at the previous site of Springtown settlement and was incorporated in 1860. Colquitt was named after 
Walter Terry Colquitt, a noted lawyer, judge, state senator, U.S. Congressman, husband, and father of twelve children. (4)

\section{Figure 1: Map Colquitt, Georgia}

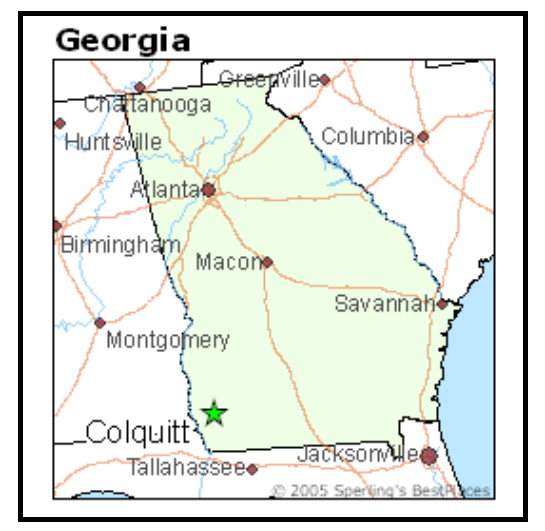

Late nineteenth century Miller County was characterized by hard work in

a pre-industrial agrarian landscape.

Miller county pioneers began developing this virgin area by everyone working from dawn to dusk. The men and boys made fields from forest. Never having heard of fertilizers, they succeeded as a part of daily living with practical organic materials... Much hunting was done... [and] mulberry, peach, pear, pecan and apple trees were planted... These were poor people, not because they had lost their wealth, but, because they had never had it... Practically every white person in Miller County was of English, Scotch, Irish, or German stock. Money was scarce and these people lived simply. Many amenities were denied them, but the decencies and necessities were not. There was little education in the sense of schooling; yet, these people were not ignorant. They educated themselves and acquired culture by self-help and in the school of experience (Davis 1980, 37-40).

Very little information is available today concerning Miller County in the pre-Civil War plantation era. This is potentially due to the late development of 
this section of Georgia in comparison to the rest of the state. The only recorded insights into life in Miller County in the 1870s comes from the Bainbridge Argus (newspaper) in the form of a story about a Bar-B-Q social gathering that took place in Miller County on August 6, 1870. Bainbridge is a city 20 miles south of Colquitt in neighboring Seminole County. The article was found by Nellie Cook Davis and included in The History of Miller County Georgia. There is a lingering flavor of the Plantation South in the story. Davis surmises that John Pierce, the host of this festive gathering of 800 to 900 persons was probably a plantation owner (Davis 1980,59). The festive event consisted of elaborate outdoor staging areas and every known form of barbecued meat that was common to the area. The occasion was "purely social... [where] people had met to talk to each other, to extend those kindly greetings and cheerings and interchange those generous feelings and sentiments toward each other, with which their hearts were so full" (59). The event consisted of a couple of speeches on the topic of "social ethics," advocating for "matrimony," or family, in lieu of the pursuits of the "self" (5960). The event also included music and dance. Of particular notice is the reporter's mention in the article that there was "a very slight sprinkling of $15^{\text {th }}$ Amendments" in attendance at the party. This was the reporter's way of referencing the few Blacks in purely legal terms, derived from the fact that just 
months before the party the $15^{\text {th }}$ Amendment had been ratified thereby giving all men regardless of race or prior servitude the right to vote (59).

In 1897 the Miller County newspaper The Liberal issued its first edition. It has remained the only newspaper in Miller County since its inception. Davis described the founding editor Zula Toole as a school teacher who as a news writer "wrote in the same vein as all publishers of her day-the unvarnished truth with her ideas and beliefs paramount" (117). This unabashed subjectivity about what is true in a given situation can be interpreted a variety of ways. At best, perhaps it conveys a regional assumption that most of what we proclaim to be true is actually conveniently framed self-interest. Perhaps acknowledging such subjectivity decreases the expectations about discourse and anticipates that similar self-indulgent framing was also practiced by others. Today, Colquitt's only newspaper, the Liberal continues to be owned and managed by direct family descendents of Toole.

After the $15^{\text {th }}$ Amendment, sharecropping replaced the old plantation slave form of farming and became the dominant form of agriculture industry in Miller County until the middle of the $20^{\text {th }}$ Century, when the shift to mechanization replaced it (Davis, 1980, 58). Farming in its various forms has been the main source of income in Miller County from 1830 to present. The 
Georgia Pine Railroad was completed in 1895, dramatically improving the distribution of farm products to regional markets. In the early $20^{\text {th }}$ Century cotton and corn production began to yield ground to peanut crops. Between 1933 and 1979 traditional forms of farming began to give way to "agribusiness..., [where] farms began growing from small acreage to plantation size" due to the new benefits of machinery that replaced the farms dependence on human labor (239). "Crops changed from cotton, sweet potatoes, rice, syrup and butter to peanuts, hay, soybeans, wheat and pecans.., while corn remained a constant" (233-239). Today the city of Colquitt has a total area of 8.25 square miles, and a population of 1,917 persons. Colquitt is the county seat for Miller County, population 6,125. The population is largely made up of African Americans and Whites, with less than 2.3 percent of the population representing all others. African Americans make up 28.1 percent of the population in Miller County and 49 percent within the city limits of Colquitt, while Whites make up 69.6 percent of the population of Miller County, and 49 percent within the city limits of Colquitt. The counties that border Colquitt all reflect that African Americans make up the majority inside the city limits of the county seat, while in Colquitt there are 943 Whites and 942 Blacks (U.S. Census Bureau, 2010). 
U.S. Census Data comparing Colquitt with state averages consistently reveal that Colquitt lags behind in virtually all categories (Table 1). Roughly 4 out of every 10 Blacks (38.6 percent) live below the poverty line in Miller County. Statistics indicate that 45 percent of the work force is employed outside of Miller County (Southwest Georgia Regional Development Center). Yet, as noted below, the average commute is still less than the state average. As such, life in Colquitt is comparatively localized. State studies have concluded that 3 of the most pressing issues are: "graying of the population; youth outmigration; and low educational levels".

Table 1: U.S. Census Bureau, 2010 Census Data

\begin{tabular}{|l|r|r|}
\hline \multicolumn{1}{|c|}{ Indicator } & \multicolumn{2}{c|}{ Colquitt } \\
\hline High school graduates & $73.4 \%$ & $83.5 \%$ \\
\hline $\begin{array}{l}\text { Bachelor's degr ee of } \\
\text { higher }\end{array}$ & $9.4 \%$ & $27.2 \%$ \\
\hline Mean travel time to work & 19.8 minutes & 27 minutes \\
\hline Homeownership rate & $69.9 \%$ & $67 \%$ \\
\hline Median home value & $\$ 80,000$ & $\$ 161,400$ \\
\hline Persons per household & 2.29 & 2.66 \\
\hline $\begin{array}{l}\text { Per capita monetary } \\
\text { income }\end{array}$ & $\$ 19,895$ & $\$ 25,194$ \\
\hline $\begin{array}{l}\text { Median household } \\
\text { income }\end{array}$ & $\$ 33,196$ & $\$ 49,347$ \\
\hline $\begin{array}{l}\text { Persons below poverty } \\
\text { Level }\end{array}$ & $18.2 \%$ & $15.7 \%$ \\
\hline
\end{tabular}


In 1974 the Miller County courthouse was destroyed by fire, taking with it all the official recorded archives that could reveal a fuller history of the area. As a result, the Citizens Bank of Colquitt, GA commissioned a community recovery effort under the leadership of County Historian Nellie Cook Davis. The book titled, The History of Miller County, Georgia was published in 1980. The preface states that it was a "labor of love" and the "pleasure of amateurs" - and therefore not the result of professional expertise (Davis 1980, x). The preface to the book makes an urgent request of the local citizens of Miller County: “Please keep inquiring about your family and community before the people who remember are no long with us. The surface of our history has barely been scratched" (x). They obviously wanted to know and record more, and felt that such knowledge was important.

From the 1980s up to current times (2012) agribusiness has maintained its dominant position in the Miller County economy, but not without decreasing the number of farm related jobs. Overall, opportunities for labor in Colquitt County have decreased with the take-over of farming by machines. By 1980 the number of farms had decreased to roughly one third of what they were prior to mechanization, while the size of farms had grown by 500 percent. In 1990, the dwindling labor opportunities combined with the closure of a sewing plant that 
was the third largest employer in Miller County. Hard times were taking their toll on the city, and most of the buildings on the downtown square were either vacant or falling into further disrepair (Jinks interview). To make matters worse, between 1980 and 1990 the population of Miller County had decreased by 10.8 percent, making the preservation of history that much more important (United States Census Bureau).

\section{Colquitt-Miller Arts Council (CMAC)}

No one could have then predicted that in the decade following the 1980 publication of The History of Miller County, Georgia, a new set of amateurs would involve themselves in the production of a series of plays that would prompt ongoing efforts to collect stories, and thereby help to greatly enhance the preservation of their heritage. This endeavor led them into unfamiliar territories and uncommon partnerships. Joy Jinks and the Colquitt-Miller Arts Council (CMAC) initiated and led this local charge of amateurs. Still feeling the resulting loss of recorded documentation in the 1974 fire, and looking forward at what seemed like an almost inevitable spiraling decline of economic conditions for many local residents, the situation in Colquitt seemed dire. Jinks was not exactly sure how a storytelling event was going to change anything in Colquitt and Miller County, but she and her friends at CMAC took on the task none-the-less 
with what would become a mantra of sorts in the following years - they made up their mind that they were going be a "can do" city (Jinks 2008, interview).

The Colquitt / Miller Arts Council (CMAC) was formed in 1989. Their

initial concern was to preserve the local movie theater on the square. The mission of CMAC was "to encourage, enrich, and stimulate the practice and appreciation of the arts among the people in Miller County and Southwest Georgia". However, the leadership of CMAC had wider goals in mind, including “economic development..., job opportunities and renovation of downtown buildings into productive facilities" (Davis 1980, 24).

Joy Jinks and Karen Kimbrel played a variety of leading roles in the evolving development of CMAC over the years. Jinks' background as a social worker combined with Kimbrel's interests in business created an overlapping partnership that was mutually reinforcing. Jinks along with her husband and banker Clyde Jinks had been instrumental to the formation of the Chamber of Commerce just a few years prior to the formation of CMAC (Davis 1980, 24). Immediately upon the formation of the Chamber, a contract relationship with the City of Colquitt and Miller County had been initiated that commissioned the Chamber to provide "economic development services" for the city and county (24). One of the determining factors behind the formation of the Chamber was to 
"attract visitors and gain further distinction for the community" - specifically, as a first order of business the Chamber reframed the recently launched Mayhaw Festival from a local event to "The National Mayhaw Festival." The swamplands of Miller County are home to the edible mayhaw berry, one of only a few places in the U.S. where the mayhaw not only flourishes, but can even be found. The combination of Jinks and Kimbrel and their overlapping business and community interests certainly broadened how CMAC saw itself. If "can do" was the mantra of CMAC, a fundamental strategy was to expand and activate the role of the arts to be a catalyst for economic and community development. This expanded role meant that from the outset CMAC would be involved in overlapping territory with the Chamber. It also meant that whatever traditional definitions for an arts council existed would have to be enlarged to fit the personalities and visions of the individual CMAC members. Jinks had never thought of herself as being artistic, but had been told that she was creative when it came to community (Jinks 2008, interview).

In 1990 Joy Jinks met Richard Geer, a director and advocate for community based theater. The two crossed paths in New York City at a conference about ways to utilize the arts in community building. Geer was one of the featured speakers and Jinks was attending the conference to glean some ideas 
for CMAC. About that meeting, Jinks remembers having to "imagine a screw kind of screwing up her spine in order to get the backbone to talk with Geer," who was a very outgoing and charismatic personality. Jinks introduced herself saying, "I am from a small town in Southwest Georgia. We are a poor community, and we are looking for a way to celebrate ourselves." The two of them briefly discussed the possibility of producing a play utilizing the local stories of Colquitt, Ga. At that time, Jinks saw it as a potential way of "revitalizing Colquitt and preserving Colquitt's heritage through storytelling." Efforts by the Chamber to attract outside business and industry had not succeeded. According to Jinks, Colquitt suffered from "low self esteem," and increasingly "felt left behind." The young people that left to pursue a college education were not returning to Colquitt, but going elsewhere to either set up businesses in places where their prospects for success were greater, or going where they could actually get a job and work. Colquitt was a "dying town," and most were constantly asking themselves, "should I stay here in Colquitt or leave." In 1984 the National Mayhaw Festival was launched, and became a successful celebratory event. But it was limited by the fact that it only took place one day every year. Then in 1991 the already declining economic conditions in Miller County significantly worsened when "the sewing factory and five family 
businesses closed down, putting many local residents out of work" (Jinks 2008 interview).

That same year Jinks and Dot Wainwright went to Chicago to introduce Mayhaw Jelly at a merchandising fair in hopes of finding a market for the rare and distinctive berry-fruit that was now value-added and packaged for sales as a jelly. Jinks contacted Geer who was at the University of Chicago at the time, and invited him to sit down with her and Wainwright to revisit the idea of doing the play that they had discussed in New York. If Geer could convince Wainwright then the two of them could return to Colquitt and pitch the idea to their friends and associates. Jinks felt that returning home with Wainwright's backing might decrease the odds of people thinking she was "crazy." What had stuck out in Jinks' mind from her previous conversation with Geer was his description of what he wanted to direct - "theater of the people, by the people and for the people" (Jinks 2008, interview). She felt like that might be something that her community could get excited about. This type of theater is what Geer had named “community performance" (Geer 2008, interview). 


\section{Community Performance: Theater of the People, By the People and for the}

\section{People}

The process that gave birth to community performance had its origins in an early experience of the then aspiring professional theatre director, Richard Geer. Geer had worked as an acclaimed professional director with accomplishments that included award winning productions of Shakespeare and other classic works that are common to the American stage. In 1980 Geer was directing a professional production of Dracula in Steamboat Springs, Colorado, when his theatre work on the stage intersected with an emerging crisis in the community. This intersection would later inform a conversion of sorts - from professional theatre whose market appeal was a mere two percent of the American population, to his experiments with community performance of local stories acted by local residents. Geer imagined that community performance would surely have a broader appeal as well as participation. Geer also hoped that community performance could be a catalyst for activating persons in their community for the common good (Geer 2011).

Steamboat Springs, Colorado was a town whose economy was primarily tourism, and a predominantly seasonal winter tourism that relied on the usual abundant supply of snow. During the ski season the population of Steamboat 
Springs would double with the swell of ski enthusiasts arriving from distant places. However, as coincidence would have it, in 1980, as Geer and the cast prepared to open their production of Dracula, the town of Steamboat Springs was experiencing an absence of snow, which became a devastating drain on the local economy. Neighbors would awake daily to see the latest fallout from the lack of snow in the form liquidations of various forms and closed signs (Geer 2011).

As the play opened it became apparent to Geer that the audience was connecting with the play at a very profound level. It was deeply meaningful because most realized they were seeing the story of their own town in the story of Dracula - where a single culprit slowly drained its victims of their life-blood, one-by-one. The dramatic conclusion of Dracula reveals a town putting aside divisiveness and hostilities towards each other in order to come together and defeat the common enemy. In a similar manner - though Geer does not claim any causal relationship to the play, the town of Steamboat Springs collaborated across normal lines of friendships and partnerships into what might be called odd partnerships, where they pooled their efforts to purchase snow-making equipment that would provide them a way out of the grips of the snowless winter (Geer 2011). 
What transpired in Steamboat Springs caused Geer to ponder a potential for a new type of local theatre that he later called, "community performance theater by the people, of the people and for the people". What finally explained Dracula to Geer was a little book titled The Conscious Use of Metaphor in Outward Bound. "I learned that certain actions (like supporting other climbers by holding the rope) can be metaphorical for, say, not pulling one's weight in the family. For such a youngster the rope holding creates a crisis, which if resolved in the Outward Bound experience, may change her life at home. What the girl held wasn't a rope, it was an isomorph - an event with the same shape as another event, but without the mass and encumbrance. What the girl figured out in her mind and muscles was that she could be depended on" (Geer 2011). In Outward Bound what holding the rope typically relates to is a group exercise in rock climbing. As one person is climbing, another person has to hold the rope that the climber is secured to. If the climber slips, the rope being held by the other person catches them and prevents them from falling. The lesson learned goes both directions. The person holding the rope is depended on by the person climbing. The successful exercise, while it may differ from real life, can potentially transfer to real life situations that call for a similar action. 
In Steam Boat Springs the audience had not acted out an exercise, but had witnessed a story that had parallel implications to the situation they all were facing in the world outside the theatre. The connecting question thus becomes: "what did we just experience in the theater that we are experiencing outside the theater?" (Geer 2011) Making this reflective connection is vital if the play is going to inform and/or inspire actions in a parallel context of the real life world.

During these [reflective] conversations, did Dracula cross anyone's mind? It is certainly an answer to "What have we just experienced?" As in the play, contending and disparate parts of the Steamboat community banded together for mutual preservation. Not many years before, Steamboat Springs had been a small town with one restaurant at the foot of the ski mountain, and a single rope tow ski lift. Now the town was a welter of competing interests, interests that all saw the issue differently, each with its own agenda. Despite major obstaclesprivate vs. public corporations; city, county and state governments; contending egos and conflicting constituencies, Steamboat finally followed the pattern of [the actors in Dracula]. That winter was the last time the empty sky would threaten the community. They installed snowmaking equipment. Dracula was years behind me when I made this realization. Dracula didn't cause the town to band together, but it was part of the change-making field that enveloped the little community which learned to save its own life, first through story, performance, relationship, conversation, and finally through committed action (Geer 2011).

A few years later Geer read about Baz Kershaw, a director in England who was changing community theatre by substituting local stories of historical significance in place of theatre classics. The local story was then acted out by local community member-volunteers. This strongly connected to what Geer had learned from his experiences in Steamboat Springs. He began to wonder what 
might happen if he collected local stories for adaptation into a script to be acted out by local community members. Geer pondered further -- could this be a form of "outward bound for communities?" Geer had a strong hunch he was onto something important. He began to speak about the possibilities that this new form of theatre might hold for communities, which prompted him to replace the more formal spelling to the more colloquial and informal spelling, theater, and named this process, "community performance - theater by the people, of the people, and for the people" (Geer 2008, interview).

When Geer met with Jinks and Wainwright in Chicago over lunch the three of them discussed together the possibilities of staging a community performance project in Colquitt, Georgia. Geer spoke of the similar type of performance in England and his experiences in Steamboat Springs which had inspired his dream of community performance. Jinks remembered Geer describe anticipated outcomes such as: "opening up new possibilities; breaking down barriers; bonding; instilling community pride; and generating excitement." Jinks, being a social worker by trade could see how the process that Geer described could be helpful to Colquitt. Her primary desire was to find something that enabled the people of Colquitt to celebrate. There was only one problem, Colquitt / Miller County did not have any historically significant event to use for 
such a performance. The events in England capitalized on local historical events which could be featured in a script, and had thus only taken a weekend to pull together and perform. Geer agreed to come and help Colquitt if they would agree to gather stories from the community to use in the performance. By the time Jinks and Wainwright returned to Colquitt they were on a mission to convince their friends at CMAC that community performance was something they needed to do. Jinks felt that the process could help them further preserve and celebrate their heritage before the town finally succumbed to hard times (Jinks 2008, interview). 


\section{Chapter 2: Narrative Processes in Urban Planning}

The tension that has dominated urban planning theory since the latter part of the twentieth century has been the struggle for dominance between rational planning and participatory planning. Rational planning is concerned with constructing a comprehensive plan that solves a problem. The scale of such intervention involves stakeholders whose advantaged and dominant economic position affords them participation in expansive planning. Unfortunately the results of rational problem focused planning have failed at being effective or just. Rising up in opposition to rational planning in the name of participatory planning has been a range of advocacy planners who seek to work on behalf of those marginalized by rational plans. Both approaches are problem focused and both put the planner in a position of intervention. Between these two opposing but similar trajectories planning as a form of communicative action has emerged which has included the planner as mediator of conflict as well as a facilitator of storytelling. It is this intersection of the rise of planning as a communicative action that provides the theoretical context for the case of Swamp Gravy in Colquitt, Georgia to be studied. Beyond just narrative processes in urban planning, the Swamp Gravy community storytelling performance also involves similar theoretical crossroads that suggest the importance of narrative in 
building relationships across boundaries, facilitating experiences of community, empowering persons, re-narrating community identity and activating a community of actors on stage and in their community to work for the common good. This chapter looks at theory in relationship to all of these possibilities involving narrative processes.

The much discussed gap between these rational and advocacy planning has had a haunting effect on planners for some time. Some feel the gap is overstated, but most acknowledge that it has become somewhat of an Achilles heel for the profession. There have been attempts to bridge this gap. New Urbanism has attempted to build a live-work-play environment that claims to solve the social and environmental problems that many assign to rational planning. However the comprehensiveness of the New Urban design seems to render it more at home with rational planning camp than it does with those concerned with social justice and democratic communities. These two competing sets of practices and theories - rational planning and participatory planning, provide the context for the development of a more communicative brand of planning that now includes urban planning as a storytelling process.

In the postwar era of Twentieth century, the theory and practice of planning as a fully rational process rose to prominence. Rational planning 
featured first and foremost the identification of a problem which could be supposedly defeated through an urban planning sequence that entailed:

"definition of problems and/or goals; identification of alternative plans/policies; evaluation of alternative plans / policies; implementation of plans and policies; monitoring of effects of plans / policies" (Taylor 2003, 68). Another succinct way of describing the five steps of rational planning is "desires; design; deduction; decision; and deeds" (Harris 1967, 325). Critiques of rational planning have centered around three main arguments: first, that the comprehensiveness is not reasonable or realistic (Altshuler 1965); second, that questions about what is good for society as a whole are never taken into consideration (Kravitz 1970) and lastly, that inclusive participation whereby what is good for all of society can be discovered, is absent from the rational planning process. Today few believe that planners are in reality neutral (Bollens 2002, 24). Some practitioners of rational planning neutralize the role of the planner as solely responsible for the technical achievement of desired ends or goals of those political and economic actors whose participation in the broad reach of comprehensive plans seems common sense and/or rational at that scale.

An important feature in rational planning is the presumption of a problem as a starting point. This helps establish planners in an intervention role. This is 
the case for many planners regardless of whether they perceive themselves as rational planning practitioners or an opponent. Some critics of rational planning place themselves in opposition to rational planning based on their conviction that it inherently marginalizes some while serving the desired agendas of powerful political economic actors. But, here as well this position begins with an assumption that there is a problem that requires an intervention. As such, planning practice and theory that reacts against perceptions and/or the realities of rational planning take on an equally interventionist posture. Concerns over rational planning created attempts by multiple planners to break with rational planning in preference for a method that had the potential to ensure more democratic end results, including social justice. Early attempts to formulate a corrective included seeing planners as advocates (Davidoff 1965). More recently planning as a tool of "intervention" carries on the tradition of advocacy planning in an attempt to correct the subversion of societal well being and inclusive participation (Sandercock 2011). Planning juxtaposed between totalizing and reactive interventions appears unlikely to achieve the kind of collaboration that can deliver what is more broadly good - meaning economic viability; social justice; and environmental sustainability. . 
These divergent streams of urban planning are not the linear progressions of a cohesive field of practice - but a growing collection of possibilities that complex planning situations can enlist, depending on the situation, or even depending on the culture that a given situation arises within. Into this planner-asintervener mix of comprehensive totalization and reactive resistance, a significantly different approach called communicative action emerged. John Forester, playing off of Habermas's Ideal Speech Act, proposed a communicative form of planning. This speech ideal hinged on four qualities that a speaker must demonstrate - four validity criteria that require that what is spoken is "comprehensible; believed to be true; sincere/genuine;" and seeks "understanding with another person" (Taylor 2003, 123,124). It is reasonable to presume that normally functioning persons possess the capacity for engaging in this quality of communication, and that the role of the planner should be to mediate different points of view through activating this kind of dialogue among diverse, and sometimes even hostile competing stakeholders.

The planner role inherent in this form of planning shifted towards an active yet more neutral position of mediator. Planning theorists such as Susskind and Ozawa have built on this communicative turn by emphasizing the role of the planner as a skilled mediator, a strategically specific form of communicative 
action. This is a significant turn away from the problem-focused planning that created and sustained the interventionist planner roles. The communicative process seeks to enlist the capacity of stakeholders to co-produce understanding and consensus from which more democratic intentions can emerge and thereby shape the resulting plan. The function of the planner is to actively interpret which requires self-reflection, while mediating the communicative participation of all of the stakeholders.

A variation of this communicative action approach that emerged in planning theory in continuing response to the intervention impasse was planning as a process of telling, listening to, and responding to stories. John Forester was one of many planning theorists to make the connection between planning and telling stories. Forester advocated that the best way to learn about planning was to be attentive to the stories that planners tell about themselves (Forester 2001, 19). Patsy Healy detailed in her article, A Planners Day, that what a good planner does in a day's work is to engage the web of relations involved in a given planning endeavor, locate motives and "structural biases," and formulate a collaborative plan through acquired "communicative skills" (Healy 1992, 1112,). In essence, what Healy describes is planners being attentive to stories in order to reconstruct a new story. 
Over the past 10 years the number of planning theorists suggesting that the business of the planner is to listen to the stories of the stakeholders has grown (Forester 2001; Sandercock 2003b; Throgmorton 2003b; Mandelbaum 2003; Healey 1992). Planning as "listening to and telling stories, depends entirely on the transformational impact of the process to enable the ultimate construction of a collaborative plan" (Throgmorton 2003, 126). Planning theorists and literature have suggested that the dialogical engagement between multiple storytellers is what leads to the possibilities of personal transformation, reconciliation of deep difference, and the formation of more democratic communities (Sandercock 2003;Eckstein 2003;Throgmorton 2003). Perhaps there have been simply too many modern project disasters to continue to ignore. Or maybe the unreflective pursuit of progress is slowly taking a back seat to preferences for more sustainable and democratic futures wherein all stakeholders partake in a more equitable economy. Regardless, in narrative processes the stage has been set for previously unchallenged actors hiding their plots behind technical language to now sit across the table from the previously marginalized and enter into a responsive and reciprocal storytelling process through which a collaborative vision of the future that is good for all might emerge. 
Planning as telling, listening to and responding to stories depends on the transformational impact of the process to enable the ultimate.

Much initial theorizing on planning as a narrative process has focused attention on the role of the planner as a storyteller. One must "think of planners as authors who write texts, ... [which] shape the reader's attention, turning it this way instead of that" (Throgmorton 2003a, 127). Planners need to acknowledge that they too, are embedded in a complex web of relations in the midst of a "multiplicity of narratives". The planner as storyteller has to demonstrate an "ability ... to imagine one's self in a different skin, a different story, and a different place and then desire this new self and place that one sees" (Eckstein 2003b, 24). Storytelling is not a tool of deconstruction and domination, but of reconstruction and dialogue (Eckstein 2003b), as well as a complimentary tool to the technical constructions of knowledge (Mandelbaum 2003). Storytelling thus avoids being viewed as juxtaposed against or competing with technical knowledge, but provides the context that informs how technical knowledge can be more meaningfully applied. The storyteller should have the "ability to make a narrative and physical space in which to juxtapose multiple stories so that they enrich, re-narrate, and transform that space rather than compete for ultimate control of a single, linear, temporal history of an impermeably bounded 
geopolitical place" (Eckstein 2003b, 24). Eckstein makes a critical distinction by asserting that "the storyteller is the one who actively makes space for the story to be heard" (35). This suggests that being a storyteller necessitates an opening out into a reciprocal relationship of dialogue- one in which the true storyteller listens and responds, becoming what Martin Buber describes in reciprocal relationships as, both an "I" and a "thou" (McFadyen 1990, 9).

Storytelling as a community forming process of civic theatre may seem miles from the urban planning table, but this perceived separation has begun to narrow. Civic theatre is now being enlisted to gather and present community interpretation that informs what can be in regards to urban development and public policy. Sojourn Theatre in Portland, OR created a dialogical research and performance piece titled One Day in collaboration with visionPDX sponsored by Portland Mayor Tom Potter. The mayor wanted this 2006 project to help him discover what local citizens desired in respects to the future of Portland. What he got was much more than he had anticipated. He was made aware of the challenges that a group of average citizens face in trying to fulfill their desires as residents in Portland in a given 24 hour day (or, One Day). Issues of social justice, gentrification, immigration, sustainability, and race were among the realities that were exposed in the narratives of eight individuals' whose stories were 
connected in revealing ways. The performance also invited audience participation through questions and dialogue with the characters about the stories in the play - all of which were collected and reported to the mayor's office. At the conclusion of the play the audience members were asked what they might do in response to imagining themselves in each character's shoes. This is an example of how the distance between theatre and the governance is shrinking which has the potential to expand our experience of knowing and understanding. Drama in a theatrical setting can employ a multitude of dramatic devices including lighting, sound and music. All these devices enhance storytelling venues, capturing potentially more of the attention and imagination, as well as making oft-hidden meaning more accessible. Staging One Day in familiar venues such as local neighborhood schools increased audience accessibility and participation. (Sojourn Theatre and visionPDX 2006).

Planning educator Teresa Cordova asserts that if planners are to become agents of equity, they will need to fulfill the task of hearing the voices of the disenfranchised in lieu of the voices of experts. Any credible storyline about the disenfranchised must come from within (Cordova, 1994). At the same time, Bollens (2002) adds that there is no such thing as a position of neutrality in conflicted situations between different groups. Planning as storytelling has the 
capacity to address societal conflicts. Story, being of universal form, provides planners with a mechanism that is fundamental to all events. Thus, conflicting stories naturally bring forth perspectives that seek to be reconciled in order to provide a future vision of a democratic and just society in the midst of diversities.

Bent Flyvbjerg (1998) asserts that the practice of modern planning has often been an accomplice to the complete hijacking of all rational discourse by rationalizations -- so much so that the notion of rational discourse is no longer meaningful. This assertion presents problems that need to be addressed by proponents of narrative processes. First, storytelling must be seen as a rational process and not as something different or contrary to rational. Secondly, all rational discourse is embedded with emotions to some degree. There is no separating rationality and emotions as they work in concert (Nussbaum 2001). As for the long-term manipulation of the planning table where some have conveniently disguised rationalizations as rationality, correction may be less problematic than abandonment of rationality. A narrative form of discourse would allow one to discover when discourse that is projected as rational is actually propaganda that conceals a plot. This can put rational back on track via a narrative interpretative process. Abandoning narrative as the rational process 
that it is could undermine the potential for transformation and revision that narrative processes can and quite naturally do make possible. By combining the Habermas speech ideal with the responsive interpretation of meaning that is at the heart of storytelling, one ends up with a process that is mutually inclined towards discovery. This combination could be articulated as the wholehearted intention to communicate clearly meaning or meanings of a given context (a story), and to do so honestly, sincerely, for the intended purpose of being understood by an other or others. As such, the communicative parties can be seen to take the form of storytellers, where their engagement is storyteller to storyteller.

If narrative engagement is a process in good urban planning then the narrative procedure of planning can no longer stay in isolation from the technical sciences (Mandelbaum 2003). These two sides of planning must be seen as cooperative and not in opposition. The Urban Institute has issued a report that reached several conclusions regarding those who participate in the arts. The most obvious result in the report concluded that participation in the arts resulted in an increase in civic participation (Urban Institute 2003, 1). This demonstrates that the arts - of which story is part of, progress naturally to civic matters and the concerns of communities. Richard Sennett asserts that "the essence of urbanity [is 
demonstrated when we] act together without compulsion to be the same" (Sennett 1977, 255). Can the arts and the technical sciences partner together for the good of people and places? Perhaps narrative is that bridge to a more sustainable union between the arts and the material technical sciences as well as to a democratic process that can lead to more democratic plans and thus ends.

\section{The Narrative Turn in the Social Sciences}

There has been a general turn to narrative in the social sciences as well. Walter Fisher frames this change as the replacement of the modern rational paradigm's five postulates: "people are all essentially rational; we make decisions on the basis of arguments; the type of speaking situation (legal; scientific, legislative) determines the course of our argument; rationality is determined by how much we know and how well we argue; and the world is a set of logical puzzles that we can solve through rational analysis" (Griffin 1994, 321-322). This approach assumes the Cartesian model of detached expert analysis that comes from outside the observed situation. It also embodies Max Weber's assertion that modernity was infected with the notion of "disenchantment- ... [meaning that] there are no mysterious incalculable forces that come into play" (Weber 1958, 139). More telling perhaps is that responsive communication with an other or others is nowhere to be found in the rational paradigm. Individual 
mastery of the construction of truth is imagined to be entirely reachable inside the isolated vacuum of singularity.

Fisher counters the modern paradigm with an emerging narrative paradigm, asserting that: "people are essentially storytellers; we make decisions on the basis of good reasons; history, biography, culture and character determine what we consider good reasons; narrative rationality is determined by the coherence and fidelity of our stories; and the world is a set of stories from which we choose, and thus, constantly recreate our lives" (Griffin 1994, 322). This seems to suggest that the various assumptions of detached individual mastery are common due to a lack of awareness, that in reality we live with stories. Maines adds that "with the emergence of institutionalized science..., precision was thought to come thru enumeration and mathematical representation" (Maines 1993, 19). However, diverse disciplines within the social sciences have begun to conclude that all discourse is embedded in a web of social relations, including “community processes, planning and policy making” (20). Maines adds further clarification by pointing out that "all narratives are potentially rational accounts..., but, [that] all narratives are ultimately incomplete," which implies a more interdependent and responsive posture that is both inviting and even anticipating of reconstruction (21). This shift to narrative serves as a potentially 
significant alternative to the modern paradigm in that it places all discourse about the social world inside webs of relation where meaning is communicated by stories in order to render understanding. This realization both humbles and thereby civilizes previous confidences about applying abstract truths to solve problems in lieu of the work of contextual interpretation in communication with others in order to understand a given situation deeply.

It is important to understand what the elements of a story are. The five elements of a story can be described as follows: A (character) is in a (situation) and must accomplish a goal (the plot). But, does the (character) defeat the (opponent) when the (climax) happens? Though this is a simple story formula, one can recognize that when it comes to the social world, everything that people do happens within the context of an unfolding story. As such, everyone is living in stories. The only question is whether a person is consciously aware of this reality.

It is easy to see why a developer might want the numbers that his accountant has configured to demonstrate that a new development will be beneficial to a city - and for those numbers to be seen purely as an objective and rational argument, and not a story. After all, everyone knows that the numbers don't lie. An interesting side note is that one common way of describing the act 
lying is by saying that someone is telling a story. There is a common sense at work involving how we think about numbers, rationality and story that has been in play for some time. However, to understand what is true in a given social situation, one has to look to stories, which provide meaning.

Psychiatrist turned novelist Walker Percy stated that the story is the "only instrument we have for exploring the great gap in our knowing, knowing ourselves and how it stands between ourselves and others" (Percy 1991, 216). Percy's description of story as an instrument or capacity implies that it can remain unused and/or dormant. This would constitute a passive state wherein an individual would be externally determined. In a similar fashion, when Bales comments that "myths and metaphors, parables and paradigms are the way that real people process information and experience to make sense of the world," the words real people suggests that there is an ontological importance to being a storyteller. And conversely, if an individual doesn't interpret or story their situation, it leaves them complicit to being seen as an object that can be determined by objectifying forces (Bales 2007). Percy's ideas on narrative and the communicative social processes of becoming a person are derived from Charles Peirce, the founding father of semiotics. Percy asserts, that "from that earliest of utterance where human sound moves from the realm of stimulus-response 
through some mysterious transition to become something more - the naming of a thing is nothing short of the emergence of a person in relation" (Percy 1991, 131139). That person in elation is an interpreter who is naming what a thing means, which is an open and responsive act from the very outset of the work of constructing a story.

Constructing a story is an active response for the purpose of discovering meaning. Without a story, abstract facts remain meaningless, or ungrounded, where they can be conveniently discarded as irrelevant, or co-opted by actors to support their individual agenda and/or to further disguise a plot. Another way of saying this is that, what a thing or action means can only be discovered by locating the thing or action in a story. Perhaps the greatest benefit of story is the way in which it reveals the personhood of an individual. Narrative theorist Mikhail Bakhtin conveys this conviction in his comments about the stories of Dostoevsky. "To portray the inner man was possible only by portraying his communion with another. Only in communion, in the interactions of one person with another, can the person be revealed, for others as well as for oneself. In stories the person becomes for the first time that which [she or] he is- and we repeat, not only for others but for himself [and herself] as well" (Frank 2002, 15). Elkins also asserts that, "we don't see ourselves clearly as persons in the activities 
and work that we do until we recognize the story that we live out in our work and in our lives"' (Elkins 1985, 140). Status and role thus don't determine the identity or personhood of a person. Like a static and totalizing ideology, the framing is too narrow and restricted to reveal a person or a community. An individual can be a great football player, and not be a person in communion, which requires being in a certain quality of responsive relationship with an other or others. Thus, instrumental performance-based identities can render an individual vulnerable to being seen as instrumental one moment, and irrelevant the next.

\section{The Narrative Path to Active Communities}

It is plausible to ask the question, can community even exist without some form of open and inclusive storytelling? "Within free public spaces, face-to-face relationships can be formed and developed through processes of storytelling and dialogue..., [where] sharing and listening across diverse experiences and perspectives [co-produces] an understanding of each other's perspectives" (Rossing and Glowaki-Dudka 2001, 732,737). Bender reinforces this idea in his description of Tonnies's gemeinschaft and gesellschaft theories of social forms (Bender 1978, 17). Regardless of the form, quaint small town or large modern or postmodern city, community is neither subverted nor presumed as inherent in 
either. As Bender puts it, "community happens where it happens" $(1978,6)$. It is a quality of experience that occurs in various types of places - not independent of a particular social form or type of place, but not determined by that form either. As such, there appear to be two features - the communicative posture of persons with each other, and adequate public space where these interactions can take place without being predetermined. Denizen and Lincoln have noted that we are witnessing in American society a "shrinking public sector" where safe spaces might have previously existed (Denizen, Lincoln 2003, 194). They also suggest that such safe spaces can be commonly found within "cultural arts programs, where men and women join self-consciously across racial and ethnic borders, to create what is not yet, a space of images, a series of aesthetic products that speak of a world that could be" (194). The arts may indeed provide the kind of public space where the depth of community forming interaction can take place.

Lane and Dorfman describe the kind of relationships that come from diverse persons engaging in dialogical engagement as "active relationships..., [defined as] relationships that cross role boundaries" (Lane, Dorfman 1997, 7). They assert that when "active relationships are weak, then community infrastructure is weak" (8). Furthermore, they assert that "communities that exhibit this type of active relationship present the greatest potential for 
sustainable community action and renewal" (9). Similarly, Wilkinson identifies community well-being as resulting from five general conditions: "distributive justice; open communication; tolerance; collective action; and communion" (Brehm 2004, 411). However these conditions have to be cultivated or catalyzed by something. By applying our previous discussions about knowing through narrative processes, it is reasonable to expand Wilkinson's open communication condition into a process of listening to, telling, and responding to stories as a catalyst for the other conditions to emerge - distributive justice, tolerance, collective action and communion. How can we know what justice is in a given context, without entering into the more expansive narrative process of open communication, that reveals setting, plots, and actors - all vital to understanding a given context. Religious philosopher Iris Murdoch confesses that "to respond to the world justly, you first have to perceive it clearly, and this requires a kind of unselfing" (Murdoch 2001, 82). What we could infer from Murdoch's words, is that to respond to the world with sustainable intent (social justice, economic viability and environmental stewardship), we have to enter an inclusive storytelling process so attentive and committed to discovering meaning in a given context, that individual agendas of the self slide out of the driver's seat where they can be altered as well as guided. This means that loosing oneself 
from the agendas of the self is a by-product of fully committing oneself to the active work of responsive interpretation that is found in genuine storytelling.

It can be argued that the status of a given sense of community can be determined more by analyzing processes than by categorizing individual attributes. In contrast, in much previous community analysis "it has been assumed that the sum of the parts will provide an indication of the overall sense of community for a particular group" (Sonn, 1999, 211), or that community may be understood by simply adding up the tendencies of its members" (Mankowski \& Rappaport 1995, 214). Instead, we need to see "beyond the [individual] components of community and explore the shared understandings group members have of their communities and the processes that foster community and lead to community formation. Communities are more than structures and are constructed by their members and a combination of social, political, economic, and cultural factors"'(Sonn 1999, 211). The resulting broadened identity of each other in community can replace a more limited understanding based on predetermined categories of status and role alone. This broadened understanding of self and others in community can lead to the discovery of not only new capacities, but of new ways of visioning those capacities to serve what is most meaningful and good for everyone. 
Creating a public venue for staging a community's stories can render a more inclusive identity in contrast to those proposed by the more instrumental frameworks. The importance of community storytelling platforms is highly significant, although these platforms are typically relegated to cultural heritage centers. "Shared history and systems of meaning are foundational to the development of a sense of community" (Sonn 1999, 212). In contrast, surveying in order to come up with the cumulative total of individual and institutional attributes comes up short of the broader identity and discovered attributes that inclusive storytelling can bring to light. There are a growing number of initiatives that demonstrate the evolving role of narrative processes and the arts in community building and development. The website communityarts.net, though currently in a dormant status, still remains an accessible source for dozens of archived articles and stories about art initiatives that have worked towards "animating democracy" (Burnham 2003). The Orton Foundation out of Denver, Colorado has been instrumental in advancing and funding arts-based story projects as a means of community building and place making across the country. Sojourn Theatre based in Portland, Oregon has created a number of projects that have brought to the stage real stories of local people around issues of the built environment, questions around the city's future and bringing to light 
the personal relationships of urban- rural interdependence (regionalism). It is perhaps in these public storytelling venues where "two [or more] social and psychological worlds" overlap, that provides the "creative disorderliness" where pause for responsive interpretation is most afforded (Bender 1978, 146).

\section{Story and Critical Race Theory}

Public storytelling demonstrates potential for creating new understanding where the deepest differences come together. Critical race theorist Derrick Bell has moved the issue of racism from the struggle for structural justice to a more realistic analysis - one that asserts that expressions of racism are deeply embedded in the American way of life itself in the form of a totalizing ideology. Such an ideology can become Gramsci's notion of common sense. Bell assesses that the agenda of White America is to acquire property and wealth while climbing the ladder of status, which positions Whites in a race to the top. These race agendas of White Americans are driven by this imbedded cultural mandate to acquire, which also encourages varying degrees of enlightened patronage that serves to reinforce the perceived status of White superiority. These perpetual White race compulsions serve to undermine the possibility of new discovery as well as the experience of community where personal relationships are formed (Bell 1992). 
In considering his analysis, it is interesting that Bell uses stories to reveal what is really going on at the most mundane depths of American culture. Stories discover the plots, attitudes, behaviors behind the ideologies that guide the unsuspecting on both the winning and losing side of the American Way. Bell doesn't seem to be using story in its popular agenda-driven way of advocacy for victims and against victimizers, but as a means of getting to the real, and as such exposes plots behind actions. Getting people to truly enter into stories can be a subversive process that may temporarily suspend race agendas, so that deeper understanding or even awareness can be awakened. What is suggested here is that getting to an understanding of the realities of racism requires agendaseeking individuals to lose themselves into meaningful and transforming discourse, which renders active their capacity for listening to, telling, and responding to stories.

\section{Communicative Agency and Storytelling in Community}

It is the assertion of this study that communicative agency is a narrative adaptation of Habermas's ideal speech act. It is operative when a person makes an honest and sincere attempt to convey meaning to another that invites response for the purpose of bringing about new understanding of both self and the other. Being a storyteller - adding observations up to construct a coherent 
whole that includes all the elements of a story--requires demonstrating a certain quality of being on two fronts. First, honest interpretation is demonstrated by being open to new discovery. Second, one sincerely constructs and communicates the resulting story all-the-while remaining totally committed to revise one's story in response to any and all convincing re-narration from others. Thus, being a storyteller brings with it a certain resiliency and freedom from external forces, while at the same time opens one out into meaningful responsiveness with others where new understanding can be co-produced. Nietzsche makes a similar assertion that "if we possess our why of life we can put up with almost any how" (Parry 1994, 1). "For Buber, [this storytelling way of being, or] existence is principally the enactment of communion. The self is transformed into an autonomous essence in the very process in which the relationship with the other person unfolds, when the self is confirmed by another person...Without the Other, the I is impossible" (Cohen 1983, 51). There is an interdependence that is inviting and responsive, but not controlling for the purpose of determining some end. All of this suggests that communicative agency can be dormant and fail to be operationalized, which leaves an individual in one of two closed systems - enslaved to the isolation of self-projection or totalized via external determination. 
It has been asserted previously that community is a quality of experience that is "mutual" and features the bubbling up of "sentiment" or affection (Bender $1978,7,8)$. What community is not, is an act of self interest, nor the result of geographical boundaries. (ibid) It is reasonable to suggest then that community can happen when meaningful interaction occurs between two or more persons. Social Theologian Alistair McFadyen would add that the resulting "sediment" of meaningful engagement with an other is actually the formation of a person in community with an other (McFadyen 1990, 7). For the engagement to be meaningful, it must be a storytelling event, as story is the vehicle of meaning. This puts the operation of narrative communicative agency between two or more people at the very starting point of the formation of a community. It is not a form of communication for fighting against powers, or for fixing problems. It is the capacity to participate in community and to begin to discover and understand what is good. This does not empower some, and decrease the power of others. Instead, it activates a different kind of power - a power with, which really does challenge the common sense of the day.

\section{Common Challenges to Narrative Theory and Praxis}

While there is growing theoretical support for narrative processes across many disciplines, challenges to the viability of story nevertheless remain. Most of 
these are imbedded in false notions about story that need to be overcome if story is going to become a widely used process for urban planning and community building. The challenges seem to loom large as there are a variety of culturally based assumptions about story that serve to undermine its validity. As has been previously noted, technical knowledge of numbers enjoys a common sense position in American culture as undeniably true, while concurrently telling a story is at times associated with telling a lie. These common cultural notions can undermine the work of interpretation and response by keeping story at arms distance from matters of importance.

A second common perception is that story is conducive with sentimentalism or emotionalism and therefore not rational. This allows for the use of story to be seen as a vehicle for exposing the emotions, wounds, complaints of an individual or group that has an axe to grind by those that underachieve. Thus social injustices are able to be reframed as the weakness of those who come up on the losing end of the race to the top. However, functioning as a storyteller enables a person to reveal that there may be a plot to deny all other interpretations, and thereby negate the possibilities of learning. In the reciprocal process of storytelling, the roles have indeed been changed, as “what was margin is now center" (Denzin and Lincoln 2003, 637). 
Martha Nussbaum has shown that emotions and rationality are so interwoven that they are virtually inseparable. This means that while the accountant crunching the numbers for a megaproject may posture himself as completely rational, objective, and un-emotional, that in reality, the accountant's emotions run as deeply throughout this process as they do inside a skilled storyteller crafting a story. The same is true of rationality, as rationality is tantamount to being a good storyteller -- otherwise you end up with something incoherent, which is the opposite of what storytelling intends (Nussbaum 2001).

Another challenge to story as a viable process is the devaluing of public spaces. The word public and the public realm itself has been the target of private interest actors intent on advancing economic agendas. Robert Putnam's book Bowling Alone also paints a grim picture of declining public encounter and exchange. However, while some public venues that have accommodated narrative encounters are in a position of decline, other places are opening up, such as public parks, green spaces, and even community serving coffee houses. Sojourn Theatre has utilized private spaces such as automobile service departments and real estate show rooms to stage meaningful public dialogue and reflection about what is Good (Sojourn Theatre 2007, Good). 
A more serious challenge seems to involve the will, the intent, and/or the conviction to make space and time for participating in a more inclusive storytelling engagement. This is less challenged by space-design issues than it is by the lack of openness and attentiveness in contrast to the obvious habits of individuals constantly seeking the fastest and least resistive path of pursuing self-serving agendas. While we may begin to correct and deepen our understanding of narrative and thus correct the misconceptions, we still find the belief by many is that progress is the result of individuals turned loose to pursue their agendas without restraint. Ultimately we are left with is the question of whether society and individuals benefit more from individuals pursuing their own agendas, or from pursuing that which is good that is potentially informed through narrative encounters with others. One is more of a straight line path while the other facilitates losing oneself in a collaborative process, only to find oneself as a person in meaningful community with others. 


\section{Chapter 3: Methods}

This research study seeks to discover and analyze the stories of local citizens about the reported results from the 1992-2012 productions of the collected stories of Colquitt, Georgia called Swamp Gravy. City officials, participants, and attendees all described varying ways that the performances had influenced the community of Colquitt. Four types of emerging results seem to stand out from the these reports: experiences of community that include the formation of relationships across boundaries of race; personal empowerment; a new community identity; the formation of new community serving institutions and economic growth. All of these outcomes were reported to be connected to the storytelling performance called Swamp Gravy. Therefore the central question in this research was to find out from the performers as well as general citizens: what does Swamp Gravy mean to the community of Colquitt, Georgia?

In light of these varying results, a subset of questions will be posed, such

as:

1. Did Swamp Gravy change people's perceptions about other persons, including persons of a differing race from their own?

2. Did the Swamp Gravy plays make people feel empowered?

3. What effects on the identity of Colquitt did Swamp Gravy create? 
4. What community serving institutions were started as a result of Swamp Gravy?

5. And, what are the perceptions about how Swamp Gravy enhanced the economic growth in the community of Colquitt, GA?

\section{Data Collection}

This research has proceeded along a narrative structure, and incorporated a mix of qualitative methodologies - specifically, open-ended interviews, field observations and documentation review. Subjects were invited that represented a wide range of Colquitt citizens, which included key informants that were central to the process, as well as Black citizens for the purpose of obtaining a racial balance. The subject guidelines thus included: racially diverse; a mix of male and female; various age groups, both the young and the elderly; persons of varying lengths of residency; participants in the plays; members of audiences; and local citizens that might not have seen or participated in the plays. In all, 47 persons were interviewed. Forty five were local residents. Two were members of the Community Performance team. Of the forty five local residents: 5 were official representatives of CMAC; 22 were Swamp Gravy volunteers; and 13 were not directly affiliated with Swamp Gravy or CMAC. Of the 45 local residents, 11 were Black. Seven Blacks were Swamp Gravy volunteers, and the remaining 5 were not affiliated with Swamp Gravy or CMAC. 
The qualitative interviews involved key persons in the original conceptualization and production as well as audience members and general citizens of Colquitt. The primary goal of the individual interview was to facilitate narrative responses from open-ended questions. These narrative responses provided cumulative perspectives that further identified and gave meaning to the results that the Swamp Gravy plays were purported to have produced in the city of Colquitt - especially as they pertained to new community experiences, relationships across boundaries of race; perceptions of personal empowerment; as well as perceptions of institutional and economic development. Persons from community serving institutions were included in the personal interviews. These institutions were written about in numerous newspaper articles in The Miller County Liberal, as well as further described by CMAC officials, the Swamp Gravy website and promotional materials including the various editions of the Cotton Hall Newspaper. All of the resulting data underwent content analysis, which interpreted the results into a categorical framework that consisted of the five subquestions to the research question.

Field research was conducted by attending five different Swamp Gravy productions between 2008 and 2011. This included observation of rehearsals, volunteer meetings, as well as becoming familiar with the ebb and flow of 
business on the downtown square - both on days when Swamp Gravy was open, as well as on days when the play was not scheduled to be performed. Field research included attendance at the funeral of a prominent cast member (January 2008), where Blacks and Whites filled the local Cotton Hall Theater for a service that featured four local pastors (2 Black and 2 White). Considerable time has been spent in the presence of the principle persons behind the community performance - Richard Geer, founding director, and Joy Jinks, the local community organizer. Field observation also involved participating in three community festivals in Colquitt between 2008 and 2010 as well as observing the community performance process that was used to develop Swamp Gravy applied in other towns (Lavonia, Georgia 2008, Hampton, SC 2009, Asheville, NC 20010).

Additional documentation was gathered from a number of sources including archived magazine articles at CMAC and historical books at the Colquitt-Miller Library. Additional information was provided by CMAC that pertained to institutional development and financial information that demonstrated the growth of the play's economic influence on Colquitt. Additional sources included the U.S. Census Bureau that provided statistical information about Colquitt and Miller County. The Center for Creative Community Development at Williams College (Massachusetts) economic study 
provided both a summary analysis of economic impacts that were realized by area businesses as a result of Swamp Gravy. Interviews were conducted using a small (1" by $.5^{\prime \prime}$ by 4 ") Sony IC recorder, which allowed for a lapel microphone to be clipped onto the subjects clothing or placed on a table next to the subject. Interviews were predominantly conducted inside Cotton Hall Theater space during off hours, where the use of a general store constructed inside Cotton Hall produced a natural conversation area. Traffic inside Cotton Hall was minimal, but offices in the building were occupied during interviews. The interview space was visible by those coming and going from Cotton Hall, as the storefront was predominantly glass windows. Additional interview notes were written on lined sheets inside of a 3-ring notebook.

Recordings were transcribed by listening to playback of the recorded interviews. The typed transcription from each interview was placed on numbered lines and coupled with the corresponding interview observation sheets. The research questions derived from the reported outcomes of Swamp Gravy were used to formulate categories that were each shaded in a specific color. The transcribed material was then color shaded to match the specific category or categories that it most closely informed. Field notes from several 
Swamp Gravy performances and one funeral combined with additional documents to provide additional layers of content that both guided the episodic interviewing as well as provided additional contextual interpretation. 


\section{Chapter 4: Community Performance: Process and Praxis}

To understand what Swamp Gravy means, a good starting point is to look at what Geer believed that he was doing. This had implications for how he and his technical team went about the work that they did - from gathering the stories, to setting the stage. While Geer had ideas that influenced what he wanted to do in Colquitt, it was not a clearly communicated formula. This was complicated even more by the fact that Geer didn't have much in the way of common ground with many of the local residents. What he had on his side was that he had not come to intending to intervene, but to use the peoples of Colquitt's own local stories through which they would see themselves and others potentially deeper, and as such discover new slants about what was good in their community that they might not have seen before.

What Geer had in mind for Colquitt was first shaped by his experiences in Steamboat Springs. The celebration of heritage that Jinks had in mind might be a by-product, but it was not the primary focus of the community performance process that Geer developed in the years after Dracula. The process of gathering stories across boundaries could coproduce a more representative local heritage. Whether this end result would lead to a celebration was yet to be discovered. Geer's experiences as the director of Dracula in Steamboat Springs had led to a 
deep conviction that theater could be used to both deepen and activate community. This notion later became his focus while a doctoral student in Performance Studies at Northwestern University. Geer began making alterations to traditional expressions of theater. The most obvious changes included: replacing the imported or familiar story with local stories; and likewise replacing professional actors with local volunteers. Drama theorists and innovators like Baz Kershaw and Ann Jellico from England had experimented with having local non-professional actors act out a well known local story of historical significance. Geer pushed beyond this innovation to feature the gathering of local common stories in the form of oral histories. These stories would be combined together through a creative process that would weave the stories into a cohesive performance script - what Geer had coined as community performance (Geer 2011). At the time of his meeting Jinks and Wainwright in Chicago, Geer had begun to describe Community Performance as a form of, "outward bound for communities." This came from Geer's early efforts to understand exactly what had occurred in Steamboat Springs that manifested collaborative applications of the play's central lesson and positively influenced the community's current situation of crisis. Geer was less sure that the Dracula play had a direct impact on guiding the community to act in collaboration, but he was convinced that it 
contributed to the field of knowledge that consciously or unconsciously informed possible responses to their crisis. Outward Bound is a two-week wilderness camping experience where campers are led into a series of challenging tasks - some that require group collaboration, and others that are intended to challenge the individual. Through the successful completion of these various challenges it was hoped that the camper would return back home where their recent success would be translated into confidence to push forward in similar challenging situations (Geer 2011). The various venues within an Outward Bound experience sought to place or stage a camper in a situation that replicated - or was an "isomorph" of a situation in their real world where they were failing to act (Bacon 1983).

While similar to Outward Bound, the staging of Dracula was still a couple of steps removed from what eventually became community performance. The Steamboat Springs audience had recognized that the story paralleled their own situation in one significant way. They too were facing an adversary that as individuals they had no power to overcome. That is, in Dracula, they saw how a collaborative effort was the only way that the villain could be defeated. So the audience recognized their own situation being represented in the Dracula story. While Geer is hesitant to suggest that the resulting community collaboration was 
a direct result of Dracula, he was certain that the degree of audience response to the climax scene where Dracula was defeated charged the audience like nothing he had seen before. The audience was on its feet during this scene. At the conclusion of the play audience members started tossing their socks to the stage. The performance had "knocked their socks off." Their charged response led him to further pursue his initial theory about the use of theater in building and activating a community (Geer 2011).

Geer eventually left the world of professional theater to direct theater made by real people out of real life. He had an intuition that people would be drawn to this kind of theater experience. Geer's main motivation was not to discover and popularize a new form of theater, but to "help communities realize themselves" (Geer 2008, interview). Geer was not sure what that might lead to in a community. His vision was more about staging something authentic. He felt strongly that community performance using real stories and real community volunteers would demonstrate the authenticity that communities needed. By authenticity, Geer meant that local stories and local actors would offer up an experience that successfully depicted local realities, thus bringing any lessons and corresponding applications gleaned from a given performance more weight in the consciousness of the audience. His experience in Dracula told him that he 
should expect some ripple effects in the community. He was not sure what that might look like in the places where he eventually took his community performance vision.

\section{Historical Parallelism: Beyond Confrontation}

One of the critical additions to the isomorph factor was Community Performance's utilization of what Geer called, "historical parallelism." Geer could see that staging a local story in the exact time and place including the real names could be problematic. Stories that contained a certain amount of "heat," for whatever reason would be best "set many years in the past," which would bestow some anonymity at the same time that it opened up more of a universal access to the story, and thereby invite unlimited applications of the story's meaning or meanings. In essence, the audience and the actors might see situations in the story that mirrored situations in their own lives, whether the situation was their own or not. Secondly, Geer did not want the plays to be experienced as a "finger pointing" session that painted a real person from the community into a totalizing and problematic corner. Community Performance tries "to discover a time period in which to set the play that is at once mythic, nostalgic, and aesthetically distant enough to handle hot material" (Geer 2011). 
By utilizing what Geer calls historical parallelism, community

performance also moves beyond a position of advocacy, which is designed to confront the wrong-doers without mincing words. San Francisco Mime Troupe is well known for this brand of theater which exposes the moral bankruptcy of a real person, persons, corporations, and/or institutions with a flair for hyperbole and satire. While this approach is both entertaining and important, the actors don't have to go home at the end of the performance and live in regular contact with those they target. In contrast, community performance, produced first in the very small town of Colquitt, attempts to stay on top of a slippery slope of not sacrificing meaning for entertainment on the one hand, nor sacrificing community with others by casting a situation that totally demonizes a community actor to the point that it renders the formation of a reciprocal relationship virtually impossible, if not altogether undesirable. The community performance path is not only potentially slippery, it is also highly nuanced. Geer, drawing from Kershaw's performative theory explains that utilizing,

the Old Timey period ..., lets us deal in lived stories too hot to tell in the present tense... We are not presenting great grandma's world when she was a little girlthough it looks that way. Such an innocent, inexact and nostalgic attitude hides a clear and strong intention. The Old Timey period lets Community Performance satisfy its audience's need for nostalgia while licensing the production to deal in parables... Take the same hot, in your face issue, and find a way to put it, say, eighty years into the past. In-your-face becomes food for thought, and our 
reception of snarling emotions becomes even handed and compassionate. When that happens, heart-change can slip right past the sleeping Ego... The stories carry in them distinctive, often contradictory, community identities. Got up [or framed] as parable and distanced in time, the community..., and individuals decide which persona (or personae) is theirs. In a nutshell, this is how Community Performance creates social change in performance. An audience member embraces the image of her community and with it an altered and compassionate viewpoint, previously not owned (Geer 2011).

Being that Colquitt is such a small town, volunteer actors still often know who a story is about, as do many members in the audience. Determining how far removed a scene needs to be, whether in time, gender, or race, is a decision which volunteer cast members are enlisted to decide together. While Geer is the director, theirs' is the role of the amateur experts who possess the local knowledge and collaborative give and take to make critical alterations to the play. This reality attempts to distance Geer and other members of the community performance team from being seen as meddlesome outsiders trying to stir up trouble. Volunteer cast members are therefore afforded the opportunity to grow into this role - one that is critical to the success of the plays. Mediating such decisions together also provides collaborative experiences that can empower them to collaborate in similar situations of daily life outside of the theater. In essence, the cast members experience what it is like to mediate responsive solutions. In the case where several stories of sexual abuse had been submitted in consideration for an upcoming Swamp Gravy, the cast were the ones that decided 
whether to use the stories or not. The cast decided to use them and the writer had to come up with a way to stage these stories that dealt with the issue, without risking finger-pointing or overt identification. Some members of the cast knew who the (deceased) perpetrator was based on prior knowledge, as did many people in the audience. The story of sexual abuse itself was significant for many in the cast and in the audiences, regardless of the specific identification of the person in this particular story (Anonymous volunteer actor, 2008).

\section{Proleptic Stories: Playing Forward Lessons for Today}

In keeping with historical parallelism, another feature of the community performance is the function of "a story of future past...," or, a proleptic story. This kind of story illustrates a solution in the past that informs a potential action that is a potential solution in a current situation. One example of such a story could be taking a piece of history such as a time in Miller County when all the forms of farming were successfully managed without having access to industrial fertilizers, pesticides, or even machines - an historical reality that was revealed in Chapter 1 of this paper. In highlighting such a practice in time, contemporary actors in response to a current agricultural crisis might find suggestive influence from the past that demonstrates a potential solution to a current dilemma. The application of proleptic stories in daily life situations often remain undiscovered, 
as audience and cast members alike turn such meaningful lessons into commonday solutions sometimes unconscious of where the solution-idea actually originated. Even when applied consciously, connecting the past story to a current solution does not always become common knowledge in the community unless someone goes to the effort of making it public knowledge (Geer 2011).

The Swamp Gravy production Visiting Hours, by Jules Corriere, demonstrates a number of lessons that have a variety of applications in contemporary Colquitt. The spine of the play is a primary story. Other stories are used to break in on the primary story, and usually appear on an adjacent stage between the scenes of the primary story. These stories are "saws" where some aspect of the primary story gives occasion for a diversion - sometimes a loosely related story, and other times branching out a story that mirrors or is closely related to the plot of the primary story (Carson 2008). In Visiting Hours, the primary story is about a lady that has an extra room in her home. It was customary in those days to put out some form of a sign (a quilt hanging in the window in her case) that let travelers know that a free room for overnight stay was available. In this case the lady of the house was a widow, and her grown children were not fond of her practice of letting strangers stay in her home overnight. The room was accessible to arrival and departure without requiring 
any face to face exchange. One frequent passerby always arrived late and departed early, while leaving behind in gratitude a cutting of a flower, vegetable or herb that the host would always plant in her garden. As the garden grew, she would share cuttings with her neighbors, and give her granddaughter seeds to plant, since many of the plants were uncommon or exotic. Her granddaughter was not impressed by the garden or the seeds. However, the garden over time became a community garden, becoming valued by many of her neighbors.

One day a flood came and destroyed many houses in Colquitt along with washing away the garden. The lady was certain that all was lost. However, it turns out that her granddaughter had held onto to the seeds that she had been given by her grandmother. With the seeds, her granddaughter with much assistance from the community was able to replant and eventually restore the destroyed garden to its former condition. In many ways, Visiting Hours demonstrates some parallels to the Dracula story with a few twists. Members of the community came together in a collaborative effort to rebuild the garden. The garden itself was made possible by a stranger who had given the cuttings out of gratitude for the open-arms hospitality of the grandmother. She had asked for nothing in return for the lodging that her extra room provided to travelers. Food for thought from this story might include thinking about community as an open 
and inviting organism whose well being comes from neighbors that you know, as well as from others from outside the geographical lines. The story also demonstrated the value of multi-generational interdependence and relationships. As such, the story taught the virtues of a vibrant community: open and inviting, valuing others regardless of their status and role or geographical roots, the richness of diversity, and the necessity of preserving local knowledge. And in this case local knowledge in the form of seeds had originated from a stranger that didn't actually live in the area.

The story in many ways reflected the Swamp Gravy volunteer community itself - a diverse representation of as many as 100 volunteer cast members and close to 100 more that volunteered in adjunct support roles - all playing vital roles in the success of the Swamp Gravy performances. One of the play's central characters was the stranger passing through the area that left behind cuttings of exotic plants in exchange for staying in the Grandmother's extra room. This role was played by a newly arrived Vietnamese resident. He was very quiet and shy, which made him perfect for the part, as his role as the traveling stranger had no speaking parts. The audience only sees him as a mysterious silhouette that comes and goes, yet consistently leaves behind cuttings for his host's garden. The play served as the apparatus through which the newly arrived Vietnamese resident 
went from being virtually unknown by most in the community, to becoming widely recognized by many in Colquitt, and loved by those in the cast. As for the practice of hosting others, the Swamp Gravy play Visiting Hours like Dracula was absorbed into the field of knowledge of the theater goers in Colquitt.

Coincidentally, the popularity of the Swamp Gravy plays has led to the increased presence of travelers coming from distant places to see Swamp Gravy. Commercial lodging availability in Colquitt has never been able to meet the full albeit periodic demand of travelers that come to attend the plays from distant places. As a result, many in the community - some even widows, have become accustomed to hosting travelers who need a place to stay, all the while expecting nothing in return, and all mediated by CMAC and the Swamp Gravy community. As such, in some instances Swamp Gravy is not just playing forward stories from the past (a proleptic), but are contributing to actually living those lessons in the present.

\section{Community Storytelling as Responsive Self-Regulation}

According to Geer, "a community is an organism [that is] constantly adopting, processing, and adapting to new information through stories"' (Geer 2011). However, this information can be provided by a number of other sources other than active storytelling. Some common sources that provide regulating 
information include: ideology; experts; status (wealth) and role (occupation); cultural norms (heritage); and religion. All of these can play a regulating role in a community as each can become an interpretive lens for defining (sizing up) an individual or a situation. When these other sources are relied upon, the responsibility to interpret the person in a context or story is relieved, which renders a person's capacity for interpretation as passive or unnecessary. However, taking the time to interpret stories creates the potential for a deeper level of community discovery, thereby informing a more contextually derived form of self-regulation. Response to others can thus emerge from a personal engagement of a narrative depth where discovery of the true person is begun. In contrast, when a community's self-regulation is already determined externally, personal engagement through a story or stories is no longer required. The external determination both informs and licenses how an individual or individuals are to react towards an other. But, how a person as interpreter responds to the other is regulated by what is discovered in a story or stories that reveal the other. In the case of a new resident in town whose origin is somewhat exotic (Viet Nam) - until it becomes known what he: does for a living; has in his bank account; believes about a local God; or, prefers in terms of politics, regulation will have to come from heritage, which in a closed system or clan will 
determine that he is not one of us. At best, a community centered on external devices of self-regulation will demonstrate an inviting curiosity until they can see how someone measures up through one or more of the lens's through which their defining conclusion is determined. Visiting Hours suggests we suspend all external devices of interpretation until we see the person in a story, and thus discern how that person acts in a situation with others (in a story). That will begin to tell us who they really are, including what their value to the community might be. This ensures that a community's self regulation is likely to be personally engaging, contextually derived, and responsive (versus reactive).

\section{The Holographic Story}

“The holographic story carries the community's entire image in its narrative" (Geer 2011). In the Swamp Gravy performance, Nuthin But a Will, also by Geer's partner, Jules Corriere, two different characters portray a holographic image that reflects the realities of their community. This storyline branches off of the primary spine or story of the play, and is about a Black teenager named Dololy, who is learning to fill the role of domestic helper in the home of a White family. She has returned home from her first day at work where she enters into a reflective conversation with her mom about the day's events. She is reporting to her mom that these White people must be rich, because they have several piles of 
money lying around their house. Her mother tells her that what she is seeing is fire, and that it will burn her if she touches it. It was common practice for White employees of domestic helpers to set out money in piles around the house to see if a newly hired domestic worker would take any of it. While a common practice, what borders on entrapment certainly demonstrates the distrust that Whites had towards Black domestic workers. Beyond the mother's initial warning to her daughter, nothing more is discussed about the practice. Audience members are left to reflect on the common practice and what it means to others.

Corriere's scripted exchange between the mother and daughter is instructive and endearing in many ways. The story expands any reductive notion of domestic work that could be demeaning, yet without glorifying the role itself. The conversation in the midst of a mother ironing a dress for her daughter is tender, patient, informing - demonstrating all of the attentive traits of personal mentoring while also carefully attending to the craft involved in ironing. The storyline highlights the loving relationship of a mother and daughter that is instructive on multiple levels. She is multi-tasking, fully present, loving, and responsive to every detail of her daughter's report. The depth of the mother and daughter's relationship - who they are as loving persons, as well as their attentiveness to craft, reveals them as persons that the audience can respect and 
love. As such, the individual's status and role have been upstaged by the quality of the relationship that they engage in, and the mutual attentiveness to craft that they both demonstrate. Corriere accomplishes all of this without either demeaning or glorifying domestic work. This story is universally instructive for all persons. The story and the conversation are simple, not embellished with sentimental music, and not overly suggestive of a conclusion - it is community performance that invites the audience in, to discover, reflect and respond. Left unresolved is what the scene reveals about a lack of trust across boundaries of race and status.

\section{Multiple Stories Provide Multiple Perspectives}

In community performance, multiple stories on multiple stages all work to provide multiple perspectives. While there is a central story that serves as the spine of the play, other stories, some more closely related to the primary story than others, all branch off of the spine. These support stories can deepen interpretation as well as contrast the primary story. In many cases similar stories are combined into one story. Or, in the case of what many identify as their favorite story - "Brown Dress," from Swamp Gravy's Blue Doctor, by Jo Carson, one story is told by two different actors. "Brown Dress" is a story of Black woman who along with her children was abused by her husband. Two women played 
the role at the same time, alternating lines. One was White and one was Black. Each one told the story on a separate stage - with the role switching back and forth from one woman to the other as what became their story progressed side by side, and line by line. The creative use of two women, one Black and one White strongly suggested that the experience of women being physically abused by men was universal. The original reason for dividing the lines was because a monologue would be too demanding for an amateur to pull off. In this case the divided role provided unanticipated benefits (Geer 2008, interview).

A Black school teacher had submitted the story after moving to Colquitt to get away from her former community where her real life story of being physically abused by her husband had come to a dramatic ending when she took her husband's life - an ending that she desired to leave behind and forget. Having tired of being beaten and watching her children being beaten, one day during one of his attacks she picked up a rifle shot him. The story staged in Swamp Gravy had one actor telling the story in response to being questioned by an actor playing the Sherriff. On a parallel stage, a White Woman would tell the next line of the story. (The use of multiple stages is discussed in the Designing Theater with Community in Mind section of this chapter.) The two women eventually moved towards each other onto a common stage where they stood 
arm in arm, each one holding the other up as they told the next line of the story, alternating back and forth one line at a time. The woman that had submitted the story was not in the play, but she proudly identified it as her story. She wanted the people of Colquitt to know who she was. The resulting food for thought involved everything from gender and race to status and cultural norms. In the end, the play had welcomed the woman into the Colquitt community baggage and all, providing another example of how storytelling self-regulates community and how community performance gets stories and storytellers to intermingle.

\section{Activating a Community of Communicative Agents}

Stories are not only tools of self-regulation, but they also make community possible. "The community may preexist this weaving [a Swamp Gravy script and performance...], or the community may come into being through the act of story" (Geer 2011). Community performance can be a rite of passage for community - moving from a position of passivity to being an active community. Many communities are passively determined by external forces. At its most reductive status, a community may be seen as a geographically bounded space where individuals exist until it is time for them to take on a role (often work or school) that requires them to leave their place of residence for a period of time. There are also structures at play including ideologies that determine what roles 
one plays. All of these are features of a passive community. However, as we have seen in active self regulation, people take the lead when they begin to listen to, tell, and respond to stories. At the individual level this requires a person to use their communicative agency.

Having individual agency has been commonly understood to mean having and expressing one's voice about a given matter. Communicative agency works with an entirely different set of muscles than just expressing voice.

Communicative agency "shifts [from voice] to the agency of participation" (Geer 2011). The participation of listening to, telling, and responding to stories with others is a complex function that is synonymous with operating one's communicative agency. This suggests a number of features that differentiates individual voice from communicative agency. When an individual is not living as a communicative agent, two postures can be seen in the individual's behavior. One of these is self-projecting, which becomes an alternate way that the individual attempts to communicate. This is seen as talking at others, as opposed to participating in dialogue with others. As such, the individual's intersection with an other can never move higher than their attempt to negotiate the satisfaction of an agenda. This individual may have voice and confidence, but as long as they remain fully captive inside this self-projecting posture, then 
meaningful communication will be negated. The second posture is reflected when an individual chooses to be a victim, or a non-actor. Put the two individuals together (the projector and the victim) and you commonly see a codependent relationship - one individual using the other and vice versa. Neither is acting in the way of community performance.

In "Brown Dress", the victim of abuse eventually acts in her story. But, she also responds to her situation when she decides to submit her story to be told on a public stage in front of her new community. In submitting her story to be used in a Swamp Gravy production, she was hopeful that her story would be responded to in Colquitt. She must have seen something in the Swamp Gravy event that had given her an indication that telling her story in Colquitt would be a good thing - otherwise, in keeping with having left her previous place of residence in the pursuit of anonymity, she might never have taken the risk of exposure. Telling one's story is really acting with others in hopes of experiencing a responsive intersection - storyteller to storyteller in community. Doing so requires exposing oneself to some degree of vulnerability. Geer poses the question, "why should we want to tell our stories? Ostensibly, we do it for our listeners, we weave community. But the storyteller's reward doesn't come from them alone. As we shape our story in the telling, our story shapes us. We gain 
new insights and meanings. Most important, we experience being alive. The experience is an encounter with one's own life and its unstoppable vigor. It is this encounter... with the other, and with the self, that is the greatest outcome. What I feel in a story sharing - one on one, or in a community performance-is love for other persons. I am drawn inside the speakers' points of view and experience with them the world of their stories" (Geer 2011).

In a community performance the storytellers are only sometimes actors in the play. Likewise, the primary witnesses during the performance are the members of the audience. The actors on the various stages have been listeners, and are now performers. It stands to reason that if the actors fall in love with the storytellers, and the audience falls in love with the actors, it is a good indicator that the audience loves the storyteller. "When, through story performance, we stand here as teller, over there as subject, and out there as listener, we are moving out of self and into other" (Geer 2011). As such, community performance can be a catalyst for new familiarities to emerge, thereby replacing old familiarities that are externally determined or contrived.

\section{Community: Performance and Mimicry}

The same bonding dynamic takes place within the Swamp Gravy actors as well, both internally within the community of volunteer actors, as well as 
externally outside the volunteer community. One Black performer commented to Geer after performing in his first Swamp Gravy play: "I felt tonight that the group really began to fall in love with one another. I saw Blacks and Whites working together and..., I could feel the love" (Geer 2011). This bonding is compounded as volunteers spend hundreds of hours rehearsing and preparing for the performance. But, beyond just the cumulative effect of time spent together, is the nature of their work together, mediating the particulars of the script and the performance, even changing the play in between performances to enhance authenticity - ensuring that community performance stays on top of that slippery slope of keeping things real, yet distant enough to be accessible without spiraling out of control into finger-pointing. The community of actors being held together by love and commitment to each other enables them to use local knowledge to co-produce the Swamp Gravy plays.

Mimicry of others leads to the realization of new relationships that informs new possibilities. Geer asserts that: "the performance of the other is perhaps the richest way humans can know. Performance is a sense beyond our five senses, a way of knowing which can lead to compassion and relationship with everything we perform. The first power of performance is to show the self to the self. The second power is to show self and other to, well, self and other. 
When we show the other, we become the other. I stand inside my partner's story" (Geer 2011). This standing inside the other's story can be a freeing experience. Many people have accepted roles in life that are not of their own choosing. Their role has been handed down to them through family influence. Others see their roles as determined or limited by cultural norms. Community performance does not seek to reinforce the notion that anybody can do or become whatever they choose - just that what one strives for is their choice. Playing in the role of an other in Swamp Gravy leads some to realize that they have such choices that they might not have realized before. Geer describes the shift in one of the Swamp Gravy actors in the following way: One actor "came off the stage and told me that he'd figured out how to be another sort of person. He would take what he learned onstage about the presentation of self and apply it to his life. The close of the season was the last I saw of him. I counted that a success"' (Geer 2011).

Sometimes the performance on stage can be so convincing to the audience that they begin to see the actor and the role as one and the same outside the walls of the theater. One audience member had driven three hours from Atlanta to see his first Swamp Gravy play, Nuthin But a Will. At the conclusion of the play he went up to a couple of the cast members and began to talk to them about their 
roles. One had performed the role of a preacher in the play. So, the audience member asked him what church he was serving in as a preacher. He was surprised to find out that the preacher in the performance was a construction worker in real life. The audience member moved on to talk with a second member of the cast, asking him how long he had worked in law enforcement, since the actor had portrayed a local police sheriff in the play. The actor remarked that he was not in law enforcement per se, but was a teacher in the local high school. Many audience members assume that actors are naturally cast within roles that they are familiar with or have prior experience. Community performance intentionally cast actors in roles that they are not familiar with, which can reshape both the role and the person of the actor. "If we cast volunteers in roles that they were familiar with, it would limit what they would learn about themselves and others" (Corriere 2012, interview).

“Cognitive dissonance, simply put, says that playing the other, changes us into the other by degrees" (Geer 2011). This intention to deepen the knowing of the self and the other differentiates community performance from the emerging public art, the new avant-garde. Grounding the world of modern art (including theatre) in contexts of location has given rise to a public art that attempts to address various issues. In this respect, community performance had moved a 
step beyond avant garde - an emphasis on exposing persons to themselves and others through local stories. The two can seem similar, but the difference is that public art focuses on issues, whereas community performance invites a deep engagement with a person through their story which can activate new possibilities for both the self and the other. Maximizing these new possibilities across the various boundaries of Colquitt would require that stories be gathered from all the diverse corners of the Miller County.

\section{Gathering Stories and Co-creating the Plays}

In order to stage a community performance in Colquitt, CMAC had to locate material that could be turned into a script for the Swamp Gravy play. There were no stories of historical significance. Nothing had ever happened in Colquitt that had put the town on the map. Geer had agreed to come to direct the project as long as CMAC was willing to initiate a process of collecting local stories broadly - meaning the stories of Black and White, as well as rich and poor, including any other identifiable group that resided in the area. The story area was centered on Miller County / Colquitt and the surrounding areas as well. Residents living in Miller County put Colquitt as their physical address on all of their correspondence. Everyone in Miller County is consequentially also from Colquitt. But, stories from outside the county were not excluded either. Life and 
stories spill over county lines every day. To launch an inclusive story-gathering process was the intention from day one of the Swamp Gravy initiative (Kimbrel 2008, interview). Story gathering notifications were announced primarily in the local newspaper such as the Miller County Liberal. A team of story gatherers was also created, with each person being assigned responsibility for a portion of Miller County (Traywick 2008, interview).

Nationally renowned playwright Jo Carson was brought in from Johnson City, Tennessee to write the script. Carson and Geer helped train volunteers in methods for collecting oral histories. The training included both Blacks and Whites. The county was divided into six story areas, and each story gatherer was assigned an area. The divisions were made in order to match story gatherer to a constituent population where they were most at home. Gathering the stories included the use of recording equipment as well as coaching on the writing of post interview notations. Stories were then transcribed into print, and handed over to the playwright. In the beginning stories were collected without any preconceived theme or subject matter in mind. After a few years the committee was instructed to seek certain kinds of stories - like stories about the train station, or work. Over the years, the storytelling committee has switched back and forth between open story gathering and thematically directed searches for 
stories. A common quote by Carson on the subject of story gathering was: "never let the facts get in the way of a good story" (Carson 2008). This was Carson's way of licensing the story gatherers to get what was important, and not worry about what was not important. Stories rarely come as a clear and sequential whole, but in pieces often intertwined with conversational diversions. What was important was to capture the meaning of what was being communicated - which pertains to the dynamics of the plot - the who does what and the why, along with what resulted in the climax of the story.

Carson was the script writer for the early Swamp Gravy plays. Her job was to read the collection of stories and find a single story that could serve as the spine, or primary story of the play. Other stories were identified that had some connection to the spine story. These stories were adapted and hung at various intervals along the spine story. As a scene from the primary story came to a close, one of the secondary stories would start up on a different stage, only to return to the further unfolding of the primary story until the conclusion was reached. Secondary stories were usually one scene long, whereas the primary story or spine involved multiple scenes - from the opening to the closing scene. While the secondary stories have some connection to the theme of the primary story, they 
aren't necessarily directly related or connected to the story as it originally occurred (Corriere 2012, interview).

There have been a number of script writers over the 20 years of Swamp Gravy, including persons from the Colquitt community itself. While Carson started the Swamp Gravy script writing process, the other primary writer of Swamp Gravy plays in the latter half of the 20 year history of Swamp Gravy was Jules Corriere. Corriere was a protégé of Carson's who lived in Newport News, Virginia, where she had been instrumental in gathering the stories and writing the script for a Geer-directed and Swamp Gravy style community performance project that involved a Mennonite community. The method that Corriere utilized was what she had learned from Carson (Corriere 2012 interview). Carson, from Johnson City, Tennessee embodied a mix of Appalachian mountain culture and progressive counter-culture. She demonstrated an overtly confident down-home presence that was playfully bold in the midst of ambiguities and contradictions, including those sometimes edgy spaces between traditional and counter-culture. A trait that further endeared her to the Colquitt community was her distrust of modernity. This along with her Appalachian dialect created some common ground that softened other differences between the progressive Carson and the traditional Southern culture of Colquitt. Her eventual departure in 1998 was the 
result of CMAC rejecting her Swamp Gravy script for that year - a play that was less a blend of stories along a single story spine, and more of a just single story, which was a significant departure from the previous Swamp Gravy plays (Carson 2008).

After a few years of experimenting with various replacements for Carson, CMAC settled in for a lengthy relationship with Corriere, who wrote from 2004 to 2009. Corriere did not have a Southern dialect. She was accommodating of others as was demonstrated by her willingness to make adjustments in response to feedback. However, she did not possess the same common ground that Carson had enjoyed with the local residents from Colquitt, nor did she arrive on the scene with the emboldened notoriety that Carson brought with her to the initial Swamp Gravy process. None-the-less, the process that she used was what that she had learned under Carson's mentorship (Corriere interview). Her skills were demonstrated in some of Swamp Gravy's most popular productions including, Nuthn But a Will.

The scriptwriter process involves reviewing 20 to 30 interviews (or stories) from which a primary story is chosen. The process allows for a primary story to emerge rather than be predetermined. The story that emerges does so by being deemed a primary story that completes, or is more complete in some form or 
fashion than the various other collected stories, some of which are folded in as "saws" that can hang along the spine of the primary story. Once it is chosen, the process continues through a precursory read-through with CMAC and members of the Swamp Gravy process. This allows for contextually grounded local knowledge from the community volunteers to be taken into consideration regarding everything from word choice to how a story is placed or displaced in a particular time and setting. CMAC and volunteers thus participate in "cocreating" the script from the development stages all the way to the final performance. In typical Swamp Gravy form, if a story is deemed too hot for the community to handle, then the script writer's job is to help reframe the story in such a way that makes it accessible without pointing fingers (Corriere 2012, interview).

If the story gathering process comes up with less than 20 stories, then the emergent process is significantly weakened. There has to be enough material to facilitate the emergent process. In one season (2009), Corriere was forced to weave a script from 7 interviews instead of the customary 20 to 30 interviews. CMAC had cut back on staffing as a result of the economic downturn that started in 2007. As a result, much of the normal Swamp Gravy operations were negatively affected. A much different result was produced in that case that resembled more 
the form of a traditional play, rather than the typical Swamp Gravy mix. One of the primary distinguishing features of community performance is the collection of enough stories that facilitates this emergence of a feature story. Without the appropriate number of story-interviews the process ends up either being more of a single story, or a collage of stories without a distinct narrative arc. The stories that are not used in the play go into an archive. Community Performance writer Corriere reports that she only works with stories that are current - meaning stories that have been recently collected. This keeps the resulting script both fresh and relevant (Corriere 2012, interview).

In more recent years the story gathering committee has dwindled down to as few as 2 persons. This decline is a result of a decreasing budget that coincided with the economic downturn in 2007. Neither of these remaining two story gathering persons are Black. Collecting stories from the Black community is performed by the person that is most familiar with the Black community. This has become the weakest link in what started out as an inclusive and participatory process. Black participation at all levels - storytelling, story gathering, acting, volunteering, and attendance are all areas where CMAC has struggled (Kimbrel interview). Geer has been marginally successful in leading efforts to enlist Black participation. He cites a number of reasons why this has been an ongoing 
struggle. Some Blacks in Colquitt lacked trust, and were therefore leery of being involved in a White project. CMAC from the outset has been a predominantly White organization - not as much by design, but more as a consequence of who started CMAC and how invitation to join an organization is often enhanced and/or limited by who is doing the inviting and who those persons are already most meaningfully connected to. There has typically been a Black on the CMAC board that share a common socio economic status with the White CMAC board members. All of the board members are of a middle class or above status. CMAC has been unsuccessful at enlisting Black board members from lower than middle class status.

The intersection of Blacks and Whites in Colquitt was not social as much as functional. The interdependence of each was felt primarily in workplaces, and not so much in social, civic or religious circles where the two races remained predominantly separate. In response, CMAC, Geer, Carson and Swamp Gravy volunteers adjusted the story gathering emphasis to the subject of work, and the play's concluding song, That's All That Matters - one of only three song staples in the Swamp Gravy plays that seek to connect along a common experience (Corriere 2012 interview). A recent play demonstrated a similar theme, Hard Times. 
Everybody faces hard times. It is the "great equalizer" in Black and White experience (Kimbrel 2008, 5). The lyrics to That's All That Matters are as follows:

I have worked all my life in the hot Georgia sun

And I have toiled, tilled and sweated

And left many tasks undone

But I can see my sun is setting and my

Heavenly Home draws near

So there're a few requests I'd like to make

Before I leave this earthly place here

(Chorus)

Oh bury me, beneath the shade of the tree

At the Antioch Baptist Cemetery

Bring some flowers to lay on my grave

And let the choir sing Amazing Grace

Bring fried chicken and hot corn bread

Stay up all night, cause we sit up with the dead

Say I was a good man, woman, mother daughter, son

Cause that's all that matters when it's all said and done

That's all that matters

That's all that matters

That's all that matters, when it's all said and done

Say I was a good man, woman, mother daughter, son

Cause that's all that matters when it's all said and done

(Repeat Chorus)

(Karen Smith Kimbrel 1994)

This common experience and belief by both Black and White alike is also

replicated in a story about a Black woman in Colquitt titled, Let my Work, Speak

for Me. This story is spoken about with much favor by both Blacks and Whites in

Colquitt. This story is described in more depth in Chapter 5. 
Other reasons that have been given for lack of Black participation and attendance have included more practical reasons, such as the time commitment that being involved in the play requires. These reasons may play a small role explaining the ongoing challenge of enlisting Black participation. However, from the outset, Black and Whites being involved voluntarily in an event that was primarily social, elicited warnings from some Whites in Miller County. Geer was warned that there would be "dire consequences if there was any race mixing between the sexes, on or off stage. You are opening up a can of worms if you take the race thing too far" (Burnham 2003, 2). This sentiment outside of the Swamp Gravy enthusiasts continues to demonstrate the realities of preferred social separation between some Black and White today. One White actor reported that "today it is not unusual at all for Black actors and White actors to hug each other when running into each other out in public, including the downtown square. That never have happened before Swamp Gravy" (White actor 2012, interview). While it has been a struggle to realize a representative Black participation in all aspects of producing the Swamp Gravy plays, the numbers inside the cast have lingered near the 20 percent mark that comes close to matching the Black demographic make-up of Miller County. The efforts to achieve representative Black participation in the plays, while falling short in some years, have been only 
moderately successful. And, while all cast members are equally valued, it is obvious that some individual Black contributions on the stage have loomed large. The dual acting and singing skills of 2 Black women - Veronica Haire (now deceased) and Gayle Grimsley, were critical to the early success of attracting audiences from across the South and beyond (Jinks 2008, interview).

It is important to note, that while natural talent levels do differ within the volunteer cast, no one that shows up to read for a role is ever turned away. Everyone that desires to be in the play is accepted. The only qualification is a humorous test that is administered by Geer, who holds up a mirror in front of the mouth and nose of the potential cast member. If the mirror fogs up at all, the person is accepted in as a cast member.

Rehearsal for a play that has a cast of anywhere from 70 to 100 community volunteers can be a daunting task. Most volunteers have to navigate the logistics of outside jobs and family responsibilities. But maintaining the social fabric of a rehearsing community in progress towards a public performance is the glue that makes it all work well. Rehearsal is that space where real life meets real stories. Three unique features of the rehearsals keep the process moving forward while grounding it in relationships. One is Geer's licensing of the community of volunteers to mediate the trajectory of the stories, which establishes a reciprocal 
relationship between the volunteers and the professional guides (including the writer, choreographer, set designer, and lighting expert). This activates the collaborative decision making skills of the volunteer community and strengthens their ownership of the process and the resulting performance.

Secondly, due to the lack of consistent availability of volunteer actors throughout the play's entire run, each part in the play requires 2 or 3 actors. And, everyone eventually gets into the play. When one actor is performing the part in a given play, the other 1 or 2 alternates for that show are expected to attend and participate in the full cast choruses or scenes, regardless of whether they have a speaking part that night or not. The non-speaking backup is also encouraged to support his or her acting partner during their performance. Throughout the run of a Swamp Gravy season this team that shares a particular role typically became close-knit friends. Casting these overlapping and supportive roles affords the director the opportunity to combine persons together that might not know each other or have worked together in any other capacity before the performance. Many friendships have been born through these experiences of playing the same role and thus helping each other out in rehearsals and performances.

The third feature is that rehearsals start and end with a ritual, where all those present form a circle, hold hands, air encouraging words, make occasional 
admissions to fatigue or frustrations, while concluding with prayers for the process, each other, and the production. While Geer is not a professing Christian, the cast and the population of Colquitt almost entirely identify as Christian to some degree. At the same time the play is not coupled with overtly Christian agendas. But, being representative of the region ensures that the content of the plays will at many points involve matters of the Christian faith. This reality is not perceived as a problem to be mediated by the cast as much as it reflects a current consensus of conviction.

At current there have only been a few situations where a person of a differing religious faith has been represented in the cast, with the exception of Geer, who sees the community performance process as somewhat universally accommodating. It remains to be seen what will happen on that day when the circle of prayer involves an articulated prayer from a religion that is perceived as significantly conflicting with the local preference to Christianity. Some community volunteers openly acknowledge that they would choose to leave if the process required sharing stages with an overtly competing religious point of view - meaning something altogether outside the Christian faith. At the same time, the prayers of the people in the circle are free of institutional control. Their prayerful offerings for the process and each other are not choreographed, nor do 
they articulate a particular denomination's territorial brand. Many in the cast have come to view this acting community as their church - a wilder and more participatory way of doing church with the people that they have come to love outside the boundaries of a more institutionalized form of Christian religion (Multiple actors 2008 interview). However, in recent years some believe that the prayer circle has begun to devolve into the airing of needs that people desire to have the group pray about. This is a departure from the kind of initial circle of prayer that was focused on the play, the process, the quality of the performance and the unity of each other as co-creators (Volunteer actor 2008, interview). Sustaining the unique form of community performance experience, including enlisting diverse representation and staging potentially controversial realities has never been an easy task. Community support of Swamp Gravy has reflected very diverse opinions - from enthusiastic support to skeptical resistance. As such, the history of the process itself has followed a story line of ebb and flows.

\section{The Ebb and Flow of Community Buy-in}

Creating a community-wide storytelling project for the purpose of producing a play sounds relatively harmless. To some, stories are the stuff of sitting around the dinner table, jawing at the corner store, or emerging within various leisure spaces where friends break out in entertaining story exchanges. In 
addition, for a good many from the south the phrase telling a story is what someone is accused of when they are suspected of telling a fib or a lie. A derivative of this common notion of storytelling was created by Geer and quickly became a brochure marketing hook saying for the Swamp Gravy plays. The saying demonstrated a somewhat good-natured jab at regional differences, yet it began to weave a stronger notion of storytelling as therapy: "Northerners tell stories behind closed doors and call it therapy - while, Southerners tell stories in public and call it swapping lies" (Geer 2008, interview). What Geer had in mind from the outset was to bring storytelling as an open and inclusive community building process from behind closed doors and into the public commons of the Colquitt. When Jinks and Geer first met in NY City Jinks had expressed that "her community wanted to do a play about its history... I was doing doctoral research at Northwestern in performance studies and was interested in the performance process as a tool for community building. Both goals, we thought could contribute to her town's revitalization" (Geer 1993. 33).

This tension between outward bound for communities and heritagecelebrating entertainment gets to the heart of the gap that Geer was trying to bridge. In many ways, the stage was already set for the collision of two notions of what storytelling in community actually could mean. While the slogan for 
most is seen as a harmless tongue-in-cheek marketing device, it does strongly hint that there is a significant departure from the local culture of storytelling on Colquitt's immediate horizon through the advent of Geer's community performance as demonstrated in Swamp Gravy. What Geer had in mind was going to run upstream on a number of fronts against what many local residents typically expect from a storytelling gathering.

The community performance project that Geer had in mind was also different from telling stories for fun with one's select friends. The Swamp Gravy "scripts are homegrown, [but] their purpose is only secondarily to entertain" (Geer interview). And equally significant is that Geer had agreed to take on the project under the stipulation that stories be gathered from all corners of Miller County, including Blacks and Whites, rich and poor. This degree of public is much more inclusive than the pseudo-public storytelling exchanges that take place between friends. Exchanging stories with friends is often a subtle ritual in humor that serves a deeper mission, that of reinforcing the norms and values of a particular group. As such, storytelling becomes a repetitive device for reinforcing a homogenous worldview or ideology. This may explain why when an outsider happens into such storytelling spaces that the storytelling stops. And, if the outsider lingers long enough, the group will break up and disperse. Maybe 
swapping lies is a way of calling it what it really is, not an exchange of stories to help discover what is meaningful and real, but storytelling that is ultimately a group's attempt to manufacture consensus, thereby maintaining a single interpretation about the way things are, or should be in their world.

Where Geer was headed was not the kind of storytelling where what you can tell and get away with is mediated by a homogenous subgroup that is held together by some commonality, be it religion, politics, race, gender, ideology, status or age. In fact, these were all boundaries that Geer intended to cross through to stage the inclusive storytelling of Swamp Gravy. Therefore, absent of a mediating set of story boundaries, the open and inclusive community storytelling of community performance becomes much more dangerous to the status quo - and, not just for some, but for each and every subgroup. In light of this, enlisting buy-in for community storytelling could almost become an unintended bait and switch - where community members project their typical experiences of storytelling onto what they expect Swamp Gravy to be, and thereby give an affirmative nod of the head yes, pledging their support for the story event, only to discover later that this was not what they had in mind. Pedro Sandor summed this up brilliantly when he remarked that "the Gravy Soup is a dirty trick, posing as something conservative, the celebration of heritage, that in 
reality is liberalizing, exposing people to each other, and to themselves as well" (Jones 1994, 147). Geer replied to Sandor's analysis during the first year of Swamp Gravy by saying: "I defend the bait and switch [dirty trick] because, once involved, community members control the process" (Geer 1993, 33).

Most of the early buy-in for the Swamp Gravy project came from what CMAC and its members could pull together through relatives, close friends and institutional allies. But, before the first performance of Swamp Gravy took place, the project had to weather several forms of resistance. Some resistance came from inside the process within the volunteer community of actors themselves, while other push-back came from more external sources - both institutional as well as individual. Community performance director Richard Geer was a PhD in the dramatic arts. His geographical roots were from places far removed from Colquitt, Georgia - places such as California, Colorado, Chicago, and the academic halls of the Ivy League northeast. His vocational roots were firmly professional, having worked with professional casts in lieu of inexperienced volunteers. "There was a lot of distrust in the beginning" (Jinks 2008, interview). These gaps that existed between Geer and the Swamp Gravy volunteers would be difficult for anyone to navigate successfully. Geer was a respected member of the theater profession, a PhD from Northwestern University, a northerner (or, 
yankee to many locals), politically liberal, and a nominal Buddhist. Suffice it to say, if Geer was going to be a newly imported member of some subgroup in Colquitt, Georgia, then he would likely be in a group of one, by himself. And, if Geer couldn't find a way to build community with the internal volunteer actors and CMAC, he wouldn't stand a chance with those outside the performance process.

While conducting a rehearsal in preparation for the first production of Swamp Gravy, Geer stopped the rehearsal abruptly and proceeded to tell everyone present that they were not meeting his expectations in terms of rigor and commitment to excellence. The volunteers had day jobs and many of them made great sacrifices to participate in the rehearsals. Many were also absent from practice this particular evening, and Geer felt it was time to address the problem. Geer unleashed his criticism with choice selection of expletives, that while not abnormal to the culture of professional theatre, were well beyond the realm of acceptable in the small southern town of Colquitt, Georgia, especially where women and children were present. One of the men stepped forward to inform Geer that his behavior was unacceptable, and then the entire cast walked out. As they departed the spokesperson further informed Geer that it would be in his best interest to grab his things and get out of Colquitt for good, that is, if he 
didn't want to get "beat up" (Burnham 1994, 41). It appeared that the very first production of Swamp Gravy was going to be derailed before it hit the stage for even one public performance.

Jinks and Geer retreated to her home that evening thinking that the project was done. But, Geer had not given up hope. He called one of the ministers in Colquitt and asked him if he would call the volunteers to come back together for a pot-luck meal so he could apologize for his unacceptable behavior. Through his actions of asking their forgiveness, Geer came down from his esteemed position as a professional director, and became a director with the people, what Geer would later agree was a "co-productive" form of directing. His acceptance was mediated by the group of diverse volunteers that represented most if not all of the various subgroups (race, socio-economic, age and gender) that lived in Miller County. Through this reconciliation and change, Richard had become a person in the community, and Swamp Gravy as a community building process had just begun to simmer. And perhaps more importantly, the volunteers now knew that they owned the project (Jinks 2008, interview).

The next time Geer needed to have someone deliver some critique, he decided to enlist a person from within the community. He invited a person to watch a rehearsal for the purpose of giving some feedback about the 
performance. The feedback was "extremely critical." The reaction this time was a more delayed response, but one that demonstrated a growing sense of anger. In response, Geer asked a cast member Charlotte Phillips for her opinion and advice. Phillips advised that the cast still didn't know each other all that well, and they needed "to touch". That night Phillips brought food for the 70 cast members and suggested they just let them eat (a kind of communion, perhaps). Then she got everyone into a circle and read them a heartfelt two-page statement about how important they were, spoke to their pain and sacrifice, and gave them her love. After this reading, many were in tears. Then she asked everybody to hug their neighbors and tell them how important they were in the plan (Burnham 1994, 41). A key feature of this event was sharing of a common meal together. It is as if the meal sealed the deal and they had all eaten and become Swamp Gravy, fully together for first time. They may have owned the process after reconciling with Geer, but now they owned each other, and the stage was truly set (Geer 2008, interview).

External push back from outside the Swamp Gravy volunteer community has been an ongoing reality - sometimes obvious, and other times just looming out of sight. There were concerns about the grandiose scale of the project. Some voiced their concerns over Geer being an outsider while verbalizing their desire 
to remain a closed community. Other concerns included fear that the play would create exposure of things personal as well as historical that could be embarrassing. Persons from the Black community were concerned about being a part of something "seen as a White activity," while some Whites warned of the dangers of "race mixing." Had the volunteers themselves not caught the Swamp Gravy bug, Geer would likely not have made it to the first performance (Burnham 1994, 41).

One incidence of external push-back against the staging of Swamp Gravy came in the form of protests from the Chamber of Commerce. It is the normal business of Chambers of Commerce to paint the image of the community, or tell the community's stories as a single story, and to tell that story in such a way that makes the town look appealing to outsiders. These efforts are for the purpose of luring outside business actors and visitors into some form of local investment and/or development. It is not hard to see how the staging of stories-plural might be seen as encroaching on the territory of the chamber, especially if the storiesplural were actually telling the real stories - the good and the bad, and in some cases the very bad. The Colquitt Chamber of Commerce could not see any benefit to staging stories that revealed the realities of racism and sexual abuse, much less the exposure of local forms of hypocrisy. The Chamber wanted the Swamp Gravy 
enthusiasts to stop before the doors opened for the first performance. The business community aired their complaints through the Chamber. CMAC was made up of persons of influence in the community from the same socio-economic status as the local business leaders. The main line of conflict organized around the fears that the arts were undercutting the work of the Chamber, whose job it was to attract outsiders into the community. The business community could not imagine that Swamp Gravy could do anything other than undermine the work of the Chamber and embarrass their community (Jinks 2008, interview). The protests never manifested in a show-down, but smoldered throughout the business community through informal conversations.

The internal process had begun to simmer for those involved in Swamp Gravy. As a result, CMAC and all the participant volunteers pressed on in the face of the Chamber's discouraging conversations about town. CMAC had already defined itself as having community development intentions, a role that certainly overlapped into the arena of the chamber. Now with the telling of stories via Swamp Gravy the overlapping margins of these community institutions had become contested. But, there was really nothing that the chamber could do to make CMAC stop their Swamp Gravy plans, except voice their disapproval. Jinks and her husband had been instrumental in helping 
establish the Chamber, as well as generously provided space for the Chamber to use as their offices (Jinks 2008, interview).

CMAC and Swamp Gravy weathered their first two serious threats internal and external. The gap between Richard and the now amateur-expert volunteers began to close through his full inclusion as a person in the Swamp Gravy community. This set a deeply collaborative tone that remained in place for years to come. The volunteers, later called Swampers, now owned the project in full. It had become theirs. And with this new ownership not even the Chamber of Commerce could impose their opinion about who tells the community story, and what stories gets told (Jinks interview). Push-back from individuals who found fault with the Swamp Gravy series in one form or another has been an ongoing reality. Internal trials have also come and gone over the years. And not all of the disagreements have ended in the kind of reconciliation that Richard and the Swamp Gravy volunteers experienced around that initial director tirade.

Even after the successful launching of the Swamp Gravy plays, suspicions from some continued to smolder. Two years after Geer arrived in town, he was confronted by people still suspicious of his motives. They cornered him in a local restaurant and began to ask him a series of questions. After some time, Geer realized that they were "curious about why I was in their community. I have told 
them from the beginning that my motives are selfish. I wanted to find out if performance could in fact contribute to community. But that goal makes very little sense to most people. I too, am suspicious of my motives" (Geer 1993, 35). When he first arrived in Colquitt Geer was vocal about how the process would ripple outside the theater and facilitate a shift from business-as-usual to business guided towards the community good that the Swamp Gravy would help discover. As a result of the early push-back and constant suspicion Geer began to center more of his attention to facilitating the performance process. He had even learned that the cast of volunteer actors would be the primary mediators of that process, and that he would be their director-guide.

The event that precipitated the most heightened attack on CMAC and secondarily Swamp Gravy came from a number of local residents in reaction to the installation of a Peace Mural in 1999 (Figure 2). Over the years CMAC had begun to install murals in the city that were visual representations of a key scene or story from many of the Swamp Gravy plays. By 2010 CMAC had installed 12 murals around the downtown area. As a result, the plays became a dominant visual feature of the downtown area which lead to Colquitt had being recognized as Georgia's First Mural City. The murals were largely extensions of Swamp Gravy. In classic Swamp Gravy style, the Peace Mural was created by local 
students. Each student had written a paragraph about how they felt about peace, and drew a symbol to go along with what they had written. The symbols were taken and combined to create a picture that became the mural installation. As a result, CMAC including Kimbrel and Jinks were called "a cult, satanic, new age, evil" as well as received "hate mail." The mural contained the peace sign and yin and yang symbols as parts of its many features. Though these were small pieces of content in the mural, they were none-the-less perceived as threatening to the religious and perhaps political ideology of some in Colquitt. Even the concept of peace can been threatening to some within the ultra-conservative right wing camp (Kimbrel 2008, interview). Criticism became so personal at times that Jinks briefly considered putting her house up for sale and moving (Jinks 2008, interview). And Kimbrel "sent a letter to the editor calling out the attackers: that you without sin cast the first stone. It took a long time for it to die down. Being associated with Swamp Gravy opens you up to a lot of criticism..., a sort of testing by fire" (Kimbrel 2008, interview). 


\section{Figure 2: Peace Mural}

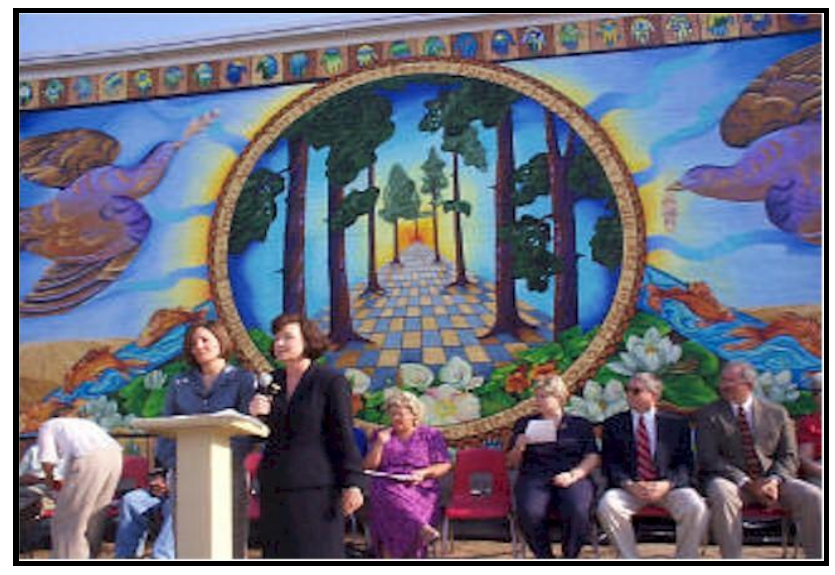

(Colquitt Miller Arts Council)

One development that involved CMAC and some of the Swampers but

didn't involve Geer or the Community Performance team was the formation of a second production called May-Haw. It had been initially titled and announced in the local paper, "Hee Haw Comes to Colquitt." As one might expect this had many of the characteristics of the nationally syndicated television show, Hee Haw - a Southern brand of down home slapstick comedy. Proceeds were to help fund the Colquitt/Miller County Fire and Rescue team's mural project featuring stories from an upcoming Swamp Gravy production, Nuthin But a Will (Toole 2005, 1). The naming of the event as Hee Haw was short-lived, as official representatives from the show contacted CMAC and asked them to cease using the name. CMAC and the cast changed the name to May-Haw, after the Mayhaw tree and festival, 
and proceeded to launch what would become, like Swamp Gravy, a semi-annual show (Jinks 2008, interview).

The resulting May-Haw show consists of an abundance of slap-stick southern humor combined with a number of community singers doing their best to portray their favorite country music singers - from Elvis to Lee Greenwood and Patsy Kline. If entertainment was a distant secondary motive in Swamp Gravy, in May-Haw it was front and center. The lone somber note in May-Haw is typically a short patriotic sketch combined with a patriotic song. One example of a more somber moment was the honoring of veterans which was immediately followed by a local singer doing a very good rendition of Lee Greenwood's I'm Proud to Be an American. It is of interest that there are local residents who have attended a May-Haw show, yet at the same time have never attended a SwampGravy play. May-Haw seems to have fit the more traditional appetites that prefer entertainment and humor to the type of community storytelling inherent in the community performance of Swamp Gravy.

The discordant trajectory that appears to exist between the two - May-Haw and Swamp Gravy, is admitted to by some, and only hinted at by others. Some are able to embrace both events without desiring to raise one above the other, thereby accepting that they are just different, and serve different purposes. 
Others claim that it has helped get community folks into Cotton Hall - people who they hope will be more likely to come back to Cotton Hall and see Swamp Gravy (Tully 2008, interview). One community member that is involved in both productions describes May-Haw as "dumb fun that you don't have to think about" (Volunteer actor 2008, interview). It is "thrown together in two weeks" with very little attention to detail (Tully 2008, interview). If Swamp Gravy is about the formation of community, then May-Haw appears to be about swapping lies. Yet, May-Haw is intended to and does play to a predominantly local audience, while Swamp Gravy draws the majority of its audience members from outside Miller County (Traywick 2008, interview). Members of CMAC and Swamp Gravy are well aware of this reality. This prompts the question, how could a community celebration that is widely purported to being fundamental to the renewal of Colquitt and Miller County, still be held at arms distance by many in its own community? By 20012, May-Haw is no longer being framed as a fundraising performance for $\mathrm{CMAC}$, and has thus come into its own as a local entertainment event. May-Haw is described in the 2012 mail-out flyer as: "a knee slapping, two had clapping, uproarious, fun, lively, glorious, earth shaking, belly laugh quaking, down-home hullabaloo - laugh until you cry...featuring the best musical talent this side of the Mississippi." The 2008 May-Haw was completely 
absent of any Black performers or audience members, but at the same time draws a numerically larger local White audience than does Swamp Gravy.

Regardless of the ebb and flows, community buy-in for Swamp Gravy has maintained enough of a critical mass of support to enable the initial Swamp Gravy play to evolve into a series that has now run for 20 consecutive seasons. Geer is no longer associated with the production, having parted ways as the director in 2010. Without Geer, writer Jules Corriere, and the rest of the CPI professional team, Swamp Gravy now relies on local talent to carry on the Swamp Gravy traditions. Much of what has followed since the departure of Geer and company has taken the form of a remount of a previous Swamp Gravy production, The Gospel Truth, followed the next year by a blending of popular scenes from multiple years and shows - a kind of greatest hits collage.

Geer's departure came as a response to a final act of community pushback - this time from CMAC and Swampers who together (though not unanimously) drew a line in the sand that Geer could not step over. A rift between CPI script writer-artistic director Jules Corriere and CMAC had become un-reconcilable, oddly enough, and Geer was forced to choose to either replace Corriere or give up directing the Swamp Gravy series. As for the line in the sand - was it an act of local knowledge? - or, was it political? Or, was it just time to let others step 
forward? The answer for many was that the line was the community owning the process. For others, the line had a distinctly racial curvature to it. A majority of the volunteer actors had come to believe that Corriere was inserting race as an issue into the stories, while a minority of the actors did not think that Corriere's script was racially motivated or constructed. The fact that no one particular set of lines in the corresponding Swamp Gravy plays have been protested as racially motivated renders the possibility that the conflict itself arose outside the lines of the script somewhere in the process itself. Coming into a town with the express intent to facilitate and not intervene over time becomes unrealistic. It is likely, that at some point an occasion that requires intervention in a given situation will eventually arise. If that intervention becomes totalizing, it can shift the perception about one's intentions.

In a few years from now it may be possible to determine just how much Community Performance influence gets retained in the transition to a new director and artistic team when there will be a larger body of Swamp Gravy experience to analyze. In 2012 CMAC hired a permanent artistic director that will direct the full menu of Cotton Hall productions, which this year includes: Swamp Gravy; May-Haw; and Seussical Jr. With the new configuration, the view from the 
Swamp Gravy website is no longer dominated by Swamp Gravy, but instead is an equally shared space where the three theater experiences are each presented.

\section{Designing a Theater with Community in Mind}

Swamp Gravy performances took place in a "70 year-old cotton warehouse aptly named Cotton Hall" (Kimbrel 2006, 19). In the first few years of the performance the set was designed and assembled inside this shell of a building that still had dirt floors. The designing and staging of the Community Performance type of theater that Swamp Gravy represented provided the opportunity for multiple creative adjustments to be made that were significant departures from traditional theater, and all with the intention of making a place for catalyzing community. "The perfect theater, we were taught, is an architecturally interesting but neutral space to which each production lends its distinct character. It is, as Peter Brook stated, an empty space". While early on Cotton Hall may have been a somewhat empty shell, it was not an empty space, nor was it unfamiliar to the people of Miller County. "The best theater sites for Community Performance... are un-empty spaces alive with other presences, meanings, even contradictions. Such theaters are crossroads, with all the signs, dust, and rutted-ness that crossroads imply, and all the magic that crossroads connote" (Geer 2011). 
For both Black and White residents of Miller County Cotton Hall was a place of memories where the one-time dominant crop of cotton was both stored and sold. The warehouse that became Cotton Hall was the central constellation during the once-thriving Miller County Cotton industry. This prominence was short lived as 5 years after the warehouse opened the "boll weevil dethroned King Cotton, giving rise to the peanut industry" and causing the cotton industry and the warehouse to become a distant memory (Kimbrel, 2006, 19). Although dormant for several decades, the warehouse building now turned into an informal storage space was in a prime location just off the main square of Colquitt. It was in an area of Colquitt that was most proximal to Colquitt's Black community. Yet, it was a recognizable landmark in a town with only a limited number of actual buildings. Once a person gets beyond the town's square - a 1block commercial district that surrounds the County Courthouse in the middle, there are only a few buildings along the roads that spoke out from the square. Cotton Hall may have been dormant, but people knew where it was and what it had been.

Another feature of assembly spaces that Swamp Gravy altered was the traditional design and arrangement of seating that faced in only one direction, which seems to imply "a single point of view". In contrast, Community 
Performance intended to "encompass many points of view," which is more in keeping with the inherent realities of a genuine community. The delineation of performers from audience is blurred as seating and stages practically overlap at the margins of both. "Community performance uses multiple stages including a main stage (called Home Base), secondary [pod]stages of medium size, and two or three smaller platforms, all scattered around a hall and in different relationships and at different distances from the audience (Geer 2011). One way to visualize home base is to think of a basketball court with an elevated stage at one end, yet elevated higher than normal, say, 10 feet, and connected to the floor of the court by a series of cascading steps, ramps and even smaller platforms. The pod stages are arranged in various configurations across the floor, or pit area (see figures 3 and 4 ).

Home Base- This is a general playing area of large enough size to accommodate most or all of the cast in any given performance. It often has a centralized focus relative to the audience, and can vary hugely in shape and layout from site to site. It usually carries the major visual icons permanent to a given production.

Pod stages- These are platforms, three or four in number, spaced widely apart within the overall playing space. They are comparatively small, ranging from $4 \times 6$ to $10 \times 12$. They are typically used for scenes involving only a few characters. Pods facilitate a visual dynamic that expands the audience's perception of the overall space while also focusing attention on specific scenes. They can also be used as dynamic points of multiple focus where the audience is made to shift attention from pod to pod. 
The Pit- Richard originally conceived of this as an echo of the Elizabethan theater in which 'commoners' would stand, rather than sit, to observe the performance. The Pit has transformed over time. It has often served as a general space for actors to be present in when they are not in a scene. It also serves as a kind of physical glue that mediates between Home Base and the Pods. It has become very useful as a 'traversal' area through which vehicles from bicycles to goat carts have traveled, to the delight of the audience (Vargas 2011).

\section{Figure 3: Cotton Hall Home Base (Garden of Gratitude)}

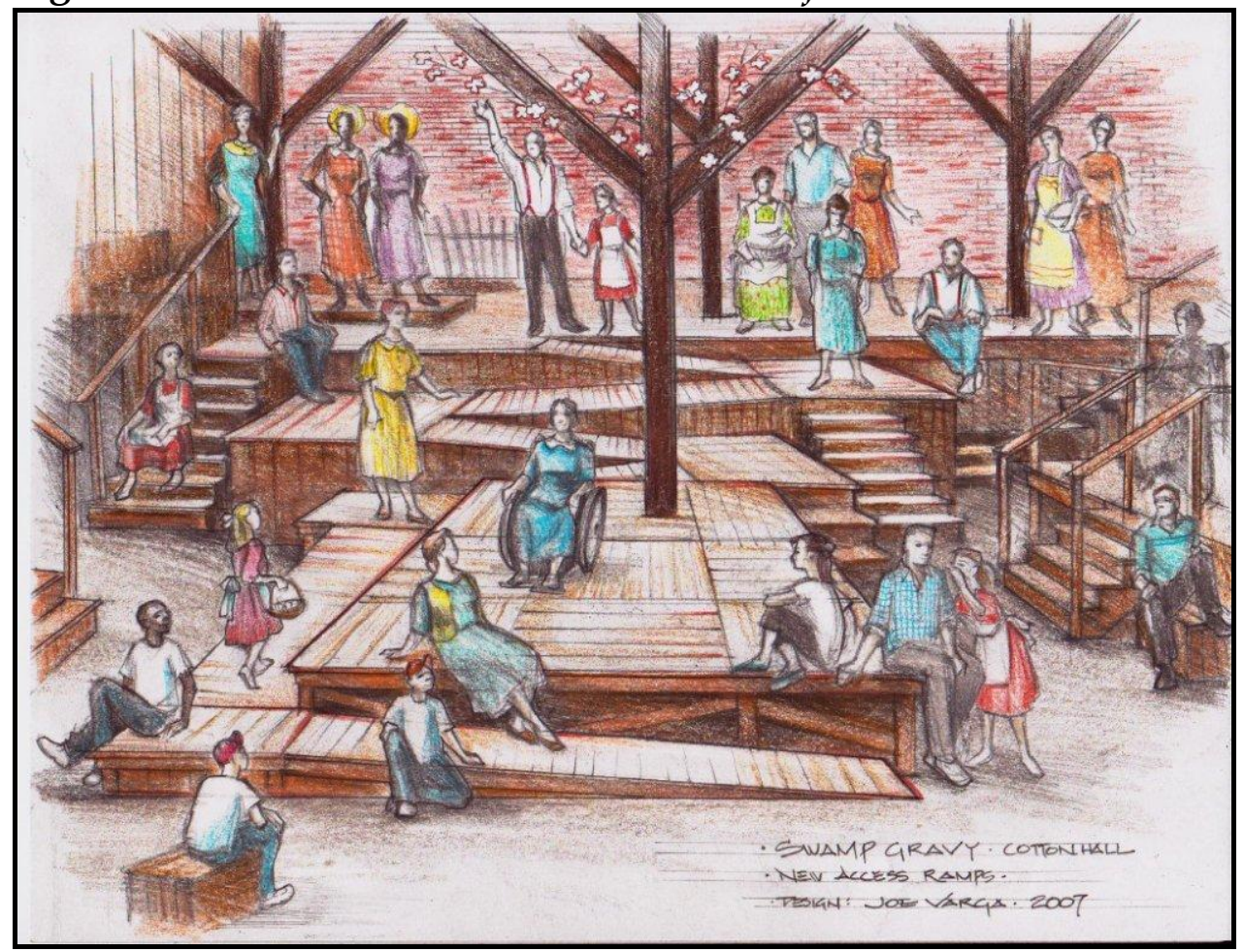

(Geer, Vargas, 2011) 
Figure 4 - Cotton Hall Early Vargas Sketch

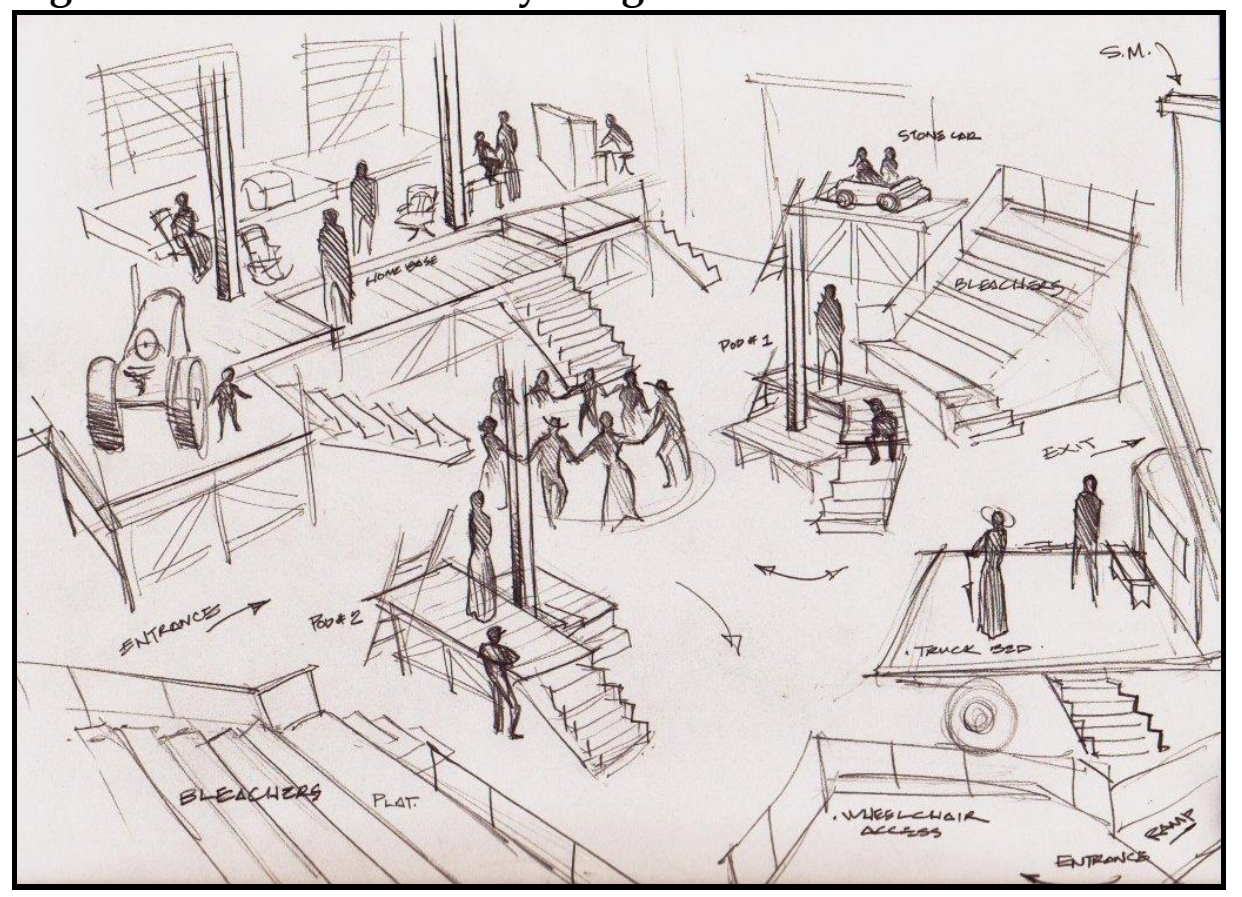

(Geer, Vargas 2011)

The audience seating areas are not on the floor of the court (the pit), but are located where the bleachers usually are on both sides of the floor of the pit, and also at the far end, occupying the area behind where a basketball goal would be, thus

rendering a horseshoe shaped seating layout. The seating is elevated a few feet or steps up from the floor or pit area. The pod stages are elevated stages that flow out from home base in various configurations. At the far end of the pit opposite of home base a pod stage has been assembled onto the bed of an old 1938 International flatbed truck, creating a farm setting to the stage. Audience members in the front row of the bleacher-seating areas are within reach of the action as it moves to and 
from the various staging areas. This design attempts to blur the lines that usually separate individuals into pre-determined and static roles of actors and audience, creating a more open and inviting dynamic that intends to envelope a type of "community in the round" (Geer 2011).

According to Geer, a model Community Performance theater space should demonstrate the following features:

\section{Historically significant to all races and groups}

Central to allied amenities like restaurants and parking. $60^{\prime} \times 60^{\prime}$ with $25^{\prime}$ ceilings (the higher the better) and not over $80^{\prime}$ in any dimension

Few or no posts or other visual interruptions in the space. (Though there are nine 8 "x 10 " posts incorporated into Cotton Hall, and they actually contribute to the ambience.)

In good repair. (Though a need of repair may speak eloquently to potential donors.)

Heated and air conditioned

In a quiet neighborhood - minimal street noise 600 amps of 3 phase power available

Adequate bathrooms, foyers, dressing rooms, shop space

Loading dock entrance at floor height with $8^{\prime} 6$ " openings

Open ceiling beams or grid from which lights or light pipes can easily be hung

Walls and wooden floors to which heavy units can easily be attached Dark walls, floor, ceiling

Wheelchair accessible Nearby to a kitchen for meals

Little or no other usage for the space Available at no cost.

(Geer 2011) 
While these physical design features are important to the unique production of Swamp Gravy as a Community Performance Theater experience, Geer also emphasizes other features that he feels are very important as well.

First, he asserts that the space that is used to stage the performance needs to be "historically significant" to all the diverse members of the community - and, based on the racial demographics of Miller County, this would mean that Cotton Hall needed to have some connection to both the Black and White residents, which together made up around 98 percent of the population. While the nature of any prior mutual experience of the space is important, it is not deterministic. The prior experiences that many had regarding growing and picking cotton in Miller County was not necessarily looked back on with fondness. At the same time Geer knows that the dynamics of the cotton field often live on, not only in memory, but in reality, and the advantages of remembered experience potentially brings another layer of story to work with rather than to avoid (Geer 2011).

CMAC purchased the adjoining structures to the newly renovated Cotton Hall in 1997, which were described by Terry Toole of the Miller County liberal as containing "the last of the old colored business district..., Martha's Flea Market..., a barber shop..., a café run by Mrs. King, and a government food distribution 
point... The old building has almost fallen down by itself, and is not only unsafe, but a health hazard... All of these businesses were run by White and Black people. My father ran Colquitt's first theatre in one of those buildings. [And,] I think the very large Black lady that was the cook at the café was Anna King. She could fix some of the best food this skinny redheaded youngster had ever eaten. I was told some of the best shine [moonshine] in the county was sold out of the same doors" (Toole 1997, 10). While these structures butted up to Cotton Hall in 1997, they were in an advanced state of disrepair, and were unsalvageable (Jinks 2008, interview).

A second desired feature was that the performance space should be “nearby to a kitchen for meals" (Geer 2011). As demonstrated earlier, aside from sustenance, a common meal can be a place where the building back of broken relationships can be fully restored. It is also a traditional place for sharing stories. And, as such, eating together is a primary place where relationships are started and sustained. All this adds up to the realization that eating together is an important community building ritual, and a desired component of the community performance process. 


\section{Collaborative Place Making}

Equally unique about the design and staging of the performance space is the communal means by which the early space characterized by mobility and impermanence was transformed into a permanent community performance theater. This transformation did not take away from the creative and intended design of the original ideas, but adapted them in full into its current built status. The resulting new Cotton Hall was not only a community statement, but an attraction in its own right. CMAC was instrumental in finding the financial support for building out the new space. By the time it was complete, the process that was done in 3 phases had cost $\$ 750,000$ (Kimbrel 2006, 19). While securing the funding that was necessary in financing the transformation of Cotton Hall was quite an accomplishment, it does not tell the complete story.

In the beginning stages of getting Cotton Hall ready to be transformed into a permanent theater facility, prisoners from the Georgia Department of Corrections were enlisted to help with the cleaning out phase. The build-out campaign had plenty of building resources, but were completely lacking in available skilled labor. Carpenters and other construction savvy residents were busy working for a living, and didn't have the time to take off from work in order to help build out Cotton Hall. The prison warden notified Karen Kimbrel 
that there were a lot of men in prison that were skilled in virtually all of the construction trades, and that they would be glad to lend a hand. So, carpenters, electricians, painters, and the like were all supplied free of charge courtesy of the state prison. The prisoners came in their orange prison garb and began the rather large task of building out the space, which included a museum, a snack bar area, a commons area, as well as the theater space (Kimbrel 2008, interview).

Kimbrel had donated some building materials including 2 big wooden barn doors that were going to be installed as a backdrop on the back wall of the home base stage area. While one door was in great shape, the other was in an advanced state of disrepair. Kimbrel wondered if it could be used at all. Without her knowledge, one of the prisoners went to work applying wood putty and hammering the door back together so that the doors could be usable as the desired backdrop. Kimbrel was checking to see how the build-out was progressing when she stumbled onto the repaired and painted doors. She could not distinguish which door was which. She remarked how incredibly beautiful the doors looked, and that whoever had performed that repair had done an incredible job. She noticed a man not far away that had overheard what she said, and noticed that he had tears coming down his face. Kimbrel asked if she had offended him in some way. He responded that she had not. He told her he had 
repaired the door -- adding that no one had ever told him that he had ever done a good job at anything (Kimbrel 2008, interview).

The work of the prisoners was another example of a labor of love. Playing such a vital role in the construction of this community space was something they were all very proud to have taken part in (Volunteers 2008, interviews). The women had brought daily meals to the inmate builders, and had also put on two steak dinners in appreciation for the inmate's efforts. The Swamp Gravy cast performed a special dress rehearsal just for the prisoners. That performance was a very meaningful experience for everyone - both the cast and audience alike (Geer 2011, interview).

Joe Vargas, a professional set designer and an original member of the Community Performance professional team described his experience with the evolving design of Cotton Hall as a process of "free exchange" - a brand of collaboration that director Geer caught a vision for at the very outset of his work in Colquitt. "Much of the regular process of making theater is collaborative, with each participant assigned a specific job title along with specific duties. In CPI we have developed a tradition of free exchange, where everyone has a say in just about everything. Richard used to say to me: “If you let me design, I'll let you direct... Of course we are fully aware of exactly what a professional designer or 
director does, but in Community Performance we have found a way of reaching out among ourselves to create and mold the shows without losing sight of our respective roles in the team. This seems to require two essential things: the presence of absolute mutual trust; and the absence of personal ego" (Vargas 2011). Collaboration amongst professionals across varying roles can be challenging.

Working with Geer on the Swamp Gravy project introduced Vargas to an even deeper level of open collaboration - professional and non-professional. Vargas described that since "I have rarely worked on a production where I and all involved became living participants in the central metaphor of the enterprise itself. Collectively we became the ingredients of Swamp Gravy... The interface between theater professionals and indigenous community was perhaps the most fascinating and exhilarating aspect of working on the project. I had no idea what to expect, so I simply decided to perform my routine duties as a designer and treat everyone, whatever their level of experience might be, with the same trust that all of us in theater regularly bestow on each other. The payback certainly proved worthy of the trust." The way they worked together demonstrated a kind of "Stone Soup" dynamic, where each participant was licensed to suggest alterations to the creative design. Vargas remembers commenting out loud that a 
particular set needed something to "brighten up one of the acting areas." By that evening "the absolutely right quilt made its appearance on the set." The commitment of local knowledge permeated every aspect of the Swamp Gravy process. Professional and non-professional boundaries became blurred in much the same way that the project continually broke through the bounded limitations of status and role, as well as race and class. Vargas further described, that “creating a setting for Community Performance (Swamp Gravy) is a unique challenge that involves input, control, letting go of control, grasping opportunity as it happens by, making wishes out loud, trusting to instinct (and not just your own), making images appear, and managing the jigsaw puzzle of space" (Vargas, 2011).

Local volunteer assistance had a direct impact on helping create the performance space. This active engagement of locals also helped with the task of both finding and acquiring valuable resources as donations for a fraction of the costs. Vargas tells about one instance, where "local volunteer stage manager and I marched into the nearest lumber supply store to get several poles that I wanted for the set. She of course knew the proprietor and personnel and they in turn were aware of our mission. I was asked to make a few selections and we were out of there in five minutes; in less than half an hour the necessary items 
appeared on site, without either of us lifting a finger... Similarly, a variety of items we needed just sort of arrived with barely the briefest request from director or designer: a 1938 International flatbed, two vintage tractors, a model T, and a collection of lush greenery in hanging pots from the town greens-man (Vargas 2011).

It is one thing to do lip-service to collaboration - and quite another to be taken up on the invitation to make changes to instructions. The professional team members that came from outside Miller County like Vargas were typically only able to get things started before needing to return to jobs in other parts of the country, and thus leaving the completion of tasks in the hands of local volunteers. Some of the wood that they had been able to acquire through community connections needed to be altered in such a way that made it appear aged rather than new. Vargas knew of a specific way to achieve this with paint products, and left town having communicated how the volunteers could achieve the desired result. When he returned and saw that the wood reflected what he had in mind to perfection, he inquired further as to what process was used that had worked so well. He was informed that someone had taken some of the dirt from the floor of Cotton Hall and added it to water, and used the resulting concoction to "dirt wash" the wood, both achieving the desired visual effect 
while also saving time and money (Vargas 2011). The resulting completed Cotton Hall project, which included a museum, offices, snack bar, restrooms, brick cobblestone open space, and the theater performance hall with multiple stages and audience seating for around 275 people was a source of pride for CMAC, the volunteers, and the community. The theater was a process of collaboration that mirrored the interdependence that is Swamp Gravy itself.

It is impossible to know what might be different or better had professionals from outside done all of the design and construction without any of the help from locals, including the inmates from the Georgia Department of Corrections. But, Cotton Hall seems to have emerged out of Swamp Gravy itself, evolving as it did one prop at a time, and then one phase at a time through the mutual expertise of outside artists and local community members. As such, it expanded in step with the Swamp Gravy performances, never upstaging what goes on once the show starts, yet grounding it all-the-while in a mutual vision held together by sweat equity and local knowledge.

\section{Experiencing Cotton Hall}

Looking from the outside at the front of Cotton Hall, all you see is a brick wall with a couple of non-descript doors (one double, and one utility). The building's brick façade was adorned with a mural and various silhouette 
paintings similar in style and content to the painted props that were often used to create a setting in and around the stages. The presentation gives little hint that a couple of times a year this space inside comes alive with performers, community members and visitors all drawn together for a Swamp Gravy production. The outside back and sides of the building are non-descript and void of any outstanding features.

Stepping inside the doors brings you into immediate contact with the past. The common area inside Cotton Hall has a museum along the northern wall that includes an original farm store where sharecroppers purchased weekly necessities including food. The remaining north wall has displays of tools and relics of the past. There are old pictures of cotton farms and cotton pickers working the field on some of the walls of the common area. In the far southeast corner there is a snack bar stand and restrooms. In the middle of the building tables are spread randomly throughout an otherwise open space. Along the south and west corner of the building you look see the back wall of Cotton Hall Theater, which is like looking at the back of an old wooden farm building or barn. At the deepest point on the south wall is the entrance into the performance space. 
Everyone enters through a common entrance, audience and actors alike. As you make your way in it is not clear who is an actor and who is an audience member. It is not uncommon to be escorted to your seat with the help of one of the cast members. It is difficult to differentiate who is an actor since costuming runs the gamut from obvious period clothing to something less identifying. Regardless, conversation between those coming to watch and volunteer greeters and cast members is noticeable, whether in the process of entering the inside of the theater or after having been seated.

Another feature of Cotton Hall Theater is that navigating into the theater space towards the seating areas leads you across the floor or pit area of the performance space, where you pass alongside many of the elevated stages. Cast members are mingling throughout this space, including sitting on the edges of the stages. In the early years of Swamp Gravy, audience members were even welcomed in the pit area or floor where they might be leaning up against a post right next to a cast member who could break out in a line or a song with no forewarning (Geer 2008, interview).

Leaving, as you might expect is much the same process as entering the theater. Most go out the same way that they came in, shaking hands with cast members and striking up conversations along the way. Cast members and 
volunteers alike mingle with the crowd, and slowly make their way out of the theater in the natural ebb and flow of conversation. Some volunteers busy about with tasks like securing and putting away props, but most exit in a similar progression as that of the audience members. Some people buy souvenir $\mathrm{t}$-shirts and other memorabilia. Some leave for home, while many others having been alerted by announcement at the end of the play about which businesses are open, make their way to such establishments as Bleu's Coffee and Ice Cream Parlor, or to the Tarrer Inn for a post matinee Saturday supper. Local members of the volunteer fire department are stationed outside the doors to Cotton Hall where they are busy helping attendees cross the street, board buses, and directing traffic.

It is feasible to come and go from a Swamp Gravy production without talking with someone, however, it is something you would have to work hard at to accomplish. And, while the cast members personalize the theater space, the space you traverse is designed to envelope the attendee with a sense of somehow belonging in this community of near 300, even if it is just for a few hours. While there are a variety of other ways that the play itself invokes participation, the sheer movement through and from the built space of Cotton Hall Theater, the proximity to the action, the multiple views, the rubbing of shoulders with local 
actors all lends itself to a much deeper engagement with a people and their stories. This is a far different experience from that of attending a play in a more traditional theater. Nancy Grow, who along with her husband Bill relocated from Chicago to Colquitt as a result of Swamp Gravy, wrote this in an article regarding her experience of attending the play at Cotton Hall Theater: "It is one of the most exciting things to participate in I have encountered in many years. The action all around you makes any sense of being a spectator impossible. You know you are living it; you know it is real; you know it is life-changing because of what it is doing to you and those around you" (Grow 1994, 8). That level of excitement is tangible at the conclusion of Swamp Gravy performances, and the lengthy amount of time it takes for patrons to exit the theater and Cotton Hall is testament to the fact that no one wants it to end.

The coming and going of patrons to see the play bears little resemblance to traditional theater. It does resemble what it might look like coming and going to church in the rural south. This resemblance does not seem to have been a design intention, as the build-out efforts were guided by the dynamics of the Swamp Gravy process, including the early staging and set design, and probably the plays themselves. However, if you were to follow Miller County people around for a week to see when their coming and going most reflects what is seen 
when they navigate through Cotton Hall to see a Swamp Gravy play - a celebratory event that invokes meaningful participation, while meeting and greeting on their way in and on their way out, then the dominant parallel would likely be going to and coming from church. Some have alluded to the fact that Swamp Gravy is akin to church outreach. To understand the meaningfulness of the plays will require a deeper look beyond the physical structure of Cotton Hall. While the original Cotton Hall's status as the central constellation in the Miller County agriculture business was cut short by the Boll Weevil, today it has once again emerged as the community's center stage.

\section{Swamp Gravy's Sacred Structures}

There are certain elements within the play that have become permanent structures within which all of the seasonal plays unfold. The plays always begin with a charismatic welcome vigorously performed on the top portion of the home base stage. A male cast member mans this inviting position in what feels like a cross between a very enthusiastic high school football coach and a revival preacher -- informing the audience of the few house rules along with telling everybody what they are in store for. Audience members are led by the actor to put their hands together in a syncopated slow clap that progressively speeds up to a fast clap - while the actor completes his welcome in sync with the conclusion 
of the escalated clapping - and the community performance has already begun.

The entire cast steps up from their various positions interspersed around the various stages and begin a somewhat progression of call and response through the play's traditional opening song. Different persons sing a verse, while the group sings the chorus in keeping with the diverse characters in The Story Song.

(Chorus-first time slowly with solos)

You've got a story

And I've got a story

We've all got a story to tell

Oh, you've got a story, and I've got a story, it's one we know so well

You tell me yours, and I'll tell you mine

And we'll put them all together and spice it all up and we'll have a storytelling time

(Repeat chorus at tempo)

(Verse 1 solos)

Well your Grandpa was the sheriff

And your Grandpa was a thief

Your Grandpa ran a moonshine still

And my Grandpa was an Indian chief

We've all got something to brag about

And we've all got something to hide

But if tell it all

The truth will set you free

(Verse 2 solos)

Well my Grandma was a teacher

And my Grandma was a saint

My Grandma was hell on wheels

And my Grandma worked from can to can't

And we've all got something to brag about

And we've all got something to hide

But if you tell all 
The truth will set you free

(Repeat chorus)

(Kimbrel, 1993)

The tone of the opening song and the single line, we'll put em all together (the stories) and spice em all up, we'll have a storytelling time, suggests that the storytelling time is going to be an experience of the humorous form of swappin lies, and, at the same time it's going to be exposing dark secrets and confronting taboos. As such, the catchy song and down home feeling is able to reel in a predominantly southern audience into the play. This first song seems to confirm Pedro Sandor's affectionate analysis that "the gravy soup is a dirty trick" (Jones 1994, 147). There is very little in this first song to indicate how far the truth telling will go in what appears to a mostly good old fashion fun time. In addition, the initial audience clapping along with the line we all have a story to tell has suggested that this event involves everyone. Some of the actors address each other during this line, while others look out at persons in the audience. A downhome easygoing tone has been set, and everyone is a part of the mix. The only line that hints of something deeper than sitting around swappin lies, is the line: we all have something to hide, but if you tell it all, the truth will set you free. These words and what they imply don't seem all that serious, subversively set as they are in this fun full-cast sing-along. The audience has no idea that what they are in store 
for might include hearing stories about: a deacon that is a sexual offender; a wife that shoots and kills her abusive husband; individuals struggling against gender and racial biases; or the lighter notes of church practices that are in reality selfserving hypocrisies. The reality is that no spice is needed. Local stories are so spicy that they have to be adjusted into parables - just familiar enough, yet not too identifying, so that the play can elicit thoughtful reflection and response rather than provoke individual reactions.

The overarching narrative (primary story) and its accompanying branches produce a result that is a mix of keeping Swamp Gravy meaningful and thus real, but with enough humor thrown into the pot to lighten it up for everyone. The use of the parable is a powerful tool, and one that might keep you from some of the dire consequences that Geer had been warned about. Most of the people of Colquitt encounter parables predominantly in church, where the Biblical intent was to provide a space for thoughtful reflection about applicable lessons - all the while not calling out the real names (Geer 2008, interview).

One story that the various writers of Swamp Gravy seem to find a niche for during each season involves the encroachment of an alligator (a species native to the area) that is too close for comfort to the territory of one woman's daily farm chores. The woman needs help from an audience member to demonstrate the 
sound that a gator makes. Rather than ask for a volunteer, the woman begins to describe the person that she has in mind from the audience with enough detail that the described actor-soon-to-be knows that it is him. He is asked to come to the stage and assume the position of a gator, and make the sound of a gator harruuumph (and loudly), as well as jump like the gator jumped when the woman grabbed her axe. This episode elicits quite a bit of good natured humor all at the expense or glory (depending on how you look at it) of the person from the audience, whose enlistment is sometimes set up ahead of time by a friend or relative. While a good deal of fun has been had, the conclusion of the story returns to a more meaningful trajectory - the eventual slaying of the gator, which became food provisions for this particular farm family, a reality that changes how the alligator was viewed, from being a threat to a provisional blessing. And, on a more subtle level, the already compromised distance separating audience from actors is now even further compromised. The play that starts as a musical exercise of call and response, has in this instance just taken a more humorous turn, but not without losing the story's original meaningfulness.

The concluding structures come into play at the culmination of the play's primary story. The entire cast migrates into standing position on the multiple stages where they face the audience, while the pianist begins to play the song 
Amazing Grace. After the first verse is sung by a soloist the entire cast hums along with the song each lighting a candle. One by one, individual members reach their candle towards the sky and address a deceased member of the community. With bold confidence individual members state a deceased person's name while looking skyward as if they are sitting in the rafters of Cotton Hall: Joe Smith, I remember you. Some actors call out names of a deceased friend or relative, while others call out a name of a friend or relative of someone from the audience. It is not unusual for the cast members to find out the name of a deceased family member of someone in the audience through one of the conversations that take place during the seating process before the play. With the lights having been dimmed, the candles burning bright, accompanied by softened background music and humming of Amazing Grace, the event is charged with meaningfulness that for many is overwhelming.

Regarding the ritual ending of Swamp Gravy, Walter Bilderback, dramaturg of Atlanta's Alliance Theater, wrote: “The roll call [of the deceased]... commemorates and sanctifies the historical experience of Colquitt and Miller County, placing it within a tapestry that includes the Vietnam Memorial in D.C. and the AIDS quilt. Anyone who witnesses Swamp Gravy (and my use of religious metaphors is intentional--no, unavoidable for a work of this power) 
gains a renewed sense of the miracle of being alive and the beauty of human community" (Osinski 1999, E1). The use of Amazing Grace as a permanent structure in Swamp Gravy goes a long way in securing any lacking cultural license that the play may have been missing, and virtually renders any critique to be unconscionable - at least for those who have witnessed the event first hand. All of the structures are familiar, inviting, engaging and meaningful on multiple levels. But, none of the structures are strategically contrived. They are contextually valid, and therefore they help to establish the authenticity of the project and reinforce the genuine-ness of the community experience. The play ends as it began, expressing a conviction that if you tell it all, the truth will set you free. Truth-telling has been mediated by the community, and become sanctified through the ritual of remembering backed by the singing of Amazing Grace. This process ensures that any axes left to grind over the content of the play have probably been blunted. And any personal applications are safely left to one's own self-reflection in digesting whatever food for thought that Swamp Gravy served up, thereby leaving attendees to respond however they choose.

It is telling, though not surprising, that some members of the Swamp Gravy cast feel that this group of people from all walks of the Colquitt community is their real church. Nan Grow adds further interpretation to the theological 
anthropology of Swamp Gravy: "What is really going on is what Ricoeur might call a ritual of closure or reconstruction. It is a liturgical act of anamnesis, of recalling the journey of the people as a whole, of existential bonding in a shared creation and in a prolepsis which guarantees that the community will never be the same again. Each performance is an enactment of communitas such as has been present in the churches at times of great revival"' (Grow 1994, 1). Grow's assessment provokes additional questions. How deep and how wide does this reconstruction of Colquitt as now being in community go? How far do the lessons play forward in the local economy, the institutions, the identity of the city and county, and the social lives of the community? Will Swamp Gravy lure in and thus reconstruct an entire county? These questions will be further explored in the upcoming Chapter 5 -- Becoming Persons in Community and Chapter 6 -- Building on Success. 


\section{Chapter 5: Being a Person in Community}

The Swamp Gravy plays brought persons into a closer engagement with others in their community. This produced a number of personal experiences, some of which involved crossing various boundaries that some in Colquitt did not support. Many that did venture out into Swamp Gravy not only enjoyed themselves, but also got to experience a number of benefits that they had not anticipated. It has become popular to imagine that community is a dominant feature of living in a small town like Colquitt. Yet, for most of the plays enthusiasts, it was the sense of community that they experienced with others that was the essence of the Swamp Gravy experience.

\section{Community as Experience}

Colquitt, Georgia with a small population of roughly 2,000 and Miller County with a total population of just over 6,000, where everyone regardless of living in town or outside of town represents that they are from Colquitt, and where everyone attends one high school, comes close to being a modern day place that conjures up nostalgic memories of a small quaint town. Many project onto such environments a depth of community experience that may or may not be real. By discovering how Swamp Gravy has affected a variety of local personal relationships - neighbor knowing neighbor, including knowing across 
boundaries of race, status and role, it is possible that additional light will be shed on what qualities of personal experience have taken place that may be instrumental to the formation of a community. It is also important to discern how these experiences both empower persons (including both volunteers and audience), as well help to frame a new community identity.

The primary goal of community performance has been to expose the community of Colquitt to itself. It was also hoped that acting on stage and even participating as an audience would inform and prompt residents to both think about and act for the common good of their community. After experiencing the impacts of Swamp Gravy during that first year, CMAC and the Swamp Gravy volunteers concluded that the play and the process should continue - meaning that each year they would gather new stories, create a fresh script, and stage a new production of Swamp Gravy. They did not know where they would find the financial resources to do so, but what they had experienced had kindled the desire to build on what they had started. The needs inherent in making Swamp Gravy an ongoing event precipitated CMAC to hire Karen Kimbrel as their first business manager (Kimbrel 2008, interview). Up until 2008 Kimbrel and CMAC have been able to achieve enough earned income, grants and private donations to sustain Swamp Gravy's continuation. The yearly schedule featured Swamp 
Gravy taking place each weekend (Thursday-Saturday) during the months of March and October. Expanding Swamp Gravy into an ongoing twice-a-year event was no small feat. The initial production had mobilized nearly 200 volunteers, and their initial successful run had energized the participants. Swamp Gravy had not only created relationships but had started to breathe new life into Colquitt. One former resident commented after seeing Swamp Gravy performance: “My initial reaction - I was overwhelmed - tears streaming down my face, because I was so incredibly proud of what this community was able to do. To come back here [from an urban setting] and see your mail man, grocer, newspaper editor, teacher, friends, grandparents, putting on this moving play..., I was so proud of what had been accomplished" (Audience 2008, interview).

Prior to the advent of Swamp Gravy as a permanent institution in Miller County, few social events brought together so many persons from so many different corners of the community. "Going to church is the place where most people have their social connections in small towns like Colquitt" (Anonymous audience member). The half dozen home games for the high school football team represent the most diverse gatherings in the County. The annual Mayhaw Festival serves as an annual community festival that also attempts to attract tourists. The volunteer community alone that was necessary to successfully 
launch a 1-month season of a Swamp Gravy production typically ran upwards of 200 persons. The volunteer group by itself represented 3.3 percent of Miller County's total population of 6000 . This already exceeds the 2 percent attendance that traditional theater productions attract from a given area for the duration of a performance season (Geer interview). An internal CMAC study concluded that in 15 years of Swamp Gravy productions that more than 500 local community members had actively served in a volunteer role (Traywick 2008, interview). With the completion of Cotton Hall, which seats about 300 audience members, a single season of Swamp Gravy can host an aggregate of around 5,000 attendees. The math would suggest that the play itself could easily be seen by everybody in the county in as little as a year or two depending on the willingness of the local population. Though the plays have run for 20 years, the saturation in terms of local attendance does not add up. CMAC estimates that less than half of Miller County residents have ever seen a Swamp Gravy production over a 15 year period of time. Attendees from outside of Miller County account for roughly 75 percent of ticket sales. And many of the local attendees are repeat customers and/or relatives of the cast members (Traywick 2008, interview). One volunteer associated with ticket dispersal estimates that outside of the volunteers and their 
families, that only about 10 percent of the remaining Colquitt population has ever attended a Swamp Gravy play.

No one knows the exact number of Miller County residents who have attended at least one of the Swamp Gravy performances. Audience members consist of all ages, young and old. The number of local attendees is commonly assumed to be a minority of the overall population. One city official said that he wished that the citizens of Miller County as a whole were as enthusiastic about Swamp Gravy as the attendees from other places were. Reasons for the lack of local enthusiasm and attendance include: access (ticket prices currently \$25 per person); not enough time or too busy; competing leisure time preferences that are more convenient (TV); a general disinterest due to perceptions about the play's intent, such as staging racial issues (Audience member 2008, interview). CMAC has made conscious efforts to get tickets into the hands of those that desire to attend through distribution of free tickets to churches where they are handed out. A lack of significant attendance from the Black community continues to stand out at all of the performances. Reasons for the lack of Black attendance mirror those previously listed according to CMAC (Traywick 2008, interview).

Even though local attendance has come up short of what CMAC and other Swamp Gravy enthusiasts have desired, the aggregate volunteer participation of 
500 is just under 10 percent of the county population. When adding in conservative estimates regarding area attendance with the number of volunteers, it is reasonable to estimate that about 35 percent of the Miller County residents have seen a Swamp Gravy performance. At the same time it is safe to conclude that virtually everyone that is residing in Miller County knows something about the Swamp Gravy plays, especially since murals from the play's stories are interspersed throughout the downtown area (Traywick 2008, interview). The eventual developments of businesses and institutions that have spun out of Swamp Gravy assures that most of the Miller County residents have experienced some connection to Swamp Gravy, even if just having had a meal at the Tarrer Inn, which is the premier food and event establishment in Miller County. Tracking some of the personal experiences that bubbled up from Swamp Gravy plays helps illustrate and describe some of the individual and community effects that the play produced in Colquitt.

\section{Community Experience Tracks}

Over the twenty years of Swamp Gravy plays the Miller County Liberal (the area's newspaper) has covered dozens if not hundreds of Swamp Gravy related stories and events. The newspaper's offices are located across the street from Cotton Hall. Swamp Gravy has probably been the most covered ongoing event 
over the last 20 years in Miller County. Karen Kimbrel first heard about the Swamp Gravy project by reading about it in the newspaper. Kimbrel has a business degree from Troy University. But she is also a gifted, albeit self-taught musician and singer-songwriter. Kimbrel and her somewhat reluctant husband Billy decided to get involved in the play. Both became valuable contributors. Karen helped with writing many of the songs and also acted various roles in the plays. Billy, being an auctioneer by trade had a natural propensity to act, which enabled him to quickly become one of the more recognizable members of the cast. Neither had acted previously. Neither had ever personally met Joy Jinks, nor many of the other cast-members in Swamp Gravy. Participating in the plays with all of the other volunteers puts people together over long periods of time, which combined with the collaborative nature of the process encourages "the formation of a community, if not a family" (CMAC official 2008, interview).

When CMAC decided to make Swamp Gravy an ongoing event it opened the door for Kimbrel with her business degree to expand her role to now include being the CMAC business manager. During the first year of Swamp Gravy Kimbrel had been employed in Bainbridge, Georgia, a larger city 20 miles south of Colquitt. She had always looked forward to that day when she could once again find employment in her home town of Colquitt. Kimbrel's role in CMAC 
and Swamp Gravy had provided the occasion for her getting to know Joy Jinks as a collaborator and friend. Jinks and Kimbrel quickly formed an informal partnership that combined Kimbrel's talent as a business woman with Jinks' passion as social worker. Jinks' early interest in life had been to study theology and theater. In keeping with her role as a social worker Jinks' desire was to see her town feel good about itself, celebrate its heritage and boost its self esteem. Kimbrel's initial interests had been music, but it quickly evolved to business and economics. The two women came together under CMAC's bold vision that included community development. The two worked together using their combined skills and enthusiasm to grow Swamp Gravy into an established community institution. Geer's vision was to do community performance in order to expose community members to one another on a personal level, and thereby activate a community of actors whose experiences inside the theater would inspire and inform how they might act outside the theater in the community. The three together represent somewhat different focuses: activating community; promoting community self esteem; and developing local economic viability. Synergy is a condition where diversely functioning parts (or, in this case persons) form a partnership where the contrasting directions counterbalance each other, which enables an optimally functioning whole to emerge. This trio of 
Geer, Kimbrel, and Jinks at times demonstrated such synergy. They were certainly an odd partnership (Jinks 2008, interview).

Veronica Haire, an African American woman, was another community member who got involved with Swamp Gravy during the first year. Haire and Kimbrel had not known each other at all prior to working together in Swamp Gravy. When Jinks had invited Haire to get involved, Haire's mother had encouraged her by saying, "you never know where it might take you" (Jinks interview). Prior to Haire's involvement, most of the White people in Colquitt had never spoken to her. Jinks had gotten to know Haire, and had invited her to get involved in the play. Haire's status in Colquitt was measurably humble. When walking through town she consistently looked down at the ground, choosing not to make eye contact with any others. Jinks thought that getting Haire involved in Swamp Gravy might help her come out of her shell. No one knew that she would become a force to reckon with on stage - not just in delivering time sensitive spoken words and amazing facial expressions, but in singing as well. Her sense of performance timing was uncanny (Jinks 2008, interview). Her voice was even more impressive. When Swamp Gravy performed at Atlanta's 7 Stages Theater in 1995, a reporter for the Atlanta Constitution wrote that Veronica Haire "sings with the force of Mahalia Jackson" (Osinski 
1999, E1). Haire and another Black female cast member Gayle Grimsley were foundational performers in the early Swamp Gravy series. Outside of their work with Geer, neither had ever received any professional coaching or development. Like Jinks, Kimbrel and Geer, Grimsely and Haire eventually became partners too. Their relationship in the Swamp Gravy productions eventually resulted in their collaboration off stage where they co-founded a community serving nonprofit for the area youth called The Miller County New Vision Coalition (Jinks 2008, interview). (The Miller County New Vision Coalition is discussed further in Chapter 6.)

Being in Swamp Gravy together enables acting together on stage that often extends outside the confines of the theater. This is certainly what Geer had hoped would happen. Kimbrel and Haire had also developed a deep and loving affection for each other through participating together in the play. They had not known each other prior to Swamp Gravy. And, their social circles outside of Cotton Hall had never overlapped. The most contact they may have had with each other previously was an occasional passing of each other on the streets of Colquitt. Outside of work and school situations, the personal worlds of Blacks and Whites typically never intersected. That changed however when the newly forming Swamp Gravy relationships overlapped into Kimbrel and her husband's 
$25^{\text {th }}$ anniversary party. When it came time to put together the guest-list for the party, Kimbrel included all of the members of the Black and White Swamp Gravy cast. The event was held in their home. Kimbrel's father (in his 80's), and like most men his age in Miller County, was unaccustomed to attending social events where a mix of Blacks and Whites were present and interacting together. Her father was "typical" for his age and cultural surroundings - meaning that while he was not an "active racist," he was none-the-less "privately prejudiced" about members of the Black race. As a result of this new social mix, Kimbrel had some trepidation as to how the event was going to turn out. The party actually turned out well, as Kimbrel watched her father and Veronica Haire spend the majority of the afternoon talking with each other and having what she described as a "great time" (Kimbrel 2008, interview). Swamp Gravy friendships had begun to spill over into the private social spaces to everyone's mutual enjoyment.

Haire had bloomed on stage, and now had interacted with diverse others in private social circles to everyone's mutual enjoyment. Her new-found confidence didn't stop there. She gave everyone a taste of Swamp Gravy's politics of power in a local government controversy. A private corrections company wanted to build a county prison in the section of Miller County where most of the Black population lived, including Haire. The county commission had given 
the company behind-closed-doors assurance that they intended to go along with the company's plans to purchase the property by unanimous vote. The commission had not made any public announcement about the company's plan nor about their intentions to approve it. The dealings had not been disclosed outside of a small circle. However, the word leaked out to persons connected to CMAC, who in response became the organizing force that spread the word to the general public, encouraging people to show up at the county commission meeting where the proposal was to be formally voted on by the commission members (Kimbrel 2008, interview).

The commission consisted of an all-White cast of local leaders. As soon as the meeting convened, the chair of the committee announced a motion to forgo discussing the company's plan and move immediately to a vote. Billy Kimbrel stood up and said, "no mam! There are people here tonight from this community, and they have questions and things they want to say, and we need to hear them!" Billy and his wife Karen were there to support their friends that they had gotten to know through Swamp Gravy, which included their good friend Veronica Haire. Several members of the affected community had things to say, including Haire. When it was her time, Haire got up and began to scold the commission, telling them she was "offended" that they would try and pull this 
on her community. When Haire was finished, the all-White commission voted unanimously to reject the private company's proposed plan. Haire had brought the strong voice that she had on stage with her to the meeting - a voice that had been activated and strengthened through the various roles that she had played on stage. When she expressed her objections to the all-White commission, no one had another word to say. The plot of an outside company had been discovered and foiled. Haire and friends had now successfully acted on a public stage in Cotton Hall, gathered leisurely with friends in a mixed private social occasion, and now had demonstrated power on the political stage. The cast had all gotten to know and care for each other, as well as started to witness the different conclusions that a community of actors can make happen in their community (Jinks \& Kimbrel 2008, interviews).

It would be easy to write off Haire's political scene as nothing more than a NIMBY (not in my backyard) reaction. But, the dynamics of the situation beg a more contextual interpretation. Knowing Haire's previous stature in the community as virtually invisible makes her speaking out significant. When you add to that the dynamics of an all- White political system that was not accustomed to being scolded like a family member by a local Black person, the significance looms even larger. This was an un-choreographed public event 
where White support of Black community members was demonstrated. It is also important to note that it demonstrated the power of actors knowing that this is just another story to act in - as well as knowing who in the story has to play the primary role, and who needs to play support. Billy Kimbrel played a critical role by demanding that key stakeholder voices needed to be heard. B. Kimbrel as storyteller-facilitator understood where his role started and ended. The neighborhood stakeholders stepped up from there to fully expose what story was unfolding from their point-of view.

Haire had been up to the task. Her scolding of the commission demonstrates a family form of relation that is potentially rooted in her having become a person in the extended Swamp Gravy family - a group that included Black and While community members as well as persons from across the entire Colquitt socio-economic spectrum. However, by virtue of her role in helping tell the stories of the community, it appears that she saw herself in an extended family relationship with the Colquitt community as a whole, which included institutional structures of government. She had been a primary part of the Swamp Gravy performances that had been a catalyst for helping form Colquitt's new and emerging identity. (The formation of community identity is further discussed in Chapter 6.) 
Haire's next stage was education. Haire and Gayle Grimsley had also become close friends through their work together in Swamp Gravy. Their friendship ultimately led them to start a non-profit together, The Miller County New Vision Coalition, an after- school educational program for youth. Their emphasis was simple - no pregnancies and everyone must graduate from high school. (This program is discussed in Chapter 6 in more detail.) Haire and Grimsley together had paid close attention to how CMAC had been able to raise the money through grants to fund Swamp Gravy from a dream to an enterprise that employed a number of community members and owned several pieces of property. Grimsley had also watched children wander around her neighborhood after school. Lacking a guiding structure these children were on their own often until the parents returned home from work. They knew that establishing a youth program was important, and they believed that they too could succeed in raising the necessary funding. With assistance from CMAC and others they were able to find enough money to launch and sustain the after school program that they had envisioned. Today the non-profit continues under the sole leadership of Grimsley (Grimsley 2008, interview).

On January 6th of 2008, the 51 year old Veronica Haire unexpectedly passed away while asleep. She had been out of the cast for a few years, but had 
just returned to start preparation for performing in Nuthin But a Will, which had been invited to go on the road. Nuthin but a Will was largely about Haire's son Emanuel, who as a child had started a bicycle brigade consisting of a band of Emanuel's friends who showed up on their bikes at every emergency situation that required the response of the volunteer fire department. They had their own police scanner which they monitored religiously. In the beginning the fire chief had tried to discourage them. But, their devotion to show up every time regardless of the nature of the emergency had at times upstaged even the firemen's devotion. Emanuel's experience with the unofficial bicycle brigade deepened his desire to be enlisted in a more official capacity as a cadet. Fire Chief Craig Tully agreed to enlist Emanuel conditioned upon his maintaining a certain grade point average in high school - which Emanuel fulfilled. Nuthin but a Will was a very appropriate show for Veronica to stage her comeback reunion with her Swamp Gravy friends. However, her comeback was cut short. 
Figure 5: Veronica Haire

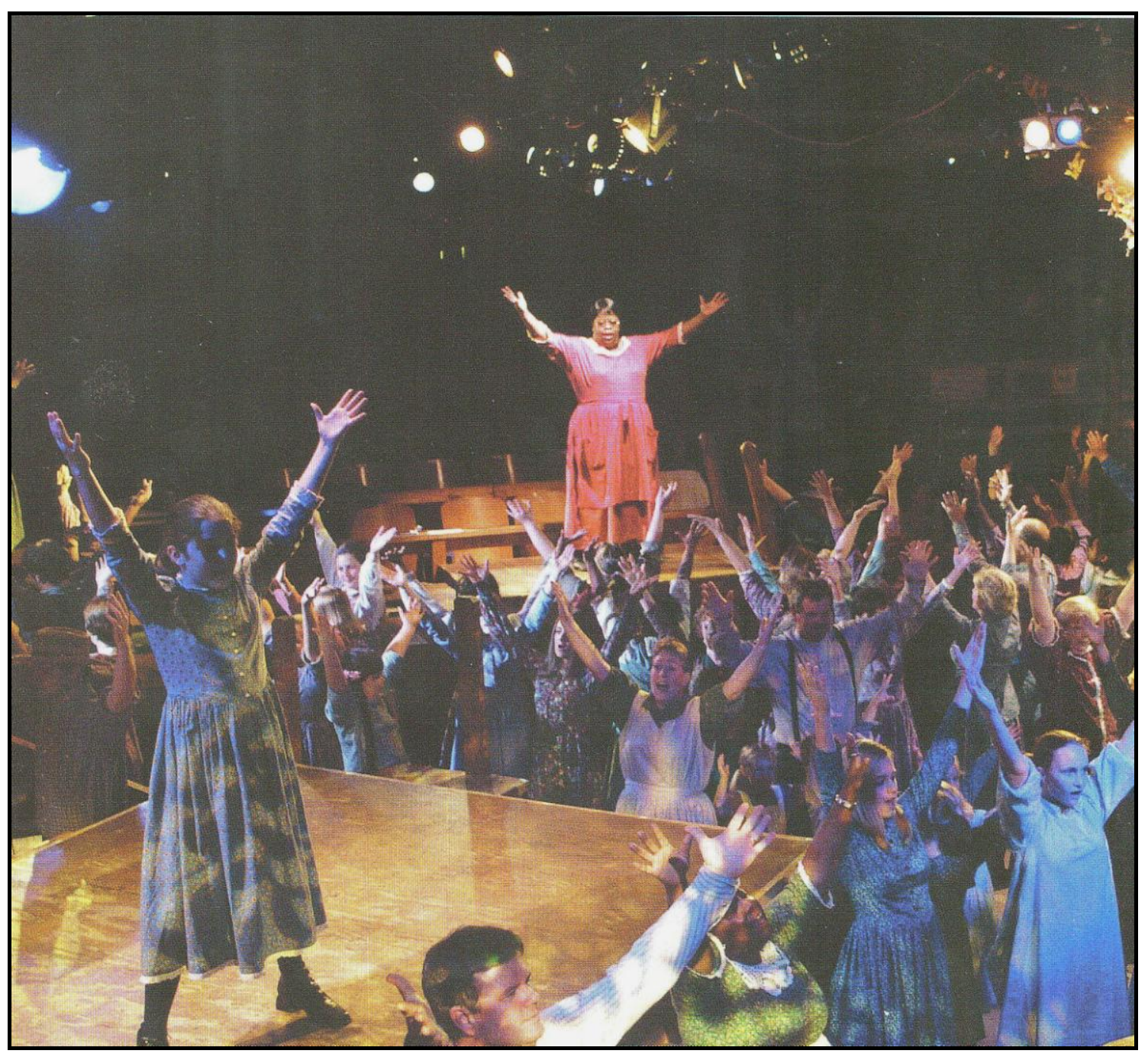

(Kimbrel 2007)

Once they received the news of Haire's death, the Swamp Gravy

community became activated on multiple fronts. The volunteer fire department gathered at Veronica's house and started cleaning the yard. The women from Swamp Gravy focused their efforts on cleaning the inside of the house. And, in collaboration with women from Veronica's church, all the women started 
cooking food together - members of Swamp Gravy alongside of members from Haire's church. The mix was not typical. But, at the same time it made sense that Haire's two communities responded in such a loving manner. The number of people that were expected to attend the funeral posed a problem. Her church was not big enough to accommodate everyone. As a result, the Haire family approached CMAC and asked if it was possible for them to have the funeral at Cotton Hall? CMAC gladly agreed to let the family use the theater space for the funeral (Traywick 2008, interview). Haire's family was not prepared for her death, and did not have adequate funds to cover her funeral costs. But, contributions were made by CMAC, Swamp Gravy, the Fire Department, and many other citizens (Jinks interview).

During preparation for the funeral, a distant all-White church community in Florida about 200 miles west of Colquitt had gotten the news from one of the Swamp Gravy cast members that Emanuel Haire's mother had died. This particular group had attended a performance in Colquitt a couple of years before. After they had loaded up on the church bus to return home, they realized that the bus was having mechanical problems. Emanuel (then a teenager), was in the vicinity and came to their aid. He called a local mechanic, and let them in the air conditioned fire department where they had access to restrooms. Emanuel 
stayed with them until a replacement bus came and picked them up. The church group had never forgotten the generous assistance that they received from Emanuel that day, and had written a letter to CMAC and the mayor of Colquitt to express their gratitude for his assistance. The mayor gave a public commendation to Emanuel for his diligence as a servant to the Colquitt community. And, in response to the news about Emanuel's mother, the church sent a generous $\$ 300$ contribution along with heart-felt condolences to Emanuel and his family (Tully 2008, interview).

Haire's casket was placed in the center of the theater's pit area, with members of the Swamp Gravy community sitting across the various other stages behind her. The bleachers were filled with people from all parts of the Colquitt community. On this day the attending crowd was made up equally of Blacks and Whites. Ministers (two Black and two White) from four area churches sat on the elevated stage next to the casket, each having prepared a message to deliver. The Swamp Gravy cast started the service by singing the Negro spiritual Wade in the Water (original author unknown), a song that Veronica had sung many times as a part of Swamp Gravy performances. The song was a staple of the early Swamp Gravy plays, and had become somewhat of a symbolic call and response. The song always had contextual relevance to a scene in the play, but in community 
performance tradition it also implied an invitation into Swamp Gravy itself.

Haire's friend and former partner Gayle Grimsley sang Veronica's part, while the chorus was performed by the attending Swamp Gravy cast members.

Chorus:

Wade in the water,

Wade in the water children.

Wade in the water

God's gonna trouble the water

Who's all those children all dressed in Red?

God's gonna trouble the water.

Must be the ones that Moses led.

God's gonna trouble the water.

Chorus:

What are those children all dressed in White?

God's gonna trouble the water.

Must be the ones of the Israelites.

God's gonna trouble the water.

\section{Chorus:}

Who are these children all dressed in Blue?

God's gonna trouble the water.

Must be the ones that made it through.

God's gonna trouble the water.

Chorus:

(Author unknown)

Then, on the last note and the last snap of the fingers to the song, the lowering casket lid was closed. The timing of the song's ending was performed in perfect 
sync with the closing of the casket lid, ironically mirroring Veronica's own uncanny sense of timing.

Following the song, a substantially integrated church service followed as two Black and two White ministers took turns preaching. Veronica Haire had become the occasion for yet another breakthrough - the unification of Black and White in a bi-racial church service. Cotton Hall was finally filled with a significantly Black and White crowd. Words that day from both Blacks and Whites referenced the moment as symbolic -- where two families for at least this occasion had become one through the fond remembering of their mutual friend. One elder Black woman noted a couple of weeks after the funeral: "It made me feel real good -- what the Swamp Gravy folks did for my friend" (Black storyteller 2008, interview).

Many in Miller County remember her as one of two surprising and instrumental Black women of "talent" - someone that they never knew possessed such "talent" (Buisnessman 2008, interview) until they witnessed Swamp Gravy - someone that many had written off as not having anything of value to contribute to the Colquitt community. Only a handful who were present with her that night remember her role in standing down the county commission who had secretly plotted with a private corrections company to locate a jail in 
her neighborhood. Veronica Haire was one of the many valued cast members in Swamp Gravy. She was not necessarily described as a charismatic community leader. But, she did possess the ability to rise to the occasion in a given situation. She was a community actor - and she acted both with and for the Swamp Gravy community. She remains a part of the Swamp Gravy community performances and is commonly remembered in the closing ritual of most Swamp Gravy productions along with the many others whose absence is felt in the hearts of the community.

To the Swamp Gravy community, she was more than a talented voice and actor - she was a person that was loved and valued by her family of friends - her community. One CMAC leader remarked that the funeral might be instrumental in helping Swamp Gravy finally become that needed place of reconciliation: "It was amazing to see that half of funeral attendees were White and half were Black, and both sides talked about the healing process at the funeral. In her death there was almost a redemption of circumstances - the love and support that was shown during the whole funeral process is hopefully something that will lend credence that through Swamp Gravy there can be an avenue of communication and healing that you don't find in this community" (CMAC official, 2008). 
Craig Tully is the Chief of the Colquitt-Miller County Volunteer Fire Department. Tully grew up in Colquitt, and graduated from Miller County High School. When Tully first heard that CMAC was talking about putting together a play from local stories, he was very vocal and expressed publically that he thought that "it was the stupidest thing that I had ever heard of" (Tully 2008, interview). Tully was one of Colquitt's most visible and popular leaders. Yet, he didn't see how anything good could come from making a play about life in Miller County, and then having the play be performed by local volunteers. It made no sense to him. Coincidentally, the building that served as the headquarters for the volunteer fire department was located across the street from Cotton Hall, where the play had set up its performance stage and held its numerous rehearsals. Tully had no interest in taking part and kept his distance from the project. Even as Swamp Gravy gained increasing attention and early success, Tully maintained his position as an unwavering critic. (Tully 2008, interview).

Geer and his aspiring volunteer actors however could not return the favor by keeping their distance from the Volunteer Fire Department. In the early Swamp Gravy years there were no restrooms in Cotton Hall where the cast rehearsed virtually every evening but Sundays. The closest restrooms to the 
rehearsal space at that time were across the street at the Volunteer Fire Department Building. So, Geer and company made regular trips across the street where they would use the fire department's facilities. This was Tully and the other fire department members' only interaction with the cast from the play - a cast that included Black and White, rich and poor, as well as young and old local residents. What was then an all-White Fire Department accommodated their needs, but continued to be non-supportive in every other way. One of the young children whose mom was in the play actually preferred to hang out with the Fire Department guys rather than sit around over in Cotton Hall. This was Veronica Haire's son Emanuel, who wasn't nearly as keen about being in a play as he was being at the Fire Department. Thus, while his mother was across the street taking part in rehearsals Emanuel shadowed the men at the fire departments every move. Emanuel was fascinated with the fireman and their equipment. Everytime Tully turned around, there was Emanuel. So, Tully gave Emanuel the nickname, Shadow. Emanuel eventually talked Tully into letting him do odd jobs around the building like sweeping up the floor and other cleaning assignments. By the time Swamp Gravy opened for their first season, Emanuel had become a regular visitor at the Fire Department (Tully 2008, interview). 
One day during one of the Swamp Gravy performances, Tully got called over to Cotton Hall. One of the audience members had fallen and needed to be taken out on a gurney. Once Tully got inside, the man informed him that he would only go with him if he would let him watch the rest of the show. So, Tully sat with the man for the remainder of the performance. When the performance was over, Tully and his crew wheeled the man out on the gurney. But, what Tully observed in that short time had so changed his opinion of Swamp Gravy, that he came back to see an entire performance. From that point on, Tully attended every single performance of Swamp Gravy, unless he was out of town for some reason. He became the play's most enthusiastic fan and loyal supporter (Geer, Tully 2008, interviews).

The following Sunday morning after he attended his first full Swamp Gravy play, Tully got up from his seat at the local Primitive Baptist Church and talked about his experience. He confessed that he had been wrong about the play. There were several members of the church that were a part of the play's cast. Tully concluded his confession by telling the church crowd that "Swamp Gravy was the best thing to ever happen to Colquitt," and that from then on he intended to support it in every way that he could. There had not been any one thing in the play that led Tully to the shift from skeptic to Swamp Gravy believer 
and enthusiast. It was the meaningfulness that was so rich throughout the whole performance that had won Tully over. It had taken him by complete surprise (Tully 2008, interview).

Tully's support did not come without his own shaping influence on Swamp Gravy. Tully insisted that Cotton Hall had to make a lot of changes in order to provide a safer situation for its patrons. During the first year of Swamp Gravy many of the attendees were allowed to stand in the pit area alongside of the actors. This was a creative design strategy that was intended to help blur the categories between the actors and the audience, and thereby literally envelope the audience into a deeper experience of the community performance. As Cotton Hall evolved into a completed theater structure, the creative design continued to reflect this blurring intent to see all as active participants. But the cast had to concede to discontinue allowing audience members into the acting space in order to comply with safety codes. After his Swamp Gravy conversion, Tully was at every play, both as a participating audience member-fan, as well as in his role as an on-site safety guide and emergency service provider. Tully both contributed to and gained from the Swamp Gravy plays (Tully 2008, interview). Tully's Swamp Gravy enthusiasm also helped influence a disinterested Volunteer Fire Department staff from their distant skepticism into supportive 
roles of the performances. The Firemen became the equivalent of traffic control by helping guide buses to and from the front door where they would assist attendees in both their arrival and departures from the play. They also helped people cross the street to the get to and from the parking lot. In time, several members of the fire department went the next step and participated in various roles in the Swamp Gravy play itself. Tully did not take that next step of becoming an actual performer, but, his involvement and that of his family continued to evolve. As a result, CMAC and the Volunteer Fire Department developed an odd partnership through Swamp Gravy. The two organizations put their heads together to come up with fund-raising ideas that they launched together for their mutual benefit. One such collaboration featured the firemen holding a cookout in conjunction with a Swamp Gravy performance for the purpose of raising $\$ 10,000$ with which the fire department was able to pay off their building. Prior to Tully's conversion to Swamp Gravy there was virtually no common ground between the two organizations, and certainly no one could imagine the two ever collaborating together (Tully 2008, interview).

Tully had learned a very valuable lesson through what became a highly successful albeit odd partnership with the arts council. Years later the Volunteer Fire Department was approached with the idea of evolving even further by 
investing in the requisite education that would enable them to become a professional fire department. The suggestion was perceived as being in total conflict with the culture of most every volunteer fire department that Tully knew about. Without experiencing Swamp Gravy, the prospects of his agreeing to even consider this shift was just as unlikely as was the fire department's initial potential for being involved with the Swamp Gravy plays. Swamp Gravy "changed my whole line of thinking. We are the only city anywhere around here that has done this. Two totally separate cultures - emergency medical and volunteer fire department. It [Swamp Gravy] enabled us to see two cultures can work. Nobody wants to say we need to find common ground. Swamp Gravy enabled us to see, hey [Swamp Gravy] done it, so we can do it. That is the point that it played. I have had a lot of mentors around the state - older conservative fire chiefs that were very engrained in how it should be... The fire service is not big on change, but Swamp Gravy kindly shed a little light that if you don't change, you gona get left behind. I saw Swamp Gravy do that, accept change and make it work." After listening, studying the implications, and consulting with the staff and city leaders, a decision was made by Tully and the other Volunteer Fire Department members to move forward and begin the necessary steps that would result in the professionalization of the volunteer fire department (Tully 2008, interview). 
Tully is quick to admit that without going through the conversion process that he experienced in coming to love and value Swamp Gravy and CMAC, he would never have given the opportunity to professionalize the fire department a second thought. Tully also confesses that Swamp Gravy "changed my total outlook to the community of Colquitt... It changed me to being more open to change in things I never thought I would be - like the arts. I love it now - plays. I watched what it did for Matt [Tully's biological son] and Shadow - and what it did for them. I learned that well maybe I'm wrong and everybody else is right, so I started appreciating things I never thought I would". He had learned the value of an odd partnership and what it might lead to. As a result he was not only willing to listen to the proposal, he also wanted to hear what others outside the fire department thought as well. The Volunteer Fire Department culture that was static and closed became open and responsive. A stubborn common sense that was reinforced by a homogenous and static culture had been replaced by a collaborative culture that valued diversity and creativity - a lesson they learned inside Cotton Hall Theater (Tully 2008, interview).

Tully practiced in public what he had learned inside of Cotton Hall - that being "open to change was a good thing, and that local stories can teach us that if we truly listen. I saw where it blossomed into things - making people in the 
stories better, made them more appreciative of the town and the people. The older day stories makes me appreciate what my ancestors went through to get us where we are today. And, it is very important for a town to tell as many stories about what went on as they can. Made us aware. It's sort of like a chronological deal of - here is where we were, and here is where we are at now, and we are going to build on that and here is where we are going - is how I look at it." The reflecting process Tully speaks of ties past and present together in such a way that informs a vision of the future that builds on a new awareness of what is good that the community could build on. Storytelling as a teaching form of historical parallelism worked as far as Tully was concerned. The picture Tully paints from his experience of Swamp Gravy is that the community storytelling (narrative process) had been a catalyst for creating a learning community, and the lessons learned included those about oneself, others, heritage and the present - and that they were "very important" to the guiding the community forward to achieve the "common good" (Tully 2008, interview).

While Craig Tully became Swamp Gravy's most loyal fan, another story had unfolded at the Fire Department across the street from Cotton Hall. Veronica Haire's son Emanuel had plotted his way into full-fledged acceptance at the Volunteer Fire Department. As has been mentioned this path was not without its 
own challenges. But, he persevered, and in time with a lot of hard work his diligence paid off. Through his initial experience with the Bicycle Brigade, Emanuel became the first Black community resident to attain official membership status within the volunteer fire department. Over the years that followed the Fire Department welcomed other Blacks in the role of volunteer firemen. Shadow and Tully formed their own version of an odd partnership, and Tully informally adopted Shadow as one of this own. Once he was old enough he went the next step and became a full member of the Colquitt-Miller County Volunteer Fire Department. The proximity of Cotton Hall and the transformational catalyst of the plays together had led to the development of mutual affection and facilitated an interdependence between these two unlikely partners. It also facilitated another consequence as well - the integration of one of Miller County's most cherished institutions, the volunteer fire department. 
Figure 6: Volunteer Fire Department

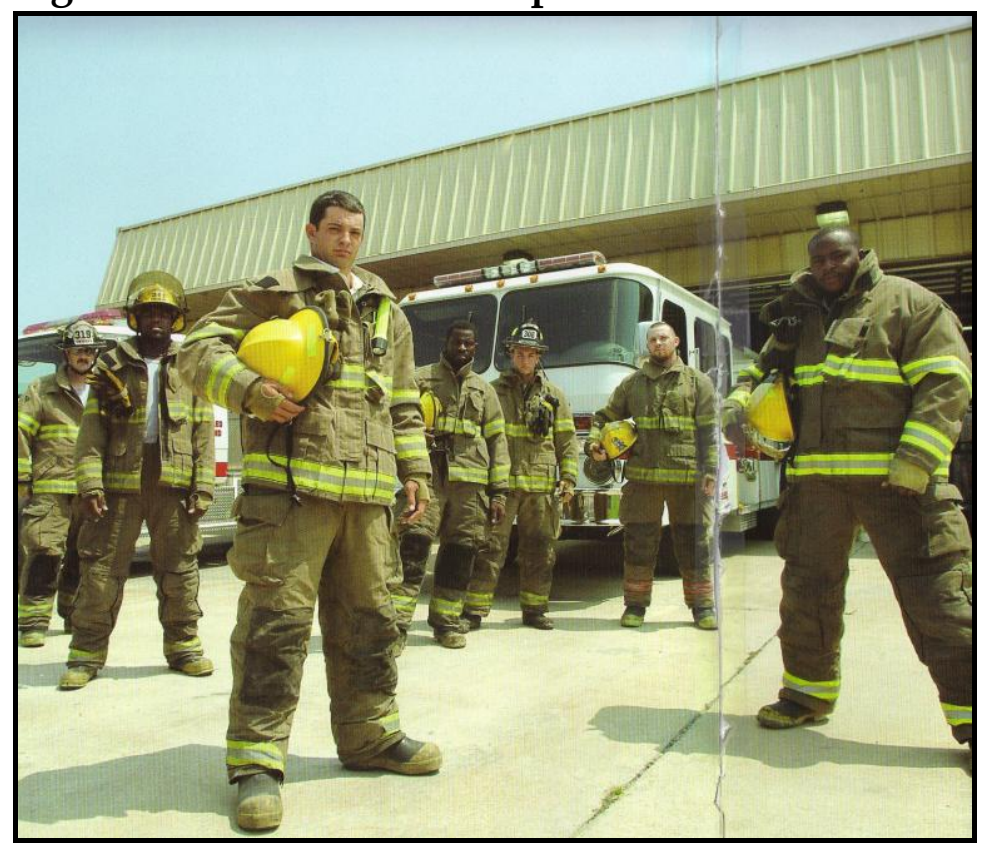

(Kimbrel, 2007)

Figure 7: Bicycle Brigade Mural

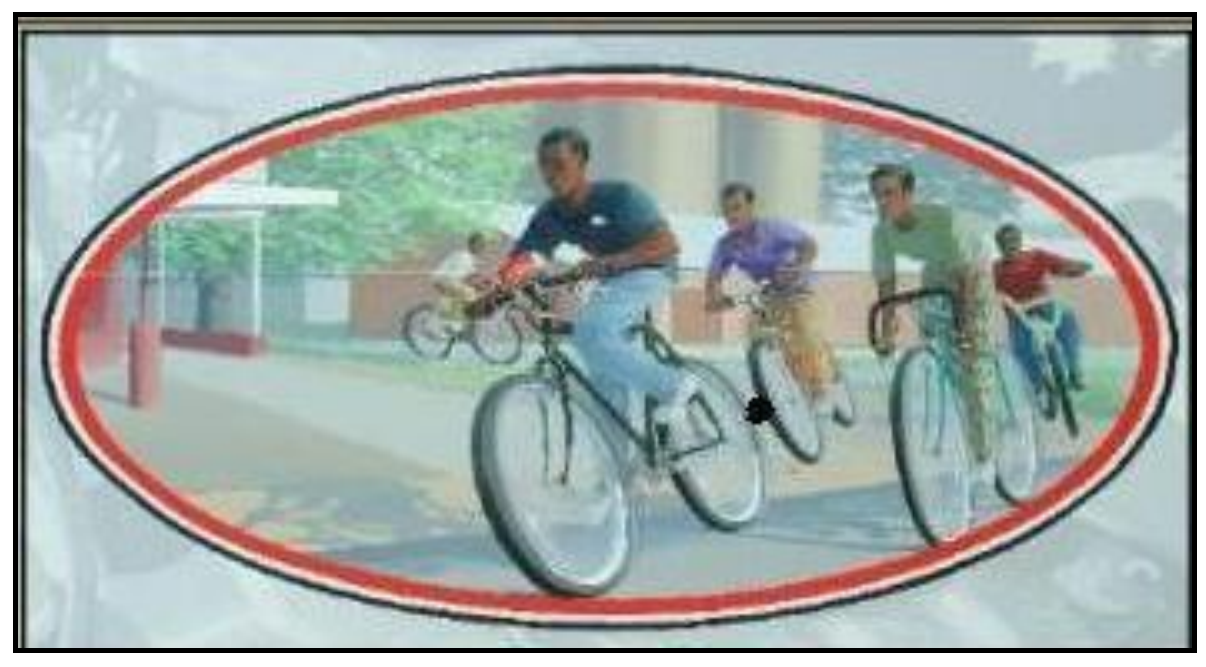

(Kimbrel, 2007)

Shadow's Bicycle Brigade story was so compelling that it was adapted to be the primary (spine) story in a Swamp Gravy production, called Nuthin But a 
Will. In conjunction with being featured in the play, a mural was created and installed on the north wall of the Volunteer Fire Department. The play was eventually commissioned to be performed for the Georgia State Fire Chiefs Convention in Savannah, GA.

One scene in the play features a mentoring type of conversation between a Black woman named Dololy and a young White girl who goes by the name of Monkee -- Tully's daughter in real life. Her story was featured alongside of Emanuel's story in Nuthin But a Will. Her story parallels Shadow's in that she too struggled with the fact that she wanted to become a cadet of the Fire Department, but was not allowed to do so by the Fire Chief (her father) - mainly because she was a girl. The character Dololy knew a lot about limitations based on bias, and begins to talk with Monkee about her situation. That conversation in a scene called Joy Gonna Come, went as follows:

\section{OLD DOLOLY}

Girl, slow down! Where's the fire!

\section{MONKEY}

Oh, there's a fire alright! I was the first one there, ready to roll out the kinks in the hose, just like Shadow taught me. The truck pulls up and Big Jim yells "Go home GIRL!"

\section{OLD DOLOLY}

You got to calm down before your head explodes. I'm serious. Sit here. You know, my mother had something to say about things like this. 
MONKEY

Did she try to be a firefighter, too?

\section{OLD DOLOLY}

You could say that. Listen, I know you mad. But you left one fire for the wrong reason, and all you did was start another.

MONKEY

But he sent me home!

DOLOLY

Tell me, why did you go to that fire?

MONKEY

To put it out.

OLD DOLOLY

Why did you leave?

MONKEY

Because...

\section{OLD DOLOLY}

Cause somebody hurt your pride.

\section{OLD DOLOLY}

Right now you showing up on their front porch waiting for them to give you something. If you just want your pride fed, you better find another porch to sit on. If what you want is to do something, then do it, and that'll give you plenty. Always plenty of that.

\section{MONKEY}

You don't know what it's like. No matter how good I am, I'm still a girl. It shouldn't matter.

\section{OLD DOLOLY}

No child, it shouldn't, but it does. My momma always said, Dololy, you know no matter what anyone say to me or do to me, I have faith, so I 
know I'm gonna pull through. When you understand this, whatever situation you in, you know Joy gonna come in the morning. Cause I have my faith.

\section{MONKEY}

I got faith, but they don't got faith in me. It don't matter how good I am, how much I know about fires, how many times I go to the meetings, I'm still a girl.

\section{OLD DOLOLY}

And you gonna find that over and over, and you can't run away from it. Some things don't change. You always gonna be a girl and I'm always gonna be black and that's the way God made us. Our job's to see where we fit in the world, and it ain't always easy. It don't matter how long I worked here, how much good I done, how educated I am, I'm still black.

\section{MONKEY}

It don't matter how much you clean,

OLD DOLOLY

How honest you are,

MONKEY

How brave you are

MONKEY AND DOLOLY

I'm still a girl/black.

\section{OLD DOLLOY}

It does not matter how many other peoples' kids you raised,

\section{MONKEY}

How fast you ride.

OLD DOLOLY

How long your momma worked here, 


\section{OLD DOLOLY AND MONKEY}

I'm still a girl/Black.

MONKEY

How Strong you are,

OLD DOLOLY

How Smart you are

MONKEY

How good you are

MONKEY AND DOLOLY

I'm still a girl/black.

\section{MONKEY AND OLD DOLOLY}

When I go out for a job, I'm still a girl/black, no matter how qualified I am, I'm still a girl/black. No matter anything, I'm still a girl/black. I'm still a girl/black.

\section{OLD DOLOLY}

And you know what else? It's good to be a girl. It's good to be black. And thank you Lord, for making me both. We know this, we understand it in our bones, and nothin' out there's gonna keep us down, cause what else do we know, child?

\section{MONKEY}

What?

\section{OLD DOLOLLY}

Joy gonna come in the morning. You're young. It's hard, I know. Folks don't like change.

\section{MONKEY}

I've heard. 


\section{OLD DOLOLY}

They take change better when you make it easy for them. You really good as you say?

MONKEY

Yeah.

\section{OLD DOLOLY}

Then next time, you tend to the fire, and not who you think can do the job better. Do what you need to do, and do it well, and keep doing it, they won't have a reason to tell you to go. After while, they get used to you, long as you do your part. Long as you don't give up, joy gonna come.

This scene demonstrates the kind of challenge that community

performance often has to navigate without losing its footing and intent. This scene could have been written in such a way that used Monkee's dilemma to incite the audience to be on her side - victimized as she was by those who were biased - and in this case, the biases highlighted in the dialogue include both race and gender. Her story reveals a detailed situation of gender bias, but her mentor's advice comes out of a situation of racial bias. Putting the two together softens the potential blow to a largely White southern audience concerning the realities of racial biases, while at the same time universalizes bias. Making one the feature story in the scene (Monkee), and placing the other in a more sideline mentoring role devoid of details, lessens the issue of race that much further. In essence, the script is constructed in such a way that features gender bias and confirms racial bias. 
The mentoring dialogue between Monkee and Dololy suggests that you have to be who you are, and let biases alone. Doing such, regardless of the outcomes enables one to be a person, and thus doesn't give power to a bias that has no real say over who is and who isn't a fire department cadet. As such, the outcome of being a fire department cadet is internalized, and not determined by cultural norms that are the common sense of the status quo. No promises are made by Dololy as to when others might come around to realizing that Monkee is a legitimate fire department cadet - only that she has to be one first if there is any hope that the others will ever change their minds. The reality is that they may never change their minds. But, if she only kicks against their biases instead of doing what she knows she can do, then there is no hope.

The community performance process has artfully stayed true to the stories, while avoiding the kind of advocacy emphasis that totalizes some in the role of the bad, and leaves the person victimized in the passive status of a victim. The advocacy angle may play well to certain crowds, but by doing advocacy the play would take a more agenda-driven trajectory, which is the type of trajectory that many in the South might expect from a director and writer from the North. Geer and Corriere both have a keen eye for recognizing the pseudo-stories of a victim, and affirm that a passive victim is not a storyteller or an actor. Keeping 
the community performance trajectory on target enables Swamp Gravy to avoid the pitfalls of patronizing and demonizing which would have changed the dynamics of community performance into a pulpit for preaching.

Two weeks before the play was to be performed in Savannah, Tully's daughter, affectionately nick-named Monkee died in a tragic car accident. While Monkee's story was in the play alongside of Emanuel's, Monkee herself was not acting in the play. But one of her brothers (Matt) and her now-adopted brother Emanuel were both in the play. The cast met to talk over whether they should cancel the show in Savannah. After talking with the family, they all decided to go forward and perform the play. One cast member remarked that "it was the most intensely moving performance that I have ever witnessed in all of my years of performing in and watching Swamp Gravy plays." Tully and his family were all present when his extended Swamp Gravy family gave their performance for the assembly of state fire chiefs. There were no dry eyes (Murdoch 2008, interview).

When the play was being performed in Savannah, another member of the cast, Wil Murdoch was struggling with his own life challenges of confronting cultural expectations. His role in Nuthin But a Will had very little to do with the main storyline regarding the Fire Department. He had a role instead in one of the secondary stories. In real life, his older sister, like Monkee, was a tomboy and 
very athletic. Wil had never been interested in or really gifted in sports.

However, being in South Georgia and being a guy meant that being involved in sports is a virtual cultural expectation. Being an athlete - especially a football player was the quickest path to popularity. However, Wil's interest was in theater, and especially film, which had all started with his years of experience in Swamp Gravy. He had literally grown up in Cotton Hall playing a variety of roles over the years. He was now midway through High School and in the beginning stages of pondering what he wanted to become in life, especially since the prospects of college were on the horizon. To make matters worse, Wil's older athletic sister had never really gotten what all the Swamp Gravy and theater hoopla was about (Murdoch 2008, interview).

Not until the performance of Nuthin but a Will in Savannah did Wil realize how the scene completely intersected with his own life circumstances. He had performed in or rehearsed the play dozens of times, yet never really made the connection between Monkee's challenging situation to that of his own life circumstance. While the challenges in both Monkee and Wil's life were cultural, the particulars on the surface were practically the opposite. Wil and Monkee were opposite gender, and opposite in their interests - one an aspiring fire cadet, one a theater enthusiast, and neither fit the cultural norms of gender expectations 
in Southern Georgia. When Wil realized that Monkee's struggle with cultural bias was similar to his own, he knew immediately what he had to do - devote his life to a career in film, and if that didn't work out he would fall back on theater. It was the only thing that he wanted to do, regardless of what the local expectations were (Murdoch 2008, interview).

Wil became fully aware of his own story at the intersection where Monkee in Nuthin But a Will had decided to strive towards her heart's desire - choosing not to fight against or conform to the local common sense, and in so doing she would do the work of a fire cadet and let the chips fall where they may. This new awareness alone was not the end of the story, just a critical juncture. Wil, like Monkee was faced with the decision to act out his desires. In response, Will worked even harder at leading and directing the Colquitt youth theater initiative. Like Monkee, if he desired to do a certain kind of work (film or theater), then he had to act on that desire before anyone else could be afforded the opportunity to believe in him. Under Wil's leadership, the Colquitt youth community theater initiative grew and expanded through performing a number of plays. Wil also got the pleasure of directing Peter Pan, in which his older sister made her acting debut in a role as one of the pirates (Murdoch 2008, interview). 
What started with Joy Jinks inviting Veronica Haire, who was then encouraged by her mother to try out for Swamp Gravy because of what it might "lead to," played out through a long line of interconnected stories, relationships and events. These previous stories are brief descriptions of a few of the life events that Swamp Gravy was instrumental in putting into motion. Each one of these relationships has its formative roots in the Swamp Gravy process in one way or another. As each track of personal stories unfolded, issues of race, class, status, cultural norms, personal agency, and community all played out. In order to better understand the implications that the plays have for life in Colquitt, it is necessary to look beyond this thread of stories to further assess the nature of relationships that Swamp Gravy facilitated between neighbors and across boundaries including race.

\section{Swamp Gravy and Race: Mixing It All Up}

The Swamp Gravy plays from the very outset waded into the reality of biracial Colquitt by design. Geer had agreed to come and direct a community performance in Colquitt under the condition that the stories that CMAC collected and used would have to come from all segments of the local population, which included rich and poor, Black and White (as well as any and all others)(Geer interview). No one was to be left out. The play was to strive to involve a 
representative number of Blacks and Whites, which meant that if there were 100 cast members that at least 25 should be from the Black community since Miller County was roughly 75 percent white and 25 percent Black. No other volunteer project in Colquitt had ever emphasized such a racially mixed intention from the outset that combined heritage content and participation from both the Black and White community.

To produce a public storytelling performance that was described as a "celebration of local heritage" would have to contend with the reality that with the exception of situations where Blacks and Whites naturally had to work together, there was little to no intermingling between the two races (Jinks 2008, interview). How could you celebrate the heritage of a place that was so significantly divided? To complicate matters for Blacks, what the word heritage could mean coming from Whites was White people remembering back to a more preferred time when the place of Blacks was not up for public debate or structural intervention. One Black member of the Swamp Gravy cast described that heritage was inherently a problematic point of view. "Race is always a touchy subject. You have to be very careful. For some it is pain, and for others it is what my family did. Your story may be, my father was a confederate, and you may think that is good, and then I tell my story of my father, and that 
confederate was not good for him. Everybody has a different point of view, and depending on the scene, you get flare-ups... Some people may not want to face" (Black actor, 2008 interview). Facing these differing points of view about heritage meant that the Swamp Gravy cast and the Colquitt community would find themselves almost assuredly in a position of having to reconcile what they preferred to remember about their own heritage with what others remembered about it as well from their own point of view. This would be the case because neither Blacks nor Whites were completely isolated from the other in Colquitt.

Geer's community performance design was to tread the slippery slope of realism, yet avoid Swamp Gravy being perceived as a platform where racial issues were strip-mined to be staged. Community Performance is not the middle ground between the extremes of entertainment at one end and issue-focused advocacy theater at the other end. Yet, keeping it real would upset many who wanted their particular clan's heritage remembered only in all of its glory. Sharing the stage with conflicting points of view could prevent them from the kind of experience of their heritage that they wanted to remember. The counternarration potential that each might have on the other's preferred memory represented a significant challenge - and, it was one that Geer would have to find a way to make work. As mentioned earlier, Geer depended heavily on the 
Swamp Gravy volunteers to mediate what they could stage and what they couldn't. One cast member boasted that "when race comes up, we decide how to deal with it" (Kimbrel interview). This was a shared responsibility that the cast took pride in owning. This included deciding what scenes could be too hot to use, as well as deciding what alterations could be made to a scene that might keep it real in terms of the overall story, but at the same time distancing or fuzzing the scene just enough to avoid it being perceived as playing on or reinforcing the south's regional identity as the haven of racism.

One example of such an alteration was demonstrated when 2 male cast members that were from the Western region of the U.S. were chosen to play a role in a story that demonstrated White racism. One of the two remarked about his role: "I played a person who thought that they were defending a widowers homestead and garden from a Black person. I am in the background - can't really see me, and she [the widower] runs me off and welcomes the Black person. I was cast in that role because I am not from the South, with racism being so charged as Southern. My double was from the West too. It was a conscious decision -- it would be best if my role as more of a stalker of an innocent Black man was not cast as an obvious Southerner" (Actor 2008, interview). White racism was still depicted, but without aggravating what indigenous Whites believed about how 
they are stereotypically cast as the most racist region in the U.S. This distancing enables the parable effect that Geer and the cast used in order to nudge reflection. In 2008 this particular Swamp Gravy production - Garden of Gratitude (or Visiting Hours), was taken on the road and performed in Sanford, Florida. The performance was so popular in Sanford, that a group of local citizens hired Geer and CPI to start up a community performance project series in Sanford that eventually became a sister project to Swamp Gravy called Celery Soup (Corriere 2012, interview).

Geer had established a mutual trust within the cast that enabled them to navigate the waters of their stories without becoming a bully pulpit for issues. This didn't prevent some from having their own perceptions about the process. One supporter that was living in Atlanta yet was still affiliated with CMAC and thus Swamp Gravy described the performances as depicting issues of race. "To be able to address the issue of race in a public forum that doesn't always reflect our best was startling to me. It may not be the solution, but we are able to talk about it" (Atlanta audience 2008, interview).

This lack of clarity demonstrates that the intended philosophical framework that Geer created to shape the Swamp Gravy process was not always understood by everyone. For some Swamp Gravy was theater somewhere on a 
continuum between the extremes of entertainment and advocacy. What Geer had in mind was not within this framing. He had intended to stage multiple oral histories from differing cultural heritages - some of those stories pertained to race. Because these stories were not completely isolated from each other, they could not avoid the reality that one point of view would sometimes conflict with other points of view, sometimes even counter-narrating while other times revealing surprising commonalities. Regardless of the intent, this notion of mediating diverse stories was never fully clarified enough to produce a consensus in Colquitt. And while some in Colquitt stayed away in order to avoid facing the potential of an unflattering counter-narration of their own heritage in a public place, others stayed away because they felt that Swamp Gravy was intent on staging race issues that in their mind didn't exist, or at least didn't exist anymore. Still others didn't come because of the "bi-racial cast" (Murdoch 2008, interview).

What was problematic from Geer and Corriere's perspective was that mining local stories would always face the possibility of uncovering stories that contained conflicting points of view, which in some stories exposed situations of local racism. This mining of stories could always be perceived as more of an intention to strip mine the local story terrain to intentionally find and stage 
issues of race. That perception of strip mining was always present. In most years this perpetual fear that outsiders were using the stage to color Colquitt as racist remained outside the loop of CMAC, Swamp Gravy volunteers, and even local business supporters of the performances.

Members of the Black community stayed away without divulging a clear public reason as to why. This fact continues to befuddle CMAC, who feel that their efforts to enlist a larger portion of the Black community have fallen far short of both what they desire as well as need. Most CMAC leaders can't understand why Blacks haven't stepped up to take advantage of the opportunity. One White volunteer actor has learned from Black participants that not all opportunities for them to benefit from are what they appear to be. "I did learn new stuff from Blacks -- that a lot of their culture has been lost through integration and elders aren't fond of that, because their culture has been lost. They had actually lost something rather than gained through integration and Civil Rights" (White actor 2008, interview). That this information was being passed on to Whites by Blacks is evidence that the play had facilitated some relationships of significant trust across the boundaries of race. CMAC leaders being a step removed from the daily face to face encounters that was intensified during rehearsals and productions, have concluded that the primary barriers to Black participation are 
largely due to transportation difficulties, and that many Blacks are juggling more than one job - making the lack of participation mostly logistical (Traywick 2008, interview). This convenient belief avoids the possibility that a lack of trust of Whites could be a fundamental cause of the chronically small number of Blacks in the plays. The assumption also projects lower expectations on Blacks based on the reality of higher levels of Black poverty in comparison to White.

One way of diffusing White fears and enlisting more Blacks was to emphasize the common ground subjects. Work was certainly a place where Blacks and Whites came into close contact with one another, and being predominantly an agriculturally based economy, the hot Georgia sun was familiar to all. The economics of 1992 Colquitt were such that there were fewer opportunities for Blacks, as the peanut industry had become mechanized, and other businesses were in decline or shutting down. Wealth had become less dispersed and therefore in the hands of the fewer number of farmers who were able to successfully convert their labor intensive operations over to machines. Many aspiring middle class Blacks moved away in search for middle class jobs, leaving behind a predominantly Black labor force (Traywick 2008, interview). Regardless, the common ground for the older Black and White population was through the memories of pre-industrial agriculture days, while the common 
ground for youth however, was found in the halls of education that had become integrated in 1970.

School was a place where Black and White youth began to have a significant amount of contact starting in the early 1970s, at which time integration was mandated in Miller County by the Federal Government. The transition from segregated education to integrated was uneventful in comparison to many other places in the Southeast. Local leaders made one significant albeit short term response to integration. They divided the newly integrated schools along gender lines, requiring the boys go to a separate school than the girls. This separation was maintained for a period of 6 years. After that, the genders were also mixed and everyone - Black and White, male and female, attended the same school together. Potentially a result of this staggered transition, education in Miller County remained a thoroughly public affair, unlike many other Southern counties where private academies immediately sprang up to accommodate those that wanted to avoid integration (Tully 2008, interview).

These two areas (work and to a lesser degree, school) became the territorial poles around which stories could be gathered. One story favorite of both Black and White was the story known as, Let My Work Speak for Me. This story was about a local Black woman whose aging mother had become sick and 
was no longer able to take care of herself. Her daughter had been raised and taken care of, not by her now ailing mother, but entirely by her grandmother. She faced the decision of whether to go to her mother's side and sacrificially take care of her, or to pass off the responsibility to other family members that were living in the same house with her mother. As the story goes, these family members were a bunch of "good for nothings"(Grimsley 2008, interview). So, she did decide to go to her mother's side and take care of her until her passing. Swamp Gravy cast member Gayle Grimsley played the role of the loyal daughter. Grimsley remarked that this was her favorite role that she played throughout the many years of her Swamp Gravy experience. The value of work is emphasized in this story, which for many exposed the reality that work as a value was held by both Blacks and Whites. Once common experience across race is discovered, the conclusion that "people are people" begins to be realized (Kimbrel 2008, interview). One Swamp Gravy cast member described it this way: “You learn that other people have problems and challenges just like you. Their story challenges how you look at others. Makes it easier to get involved with others. We become more familiar across race, and begin to trust" (White actor 2008, interview). In Colquitt, if the subject was going to be race, then things were potentially going to get hot, as was demonstrated by lingering fears of race 
mixing that were aimed at Cotton Hall. This combined with the inherent difficulties that the coproducing heritage surfaces for both Black and White certainly helps explain some of the difficulties that Geer and Swamp Gravy enthusiasts encountered from those who chose to remain both outside of the process as well as the theater. Up until 2008 Geer had sustained a consistent measure of trust from the Swamp Gravy cast as well as its supporters from the community. This trust enabled him to avoid being seen as an outside meddler with a bent towards exploiting issues. This trust was vital to his and the volunteers success in staying focused on real stories and avoiding provoking through staging issues. However, Jules Corriere, the Swamp Gravy writer in 2008 had come under increasing scrutiny from some in the Swamp Gravy community and CMAC. The concern, whether merited or not, reached a critical mass in the winter of 2008, when Swamp Gravy leadership convened a meeting with Geer to air their concerns. One leader asserted before the meeting: "Generally speaking the cast and the community don't want to shove issues down peoples' throats but nudging thought - [and] not what you should think. We have had a lot of controversy in terms of why we have to be so forceful with issues - not true in the beginning, but it has been recently. Not sure why that is, maybe trying to rekindle some fire. It is a big enough issue that it has to be resolved. It is a 
director - cast - writer issue. If the cast doesn't believe in the way you are doing it, then you will lose them. It is a collaborative effort - and maybe we have gotten away from some of the collaborative part" (CMAC official 2008, interview). As has been referenced earlier, the end result of this flare-up was never completely resolved, and both Geer and Corriere and the corresponding Community Performance team eventually parted ways from their professional roles with Swamp Gravy.

The community performance style of Swamp Gravy "convicted some" (White actor 2008, interview) - meaning that the nudge to provoke reflective thought in place of the intent to assign guilt caused some people to rethink their attitudes and behaviors regarding race. People came up to members of the Swamp Gravy cast on a regular basis to admit that the performance had "changed the way we see things" (Murdoch 2008, interview). Presenting racial biases in such a way that avoided aggravating the regional sensitivity of Whites enabled Swamp Gravy to avoid reinforcing the bias that some outside the South have towards Southerners as racists. As referenced earlier, this allowed the cast and the director to feature a scene where an unseen White male stalked a Black man through the woods at night in order to protect a White woman who was alone in her garden. The dynamics of the scene strike at the very nerve of racism in the 
south - the intersection of a Black man and a White woman (Geer 2008, interview). A secondary issue is how the scene provides a contrasting point of view from how a relative of, or the White "stalker" himself, might tell the story about that night - in all probability a story that would champion his role of being a dutiful neighbor. Distanced as we may be by design in time and culture, it is easy miss to the edginess of the scene, especially in light of the fact that the stalker in the story was a real resident from Colquitt, and perhaps even known by some in the cast as well as some in the attending local audience.

Swamp Gravy also had actors playing in roles across racial boundaries. Having a Black person play the role of a White person in a story had many blurring effects. Most of the cast as well as most of the local audience members could usually figure out who from their community a given story was about. Audience members typically knew when a Black actor was actually playing a role that in real life represented a White person, and vice versa. In some cases families that in real life were all Black, or all White, on stage had family members from across racial boundaries. One volunteer reported: "I get to hear a lot of audience members. Sometimes we appreciate Swamp Gravy because it is our stories. Yet outsiders see the same things you are moved by, people may be different in age race, location, but they are the same. They are touched by the 
stories that they can relate to. It speaks to them in some way. They return over and over, because it is very meaningful to them. All the different people have the same comments after the play - we are all human and the same things speak to us" (Volunteer 2008, interview).

The Swamp Gravy experience across boundaries of race is intensified amongst members of the cast due to the fact that a typical production is practiced for weeks, which adds up to 100 hours or more of working together on the performance. The production runs for a month, giving cast members plenty of experience at mediating their stories, nudging reflective thought, and discovering commonalities, as well as just getting to know their fellow cast members, themselves and their community deeper than what any of them had experienced prior to the play. One cast member remarked: “When you learn somebody's story you learn about who they are, why they are, and how they got to be where they are. The more we dig into who, the more we figure out we are alike and we are bonded in a way that you don't see every day -- once you know someone's story you are able to understand and accept" (White actor 2008, interview).

Perceptions about race within the cast still differ, and some cast members are perceived as racist by others in the cast. Swamp Gravy has not ushered in a 
consensus about race. One member states that, "it hasn't healed all the race gaps" (Grimsley 2008, interview). While others claim that they practice a more race-free way of perceiving things, as is demonstrated in the following: "I grew up in rural Georgia. I see us all as one [Black and White]. I see a chance to meet a different person... There are some people that continue to give and give, and some continue to take and take and take... I think the South is still pictured as race issues. But Chicago and New York is not. The South seems to get a bad rap. I think the North has more to move on from than we do. Sometimes its Blacks that are racist too" (White actor 2008, interview). This sensitivity to the perception that the South is inaccurately portrayed as racist is echoed by many White cast members. One Black cast member remarks that the claims of some of "not seeing color" can also be interpreted as suggesting a "level playing field. But the playing field may not be level - and that has to be addressed. Some people think all things are equal when it's not. If you are just projecting what you believe, then you are going to miss it. You have to make a diligent effort 24/7 if you want to be diverse. Diversity takes effort - it takes big people" (Black actor 2008, interview). This requirement of big people cuts across both categories of Black and White, and provides yet another possible reason why many in Colquitt have chosen to 
keep their distance from the performances - it is not easy, and it takes a lot of time.

If a White member of the cast is operating from the belief that everyone is functioning on a level playing field and the director makes concessions for a Black member who may be more challenged to make all of the rehearsals, then that White person is potentially going to interpret that the Black person as uncommitted to the play. At the same time, if the director is showing favoritism based on his own biases, then he potentially subverts the mutuality factor of being in community. The executive leadership and board leaders of CMAC in 2008 understood that not everybody in the play was working from a level playing field (Traywick 2008 interview). Mediating these realities within the cast were as important as mediating the content of the plays for the local audiences. And, it was not always easy, especially in 2008 when a tipping point of sorts threatened the partnership between the Community Performance Director/Writer team and many of the White Swamp Gravy cast members (CMAC official 2008, interview). Each cast member operates from a unique point of view, which can be influenced by pre-existing ideological assumptions. Acting together successfully requires a mutuality of commitment and time. Without that, the community weakens and trust begins to fade. Determining what constitutes the 
mutual commitment of time on a given day or during a season is no easy task, which keeps the conditions of community dependent on a quality of communication and mutual understanding. The community flourishes or recedes based on whether this high level of communication is sustained or weakens.

These different perceptions that exist about race within the cast provide the experience that helps them mediate scenes so that the story is maintained without provoking reaction from the local community. Perceptions about race outside of the Swamp Gravy cast vary as well. Some Whites in the community insist that racism or problems of race are "more a part of Colquitt's distant past" (White audience 2008, interview). Some elder White community members state that they personally "have never had a problem with 'em" - thereby interpreting racism or problems of race from an ethno-centric position. Since Blacks in Colquitt had never marched or gotten "stirred up," some elder Whites interpret that to mean that there has not been any problems with race in Colquitt (Businessman 2008, interview). At the same time, the vast majority of Blacks and Whites who have been heavily involved in the play believe that Swamp Gravy has significantly improved relationships between Blacks and Whites. One elder Black lady whose story provided one of the stories in the Swamp Gravy play summed 
up her response in just a few words - "it brought the community out" (Black storyteller 2008, interview) - meaning, out of the seclusion of clans and into the public commons together, Black and White, as well as rich and poor, young and old, etc.

One of the ways that Swamp Gravy diffused some of the sensitivities of race was by treating race as parts of a larger story - as was discussed in Chapter 2 in both the stories, Visiting Hours and Nuthin but a Will. By partnering race alongside of gender and socio-economic biases which both races could identify with suggested that racism was similar to other challenges that were common (universal) across divisions of race. Demonstrating the wisdom of how each responds to those challenging situations or plots, takes some of the heat off of racism and refocuses it on the common responses of Black and White actors in difficult situations.

It is thus telling that in the midst of the various perspectives on race in Colquitt one consensus of opinion rises to the top - that relationships between Blacks and Whites have improved significantly as a result of Swamp Gravy (Volunteers 2008, interviews). Swamp Gravy as a form of public narrative processes - listening to, telling, and responding to stories across boundaries of race "hasn't healed the gaps," completely, but has certainly started the healing 
process that is strengthening the experience of community in Colquitt (Grimsley 2008, interview). The oft-repeated and simplistic phrase that "people are people," (Volunteers and audience 2008, interviews) is a powerful indicator of the success of Swamp Gravy to mediate its own brand of racial reconciliation.

\section{Empowerment: Can Do Spirit}

Power is often identified as institutional (governmental), corporate (private business), and individual (wealth). And what happens in cities, especially in respect to revitalization usually involves a combination of these three actors working together as drivers. In Colquitt, local governmental power had been on the decrease as a result of business decline which produced dwindling tax revenues. With no business help coming from outside of Colquitt, prospects for revitalization looked dim at best. The surviving farmers that were doing well had been able to finance the mechanization of their peanut farming operations. Wealth had thus shifted into the hands of those larger and fewer farm owners. Increasingly, residents kept an eye turned towards outside corporate actors to come to their rescue. But, with a small population of just over 6,000 people, the big box stores skipped by Colquitt, opting for more populated surrounding cities like Bainbridge (20 miles to the South) and Dothan (60 miles to the west). These distant stores in neighboring counties served to further drain 
downtown Colquitt of its customer base. As a result, on Saturdays the square in Colquitt was virtually deserted. Most people adapted an inside-out gaze, and continued to hope that some business entity would decide to locate in Colquitt.

To their credit, CMAC had decided to act rather than to watch and wait. With the initial success of Swamp Gravy, CMAC began to champion Colquitt as a "can do" town (Jinks 2008, interview). CMAC demonstrated a willingness to trade on any good news they could find. Can do was a hopeful rallying cry in the beginning. With a little success it became an empowering and self-perpetuating slogan.

Gayle Grimsley summed up the can do spirit in this affirmation: Colquitt was "a community that had nothing going for it and took a play that was going to be done one time and turned it into a multi-million dollar deal" (Grimsley 2008, interview). As the play morphed into a regular twice a year event, more people caught onto the can do spirit. CMAC leveraged the growing success by launching a number of community promoting initiatives including the Swamp Gravy Institute (SGI) -- the consulting arm of the Swamp Gravy process. (SGI and other spinoffs are addressed in the section on Community Building Institutions in Chapter 6) "We want people to better understand who we are, a little better, and recognize that if we can do this, anybody can do it" (Volunteer 2008, interview). 
Their ability to leverage early successes was greatly enhanced by their ability to acquire funding for properties around the square that were revitalized (which is also discussed in Chapter 6). If Colquitt was going to be a tourist destination, then the square had to be revitalized. This was more a leap of faith than it was a calculated strategy. But local banker Clyde Jinks (Joy Jinks' husband) and director of the Jinks Foundation felt relatively safe investing in property and buildings (Kimbrel 2008, interview). Common banking sense affirmed this as well. As a result, the play would have to find additional sources of funding. With the buzz of the early plays, the arrival of outsiders, the visible realities of renovation, the community can do power picked up more steam. In addition, by tapping the Jinks Foundation for property funds CMAC was able to then leverage matching funds from other grants that could be applied directly to varying needs of the Swamp Gravy production. (Revenue, including grant amounts, is discussed further in Chapter 6). One outsider who moved into Colquitt remarked, "it was easy to see how powerful Swamp Gravy has been in the community. Without Swamp Gravy, Colquitt would have gone away. To see the tight knit group of people and what we can do together and the warm feeling of the stories," was very appealing (Volunteers 2008, interviews). 
One person who relocated to Colquitt called Swamp Gravy "a small town with a lot of spunk" (Stober 2008, interview). Over the years CMAC created two initiatives through which they sought to teach others. One, the Swamp Gravy Institute, established in 1996, took their local expertise on the road for the purpose of guiding others in the can do way of community storytelling. The more recent Building Creative Communities Conference, established in 2007 brought attendees in from other small towns from around the southeast for the purpose of learning from Colquitt first hand. One community member asserted: "We can accomplish anything we want to - the sky is the limit. We inspire outsiders and other communities to go for it, especially small little communities. I love to watch the audience and they seem in awe of the community. You can see the audience in awe that a community this size can do that" (Kimbrel 2008, interview). With Jinks' desire to see her community feel good about itself, combined with her partner Karen Kimbrel's business savvy, the twosome's power in suggesting that Colquitt is a can do community began to pay off, as new-found confidence began to become an emerging way of life amongst the Swamp Gravy collaborators.

\section{Empowerment: Confidence}

Veronica Haire was not the only community member who took confidence from the stages of Cotton Hall into other settings around Colquitt. 
Comments like, "I was shy about acting in a crowd. I would never have thought I could do it." Or, "it has given me confidence," are common responses among those that have volunteered in to be on stage in the plays (Actors 2008, interviews). The local volunteer performers were not recruited based on previous stage experience or for their demonstration of confidence. By design Swamp Gravy director Geer sought to flip typical theater procedure upside down. No one was ever excluded from being in the play. And at times, the director cast volunteers into roles intent on debunking stereotypes and bucking conventional common sense. Geer's intent has been to get volunteers to meet the rigorous demands of real theater, which Swamp Gravy is, while maintaining a nurturing and supportive community environment. These were volunteers, meaning they are there because they wanted to be and not because of payment.

The empowering benefits of participating as a part of the cast were felt by everyone regardless of age. One young father remarked about his new found confidence: “It ripples out everywhere. When I came here I didn't know I had this in me. I am singing solos in front of 200 to 300 people which is just bizarre. I didn't even know I had it in me. They have given me a voice and a aspect of my life that I had no concept of. [It had been] a nourishing experience" (Stober 2008, interview). Through working side by side with all ages of adults, children 
enjoyed an atmosphere where they contributed right along with grown-ups without being "intimidated" (Volunteer 2008, interview). Many parents began to see Swamp Gravy as a place of youth empowerment. Here are some of the comments that both parents and youth made about their experiences of being involved in the process:

My daughter was in it. Was good for her to be oriented with all these people around, a lot of people. She can get in front of 2 million people and give a 40 minute speech and it wouldn't bother her at all. Which I attribute to this theater. Set her up in life, that is most important to me" (Volunteer 2008 interview)

I saw one little girl come alive in Swamp Gravy. It brought her out - it did a lot of people, brought their personality out" (Volunteer 2008, interview).

I have seen kids self esteem built up and thus stay in school instead of drop out (Grimsley 2008, interview).

I have seen children that could not speak to you eye to eye, and then you see their head rising and their confidence grows, and our kids seem to do well when leaving here (Audience 2008, interview).

It changes you. It taught me self discipline, and confidence. I was scared and nervous, but Swamp Gravy brought me out of that. Changes me in school, presentations are easy for me to do (Black youth volunteer 2008, interview).

Swamp Gravy was a way to bring out leadership. Emanuel - has now won the hero award at the Fire Department banquet (Kimbrel 2008, interview).

It is easy to imagine how being in a play boosts the confidence level of all that are involved. But, it is important to note that the philosophy and style of 
community performance that Geer and his staff demonstrate in their guiding role is "co-creation" (Corriere 2012, interview). The previous references to the cast as mediators regarding content is expanded into every aspect of the community performance process. By doing this Geer and staff intend to propel the experiences of the participants far beyond the self-confidence that comes from being comfortable on stage, under the lights, and in front of a large crowd. Geer and staff set the stage to enlist and enhance the collaborative capacities of everyone. The self-confidence that results in the enhancement of an individual's voice may be a perceived benefit that some parents hope that their children gain from their experience in Swamp Gravy. But what Geer had in mind was the enhancement of a more collaborative listening and responding way of being with others.

\section{Empowerment: Activating Communicative Agency}

Communicative agency was not a clearly defined concept within the community performance philosophy early on. And even today there are loose interpretations of what it may mean. It centers primarily around certain characteristics that pertain to a way of being with others. One elderly woman who had never been in one of the plays, but who had attended many described what she thought that Swamp Gravy had meant to her community: "Swamp Gravy 
changes people -- makes em more friendly and aware of the needs around them. Made me more aware of the things that happened to other people. Makes people reflect on their own lives a little bit more than they would. Everything is built on others" (White audience 2008, interview). This is remarkably similar to what had caught Geer's imagination in Steamboat Springs, Colorado - an openness to stories that brought new awareness of self and others, that stimulated reflection, which would in turn inform acting together interdependently for the common good. This moved participants off the plane of individual self confidence to a higher calling - what could be called power with, or coproduction, or being in community. It was a quality of experience with others and not a static talent that could be mastered individually. Once experienced, it was expected to ripple throughout the rest of one's life in surprising ways.

Fire Chief Tully described how Swamp Gravy had changed his perception of himself in respects to the community. "It changed my identity! Made me know how much more important it is that I be a servant instead of an official figure that my job is a public servant, and that I am here to serve the public in whatever and every kind of way I can. It is totally reverse of how I see what I need to do. Instead of me just walking around and saying I'm the fire chief, and all in my business, I realize I need to be a small cog in a big gear to make the whole deal 
work - that I need to pull my weight. I am a better person because of Swamp Gravy" (Tully 2008, interview). You might say the Swamp Gravy had opened Chief Tully out of the narrow parameters of his professional role into the expanded role of being a person in his community. The description of being "a small cog in a big gear" demonstrates his new awareness of interdependency - a power with others in his community. Chief Tully to date has never been in a community performance of Swamp Gravy, but he has probably seen more performances than any other non-performing community member.

One retired Black school teacher described her experience with Swamp Gravy in a similar way." You make friends with others - become aware of other's problems, and you feel like you have another family when you join Swamp Gravy. It takes in the whole community and not just one set of stories. I used to see myself as just a teacher, and now it has gone beyond that to a volunteer. I feel more like a member - part of the community. It changed relationships between Blacks and Whites - getting Blacks to join in together for the community. You have more doers and more Blacks in politics in Colquitt. Before Swamp Gravy churches were separate - and now some go across race boundaries. I now think of Colquitt as one community" (Black volunteer 2008, interview). One result of experiencing Swamp Gravy is that people see themselves as larger and having 
expanded beyond their status or professional role to being a person in an interdependent community with others.

As has been previously referenced over the course of the first 15 years upwards of 500 volunteers have helped sustain Swamp Gravy as a community institution (Traywick 2008 interview). That number today if projected proportionately would exceed 600 volunteers, which is around 10 percent of the Miller County population and almost 33 percent of Colquitt's. One consequence of activating communicative agency is that persons get their larger meaning or sense of meaningfulness from experiences in their community, and as such are no longer determined by only their status and/or role. The respective positions in Colquitt of Chief of the Volunteer Fire Department and school teacher are both positions of respect. What is interesting is that both perceive that there is a way that they can narrowly be in those important roles that is actually less meaningful than being opening out in community with others. Or, that being in those roles doesn't necessarily render an experience of community with others and as such one can fill those roles in such a narrow way that actually detaches one from community with others, which has a reductive impact on one's own life. You can see why 500 to 600 people have filtered through Swamp Gravy based on how many describe how meaningful the experience has been for them. Before 
Swamp Gravy, "Colquitt had a few shakers and movers. With Swamp Gravy the movers and shakers grew to more, and now more folks are active beyond the small group. Many of the old timers are no longer at the center so that others can take a turn at leading" (Volunteer 2008, interview).

Another consequence of activating communicative agency is that it facilitates the emergence of a learning community. One participant describes this feature as follows: "you learn about another culture -- not everybody thinks the same -- and we need to respect that. That is the biggest asset - I learn what offends other people, and we learn to live together" (Anonymous White actor). The Swamp Gravy experience is commonly described as a learning experience. The director and staff enlist the volunteers in decision making at all levels of preparation and performance. Simple questions such as asking, "what is this story about" (Geer 2008, interview) activates the interpretative skills of the participants. Discussing the various opinions exposes complexities that potentially enrich each person's interpretation. This is reflected in one person's experience as - "it takes everybody's story to bring out everybody's greatness" (Black actor 2008, interview). Another person put it this way: "I have learned that all people have something to teach" (Anonymous volunteer interview). The fact that the learning community crosses all boundaries - not just race, but socio 
economics and perhaps even more important, generational boundaries, serves to enhance the learning experiences. "Young people began to love and respect others by seeing their stories and heritage on stage" (Volunteer 2008, interview).

As a result, "children have a greater sense of purpose and a better understanding about what it takes to make this world a better place" (Volunteer 2008, interview).

Exposing various social experiences through stories makes these lived experiences more universally inviting and accessible to others. It has already been referenced how one international audience member from Korea remarked that watching the Swamp Gravy performance had actually reconnected her to her own community experiences back home in Korea. Watching a story can be an active process that invites attentiveness, interpretation, and response. As such, stories can facilitate acting in a story. Veronica Haire had acted one way when she perceived that her community had come under attack from insiders and outsiders that didn't have her community's best interest in mind. Ironically, just days after Veronica Haire passed away and in the midst of the community making preparations for her funeral service, another outsider with big plans arrived in Colquitt to get the community's approval for his company's plans. However, this time the persuasive speech would be public. 
A community public relations representative from a prospective coal fire power had arranged to speak at Colquitt's monthly business leader's breakfast. He was prepared with a slideshow of numbers telling the audience about all the benefits to their area that the company would bring, especially jobs. Two members of CMAC were in attendance. The first one asked the presenter about the pollution realities that came with the coal fire plant that would be located about 25 miles west (which is downwind) of Colquitt. The presenter gave a well prepared answer that downplayed the pollution threats due to the new and improved technology that modern power plants are equipped. The second CMAC member waited out the discussion until near the end. She had been a member of the Cahaba River Society - an environmental advocacy organization in Alabama. She began to tell a different story with numbers that she had researched - numbers that actually counter-narrated the numbers story that the public relations representative had presented. After she presented a counter narrative about the pollution dangers, she read out a report that suggested that the number of jobs that area Miller County residents could expect to receive would be few to none. At this point the local state representative admonished the coal fire plant public relations person to tell the truth, since the CMAC representative was going to tell it to them anyway. 
Veronica Haire had risen to the occasion in a much different set of circumstances. The intentional lack of transparency that she encountered with the county commission had licensed her to speak in a scolding manner, but it was arguably appropriate in the context of the secret plot behind closed doors to sell out of her neighborhood before anyone could find out. By speaking directly into the plot and addressing them as if they were family, she had been effective. She wasn't there to argue the merit of the intended jail project, nor was anybody else. She was there to speak directly into the plot - an intentional deletion of community processes. In a similar and appropriate fashion, the CMAC representative came to the meeting with her own well researched story. The meeting was public, but the plant representative had not anticipated running into a counter-narrative with quantitative support. The prime instrument for selling his story was the numbers that gave the appearance of scientific accuracy. The CMAC representative told a story using numbers as well - one that revealed a dramatically different ending. Attendees left knowing that at the very least that there were 2 stories told that day. And the Colquitt business leaders that were always ready to listen to outside business actors walked away from the meeting without publicly endorsing the plans for the new plant. 
A key feature of the Swamp Gravy process is the valuation of everybody's story. Multiple stories are seen not as a burden, but as instrumental to enhancing the community's ability to discern what is good or accurate in a given situation. This is why one Black member of the Swamp Gravy cast asserts that being in community in the midst of all kinds of diversity requires "big people" (Black actor 2008, interview). And, you could say that it also makes big people bigger. Another community member put it this way: "It has brought the Community together in a lot of aspects, because of the people it has brought together across church and business boundaries. It has done a lot to facilitate basic interaction in the community. Everybody's story is important and needs to be told, and that a place is about its stories. It is like a small seed that bares fruit, and subversive in the way that local homegrown stories has given people a way to relate with each other and to see common identity across all sorts of boundaries, age, race" (Stober 2008, interview). Here are a few of the additional lessons that the people in Colquitt have learned:

I learned so much about me, life, people. Swamp Gravy is like a mirror that community holds up to exam itself. It has been very meaningful in my life. It changed my life (Kimbrel 2008, interview).

Yes, we are more community oriented, more willing to work together for the betterment of the community. It has brought back pride in the community and given hope and vision for the future that we never had (Tully 2008, interview). 
Relationships inside the walls of Cotton Hall go out into the community. Church affiliations changed. Baptist became Methodist -- the Volunteer Fire Department is now Black and White (White actor 2008, interview)

It was a dream come true to expand what I was already doing in my community (Grimsley 2008, interview).

Yes, the sense of community would be less broad and more clustered around status and role and race. Because of Swamp Gravy it is more open (Actor 2008, interview).

That sense of community we have here can allow you to interact with each other as human beings in a more powerful way than you can without it as individuals (CMAC official 2008, interview).

Communicative agency is not about one storyteller competing with another to win a truth contest. It is more about storytellers (inclusively) telling multiple stories and letting the stories articulate with each other so that deeper meanings and a consensus of understanding can emerge from the process - a type of power with, and not a powerf over and against others. One consensus about what arose from the Swamp Gravy enthusiasts, including volunteers and audience members, was that everyone's story is important to the Colquitt community.

\section{Empowerment: Political}

The reason that the CMAC representatives were able to be present that day to respond to the power company story was because they had become a recognized contributor to the local economy, which consequentially led to their 
being invited to the monthly meetings of the Colquitt business leaders. This was not always the case. In the first few years of Swamp Gravy they had experienced a good deal of push back from the Chamber of Commerce. Some of this was “territorialism" (Jinks 2008, interview). CMAC had a vision for community development, which put it in Chamber territory. CMAC's access to money through the Jinks Foundation provided them with grant awards that gave them the dominant hand in downtown renovation. Swamp Gravy had given CMAC a reason for renovation as it began to draw a large percentage of its attending audience from places outside Miller County. There was also a philosophical dispute regarding the nature of the stories that were featured in Swamp Gravy. Exposing what the story song concedes, that "everybody's got something to hide," (Kimbrel 2008, interview), was completely contrary to how a Chamber of Commerce typically frames an area in order to attract outside business actors, tourists and investors. In the first three years the push back from Colquitt community came primarily from the business community which originated from the Chamber of Commerce (Jinks 2008. interview). Regardless of the initial turf guarding and the push back against the real stories, within a few years all the business leaders including the Chamber of Commerce had come to realize that Swamp Gravy and CMAC deserved a seat at the local business leadership table. 
Helping the cause of political power was the fact that in 1994 the Governor of Georgia proclaimed Swamp Gravy to be Georgia's Official Folk Life Play. Combined with the increase in tourism that the play had attracted, the Governor's recognition helped to push critics from the business community into a position of silence. The official notoriety helped to propel CMAC and Swamp Gravy into a flurry of renovation and innovation that completely transformed the downtown square over the next 14 years. Chapter 6 addresses some of the specific changes that impacted the emergence of a new community identity. While the majority of Miller Country maintained a position of disinterest, the business community, especially those involved in businesses that benefited from the increase of tourism quickly warmed up to Swamp Gravy. One city official proclaimed: "I was quick to recognize that CMAC was instrumental to revitalizing Colquitt -- and that they were a major player." Some city officials perceive of Swamp Gravy as putting Colquitt in a position to grow into an "entertainment industry leader" in Southwest Georgia. (City official 2008, interview) While entertainment was never the primary focus for Geer or the Swamp Gravy community, that didn't stop some from the political arena from perceiving Swamp Gravy as a significant step in that direction. 
One Colquitt business owner admits that, "the city, mayor, have come to accept that this is a major part of the community. It took a long time for the city to come around to accept that. Swamp Gravy now has a lot of influence. Arts Council gets things that they wouldn't have otherwise. Swamp Gravy has bred volunteers, and we are much more participatory, even in other areas of the city" (Actor 2008, interview). Around 2005 "the city started to team up with us..., whereas we used to be seen as a loose cannon. They thought we would move onto something else artsy and all -- they couldn't see what it would come to mean" (Traywick 2008, interview). The relationship now is characterized by "teamwork, volunteers for other projects, the Chamber and the city reaps a lot of benefit, city manager, the merchants, we all meet together now to work on projects together." Even the volunteers that have been involved "have a bigger voice in the community than before" (Actor 2008, interview). The mayor in 2008 is quick to tout the benefits that Swamp Gravy notoriety has reaped for him in his travels representing the city of Colquitt: "Yes, [when I] go see people in Atlanta and Washington D.C. to get money, it helps to have them attend a Swamp Gravy performance -- helps us sell our community to Atlanta and D.C." (Mayor 2008, interview). 
By January 2008, Swamp Gravy was at the height of its position of power in Colquitt and Miller County. However, the financial crisis that started in the latter half of 2007 has had a significant impact on CMAC, and as such Swamp Gravy. While the accumulated political power has weakened some, it is mostly in proportion to cut backs that have downsized both its staff, and as a result, its presence at business meetings. While the overall influence of CMAC as a major player in the future business of the area has weakened, it has not gone away. The Jinks Foundation was significantly affected by the economic crisis, and is no longer in a position to fund renovation projects. But, as a result of Swamp Gravy and CMAC the downtown area today is a dramatically improved place than it was before.

\section{Empowerment: Making Connections}

Enhanced social capital is also a side effect of Swamp Gravy. As has been described previously, many have asserted that the process that Geer and Swamp Gravy have embraced can facilitate the transformation of an individual into being a larger person in community with others. This quality of experience produces mutual relationships including sentiment or affection which hinges on a form of knowing and being known that is meaningful, open and responsive. This process does not exclude the fact that connectivity and thus recognition in community 
has also been enhanced. Connectivity and recognition does not mean that a person experiences community. Self-interest is not an organizing principle or feature to becoming a person in community or experiencing. Connectivity can increase through arrangements that can be purely instrumental in lieu of person and community-forming, or ontological significant. A theme that has surfaced in one person's analysis of her experience in Swamp Gravy is that it takes a "big person" to participate in the depth of community that Swamp Gravy represents (Black actor 2008, interview). This is not so in regards to positioning oneself in such a way that social connections are made. But, as a side effect, enhancing connectivity to others is none-the-less a benefit of being in community, which is illustrated in the flow of remarks below.

I know so many more.(Actor 2008, interview).

A whole lot more folks know me than I know them. You meet folks you never would have met (Actor 2008, interview).

Every small town is clannish, and if you are from the outside, being involved in the play folks know you better on a personal level and recognize you in the community (White actor 2008, interview).

I'm more known, every year, more folks ask me to come speak, sing at weddings, funerals (Grimsley 2008, interview).

Some people who are not from Colquitt have benefitted from becoming more recognized in Colquitt. One lady described that her husband was from 
Colquitt, and after they got married they moved to Colquitt. She was typically identified as her husband's wife, and not by her name. After being in Swamp Gravy people began to call her by her name instead of by her marital status to her husband (Actor 2008, interview). Thus, being known and/or acknowledged felt less demeaning than her previous status as just the wife of her husband. While recognitions is a form of being known that emerges from her roles in Swamp Gravy, recognition alone can be less than face to face, person to person knowing that demonstrates mutuality, sentiment, and thus community.

Another volunteer member of the Swamp Gravy cast remarked that: “I have made many contacts through this play. You meet folks you never would have met. [In my public career role - law enforcement], I meet a lot of people [not typically a positive interaction.] In Swamp Gravy I meet people in a positive manor. I'd never have had the contacts to start a business [without Swamp Gravy]. It has brought us to Colquitt. We are building [another business here] which I had the contacts to help make that happen. The Jinks Foundation is helping the city finance that. If I had not been in the play, I would not have made those contacts" (Actor 2008, interview). It is clear that this Swamp Gravy volunteer is not talking about relationships and community - but contacts and business. While the two are not mutually exclusive, they are also not the same. 
While on the surface the above comments fall in line with social capital, the vast majority of comments made by Swamp Gravy enthusiasts about their identity gravitate towards the realm of community, which features a different quality of relationship. One participant remarked: “Everyone's story gets crushed in an urban suburban environment, but here it's kind of like when I think of how my dad grew up and it being full of characters, and new connections, and who knows who, more breathing going on. Having lived in a suburban and urban environment, it is much more closed, and this community seems to feed off of itself. [Being in Swamp Gravy from the outset of our arrival] integrated us into the community... we know so many more people and are more involved with others. Swamp Gravy has grounded us into this community" (Stober 2008, interview). This participant chose to relocate to Colquitt because of Swamp Gravy, which made it more appealing than other towns that were closer to the job that had brought him and his family to Southwest Georgia. When He and his family got to Colquitt they immediately got involved as volunteer actors in Swamp Gravy, which meant that their recognition in the town came primarily through their visibility on the stage in Cotton Hall. As a result, he and his family didn't feel the overarching clannishness that others had run up against. This gave them a significantly different perspective, especially since they were also 
not from the South. It is interesting that his perception of life in Colquitt was similar to the stereotype of life in small towns, where neighbors presumably all know and look out for each other, which was unlike his experiences in urban and suburban places where he had previously lived. Coming into Colquitt and immediately participating as an actor in the Swamp Gravy plays gave him the kind of recognition that fit the mythical projection that community exist in small quaint towns, when in reality the story around Swamp Gravy tells an entirely different story - that the Colquitt outside of Cotton Hall and Swamp Gravy is mostly clannish, separate, and closed off - especially from those not from the South.

As a result of the clannishness of rural places it is possible that recognition and connectivity is less accessible in more rural places. Another outsider that moved to Colquitt described her experiences as follows:

Initial impressions - more fun, more relaxed, people here are wonderful, doing it because they love to do, not as much do it for ulterior reasons, passion for everything here, which you lose in professional theater. Here is more meaningful. I had become frustrated with the lack of community or anything other than business as usual in professional theatre. But here you - from the time you are in the cast, you are cared for, not just a we need you for the show, but real relationships. The whole project fulfills something for me that nothing ever has. The best word to describe it is -soul, family, taking care of each other. People learning about each other folks that they wouldn't have known about otherwise because of financial or cultural separation, or spread. [SG] builds community but also bonds the community - part of our mission. It feels like I have found a place 
here. Before I was just a person doing a job - here I am a part of the community, not what I expected, but one of the more important parts for me. Doing a great show is important, but these are the people I care about, the pageants they are in, the A's on their test at school -- I care about these people on a personal level beyond just the show alone... (Stage manager 2008, interview)

What is described is personal, meaningful, affectionate, and reflects being in mutual relationships in community with others, and is not described as instrumental in anyway. She is describing what a person experiences inside a community - a gathering that is voluntary, openly inviting of any and all others, and mutually affectionate. There is no mention of instrumental benefits that result from new connections, but plenty of reference to affection. It is telling that when asked to compare how she has experienced life outside of Swamp Gravy on the streets of Colquitt, she remarked: “There are very few people that I met outside" the Swamp Gravy community. It is also telling that her role in Swamp Gravy is not a visible role, but a behind the scenes role, which may explain why she has not gotten to know many outside the Swamp Gravy cast of volunteers. She is for all practical purposes a stranger to those outside the Swamp Gravy and CMAC community. While the other outsiders gained beneficial connections from participating as a volunteer in Swamp Gravy, each one of them had the luxury of being visibly recognized through their on-stage roles. 
Swamp Gravy volunteers who appear on stage acquire a degree of fame based on their becoming physically recognized. This is very similar to the fame of a local high school athlete whose visibility and prowess on display in a local public ball park translates into recognition. Such athletes may inherit social capital types of connections, but that does not mean that they are really known beyond their role on the public playing field. Thus name and face recognition for many translates into instant connections. One public official remarked: "It puts you to knowing some people you thought you knew, but you see a different side to them when you see them performing and doing an outstanding job of it. I didn't realize they had that capability." Those outside the Swamp Gravy community often observe "capability" and "talent" and as such have a more instrumental framework for knowing and valuing an individual based on what they can do. Bonds of connection also form between an actor and the real person in the story that they are depicting - and even connection to friends and family members of the person whose character or story that they are portraying. This bond occurs even when the actor and the portrayed had no previous knowledge of each other.

These bonds of connectivity contrast with how one member of the Swamp Gravy community describes her experience inside the Swamp Gravy cast. "Swamp 
Gravy is about the bonding and the giving. There wouldn't be some of the relationships, because we don't travel in the same circles, go to the same churches. It challenges some. You have to realize it's not about you. You form bonds like a family, and you agree to disagree, but in the end you are there for each other" (White actor 2008, interview). This is not a kind of one-sided relationship that is organized around self interest - it takes work, commitment, and as was mentioned before, it takes a big person.

While Swamp Gravy volunteers with visible roles experience a significant boost of recognition, the vast majority describe their experiences as members in the Swamp Gravy community in terms of meaningful relationships with others. The more instrumental benefits of new connections - though real, are rarely surfaced in conversations about what Swamp Gravy means to the volunteers as persons and to the city of Colquitt. Talent and visibility both play significant roles in volunteers realizing new connections and recognition by others in Colquitt that are outside the Swamp Gravy community itself. It seems reasonable to conclude that those that come into Swamp Gravy with self-interest in mind might not stick around for very long. As one Swamp Gravy volunteer noted, "it's not about you - it's about the community" (Actor 2008, interview). For those that do stick around, their commitment is observably driven by the perceived 
goodness of their experiencing community with others, and not about the benefits of recognition. For the town of Colquitt, new recognitions have played a significant role in helping to create a positive identity for the town - something that the city of Colquitt has dramatically benefitted from as a result of the Swamp Gravy plays. These benefits will be discussed in the upcoming Chapter 6 . 


\section{Chapter 6: Building on Success}

While the Swamp Gravy process had deeply affected the personal lives of many in Colquitt, the community performances had also produced impacts on the town itself. A town without much pride or sense of an identity through the plays saw a reversal of fortune. Recognition far and wide helped to make believers out of the city leaders in Colquitt. New community serving institutions sprang up, and the influx of tourists flooding in to see the plays helped to encourage new business development that sought to take benefit from the money that had begun to filter out into the local economy. CMAC had done an amazing job of leveraging every ounce of Swamp Gravy success into recognition from outside the city that translated into recognition inside the city as well. They were enthusiastic to share what they had found in themselves - the resources for turning around their dying town into a popular destination. The new popularity slowly turned the need to celebrate the town's heritage into a new agenda activating "the arts as an economic engine" (Jinks 2008, interview).

\section{Identity}

When Richard Geer was approached by Joy Jinks to come to Colquitt, Georgia to stage a community play, there was no pre-existing story or stories to utilize. Colquitt had no claim to fame, nor any historically significant event that 
distinguished an identity. The town, just like so many other small Southern towns, had transitioned from labor driven agriculture to industrial agriculture, which had reduced the number of farms, taken the work of farming out of the hands of many and put it in the hands of a few. The largest business interest was Birdsong Peanuts. But Colquitt leaders didn't see the corporation or their own ranking in the peanut industry as an identifying attribute. The most unique feature in Colquitt was the mayhaw berry which only existed in a few remote swamp regions in the South. As a result of this discovery, "in 1984 community leaders gathered to organize a community festival and The Mayhaw Festival was begun" (Kimbrel 1976, 55). When they discovered that a town in Texas also had a Mayhaw Festival, local leaders declared Colquitt, Georgia as the home of the National Mayhaw Festival. The Mayhaw Festival was the result of the organizing efforts of the Colquitt-Miller County Chamber of Commerce. While the festival has remained an annual celebratory event, it had not reversed the perceptions that Colquitt residents had about their town as lacking any distinguishing features.

The perceptions that Colquitt residents had about their own town prior to Swamp Gravy were anything but good. One citizen remarked that she "was ashamed of Colquitt. It was not pretty, nothing happening, no opportunities, 
nothing important had happened here. I didn't think we had a culture" (Kimbrel 2008, interview). Another resident summed up that the common sentiment about Colquitt before Swamp Gravy was that it was on "fast track to being out, being gone" (Tully 2008 interview). Area youth proclaimed it as "boring, a dead city" (Anonymous Black interview). A common experience for area residents who traveled out of the area was the difficulty they had in telling people where they were from. The most common response that they got was, "where is that" (Businessman 2008, interview). Further complicating matters was that the local high school was named Miller County High School, while another high school in South Georgia was named Colquitt County High School, named after Colquitt County. Most folks seemed to associate the city of Colquitt with Colquitt County High School, which was several counties east of Miller County and the city of Colquitt. Others, as referenced before, had no idea where Colquitt was, nor did they know anything about Colquitt.

Colquitt's and Miller County's other claim to fame were the infamous Anglin brothers, whose ventures in crime had made them notorious. There notoriety was not just in crime, but also included their innovative capacities to escape from every jail within which they had ever been incarcerated. Their life of crime eventually landed them in Alcatraz. The movie Escape From Alcatraz was 
the Hollywood rendition of their successful escape. The two brothers were highly creative in the arts. Their successful escape had illustrated this fact. They fashioned paper machete figures with real hair accumulated from the hair cuts that they provided their cellmates, and placed them in their beds to cover their escape. While the Anglins had acquired a degree of fame, it was certainly not enough to establish the town's entire identity on.

The Mayhaw Festival strategy had come from the chamber of commerce. One of the common functions of a chamber of commerce is to frame an image of a city or town that makes it look attractive to outsiders, whether tourists or business actors or even potential residents. When Swamp Gravy began to take shape as a community performance attraction, the interest as well as the role of the chamber of commerce was at stake. Telling one's story in public is an invitation to reflection, interpretation, response and application. As such, there is always something at stake. Those whose stories were used in Swamp Gravy had exposed aspects of their personal lives. Swamp Gravy began to frame a different image of Colquitt, one storytelling performance at a time. That was obviously a scary proposition for the majority of Colquitt. The single image of Colquitt that the Chamber of Commerce projected was quickly outnumbered and overtaken 
by Swamp Gravy. As one Chamber of Commerce leader put it in 2008, “Swamp Gravy is our brand" (Chamber official 2008, interview).

A combination of factors enabled the wide-scale buy-in of Swamp Gravy as the city's number 1 identifier. One Colquitt resident and volunteer actor put it this way: "Swamp Gravy has overshadowed everything that Colquitt once was, to becoming its primary identification" (Stober 2008, interview). For many the contest for the identifying brand of the city was won in terms of dollars and cents. Tour buses brought in thousands of regional tourists, with the majority coming from within a 3 hour radius of Colquitt (Traywick 2008, interview). As was mentioned earlier, 75 percent of Swamp Gravy audiences were made up of attendees from outside of Miller County. The particulars of the Swamp Gravy economic wind fall are discussed in the upcoming Community and Economics section. While economics certainly played a key role, other factors, especially early on loomed just as large if not larger for the emergence of Swamp Gravy as the identifying mark on Colquitt.

During the first four years of Swamp Gravy the plays garnered public accolades from three highly significant outside sources of validation. In March 1994 the governor of the State of Georgia acknowledged Swamp Gravy as the “official folk life play of Georgia” during a session of the Georgia General 
Assembly. Miller County's State Representative Cathy Cox introduced the legislation for the designation, which included accolades for the Swamp Gravy project noting its contributions in "education and entertainment..., history..., multicultural identity..., [while probing] issues of gender, age, class and race. [Further praise was given for Swamp Gravy's role in boosting] people's selfconfidence, providing role models, and creating a new community self-image" (Toole 1994, 1). That same year a declining and old historic hotel building that was originally built in 1861 was going to be reopened as the Tarrer Inn. The building had been purchased by the Jinks Foundation and eventually donated to a local historical preservation non-profit. The building occupied one corner of the downtown square. The renovations featured the "restoration of the original staircase" as well as each of the 15 room's original fireplaces that were lined with "cultured marble." The outside would "feature a Charleston-type courtyard" and the downtown square would have 28 Charleston style lamp post lights installed. Chamber of Commerce director India Taylor exclaimed that "the town is really coming alive" (Staff 1994b, 15), Visual improvement to the downtown square, the arrival of tourists to see the Swamp Gravy plays and the official recognition from the General Assembly of the State of Georgia all combined to 
establish Colquitt as the place where Swamp Gravy took place. By this time the Chamber of Commerce had joined in singing the praises of Swamp Gravy.

All of this in 1994 coincided with the second significant external source of recognition. This time international recognition came in the form of being asked to perform two Swamp Gravy shows at the Centennial Park in Atlanta, Georgia during the 1996 Summer Olympics. The following magazine report provides details of the announcement: "The Colquitt/Miller Arts Council has won a 1994 Regional Designation Award in the Arts, which was sponsored by the Cultural Olympiad of the Atlanta Committee for the Olympic Games (ACOG). The award winning project Swamp Gravy takes place March 18 through April 10 and is a folk life play based on the documented oral histories of South Georgia residents and featuring Georgia's indigenous music, dance, and folk crafts. ... These awards play an important role in focusing an international spotlight on the high quality and extraordinary diversity of Southeastern arts and culture" (Staff 1994a, 15). Swamp Gravy had been chosen by a special ACOG committee from a group of submissions that came from all over the Southeast. The two accolades in one year were the biggest and first real source of outside recognition and validation that Colquitt and Miller County had ever experienced. 
Following shortly on the heels of state and international recognition the Swamp Gravy cast was invited to perform at The Kennedy Center in November 1996. An article announcing the event had appeared in the USA Today. It had started out: "As the line in the movie Field of Dreams proclaims, if you build it, they will come. In Colquitt, Georgia they just keep coming. The they in this case are politicians, historians and tourists who come to Colquitt to see Swamp Gravy, an extraordinary theater performance that has catalyzed community involvement and created a new sense of pride for the small town... [The Kennedy Center appearance] is part of the first annual NAPE Reddig Endowment Gala, and is co-sponsored by the Kennedy Center Education Division." (USA Today 1996) The Miller County Liberal reported after the event: “On November 22, 1996 Swamp Gravy performed for a full house of over 400 [in one of the small venue theatre spaces] at The Kennedy Center in Washington, DC - a national stage." The audience was a who's who of Washington-based Georgia dignitaries. The cast "received a standing ovation." The paper detailed many rather humorous details about the cast of 75's escapades at the Capitol. Many in the cast had never traveled beyond Dothan, Alabama or Tallahassee, Florida both no more than an hour away from Colquitt by car (Ary 1996, 1). Some traveled together on a chartered bus, while a handful of others flew to DC. 
The growing recognition and identity of Colquitt was synonymous with spreading the Swamp Gravy news. Local citizens also began to play a role in promoting their town through the play. One business traveler took brochures about Colquitt everywhere he went. The brochure was constructed by CMAC with Swamp Gravy on the front. It had become the printed representation that the Chamber of Commerce both displayed in their offices, as well as sent out in the mail to potential tourists and business parties. One retired resident admitted that while on her many motor home excursions across the country, that she made a regular practice of stopping at visitor centers and placing the Swamp Gravy / Colquitt brochures in any empty sleeves where other tourist attraction brochures were commonly displayed. She implied that there were times that she had to be creative in how she went about finding an open sleeve for the brochures (Local audience 20010, interview).

The volunteer fire department adapted the Swamp Gravy brand as well. They placed a Swamp Gravy emblem on their shirts and their fire engines. One CMAC official confirmed that, "it is the community brand. It has kind of taken over" (Traywick 2008, interview). The city website now welcomes viewers with the exclamation - "We have a story to tell you!!" - just above their "Welcome to Colquitt - Home of Swamp Gravy and the National Mayhaw Festival" 
(www.Colquitt-Georgia.com). When asked what Swamp Gravy has meant to the identity of Colquitt, one of two answers are provided. Most people say, "it put Colquitt on the map." Others add to that by confirming that "Swamp Gravy is our brand" (Volunteers and audience members 2008, interviews).

The combination of factors that helped to establish an identity where there wasn't one before included the renovation of the downtown buildings and the installment of a dozen murals. The 12 murals are a prominent feature of the downtown area - which is a 1-block square with the county courthouse in the center. The murals are discussed further in the section on Community Serving Institutions. In addition to these internal changes, the outside recognition by significant sources played another role in helping establish Colquitt's identity in a very positive light. Tourism played an important role that helped to further stimulate the renovation to include businesses that could serve the increase of outside visitors. All of these together shifted the general feeling of despair that dominated Colquitt before Swamp Gravy into a growing sense of pride. When Colquitt citizens and officials travel outside the area and have to tell others where they are from, they have grown accustomed to getting positive remarks that associate Colquitt with Swamp Gravy. That makes them feel "proud" (Business persons 2008, interviews). While the majority of Miller County 
remained outside of the Swamp Gravy performances, none have registered a complaint about the new identity. The only push back against the murals came as a reaction against the Peace Wall Mural, which did not portray a specific story from Swamp Gravy. Other than that, most residents of Colquitt are proud of the emergence of their new found identity and brand.

\section{Community and Economics}

The odd partnership of Geer, Jinks, and Kimbrel has been described earlier as demonstrating how different functions can in combination produce a synergy of action. Geer's job was to direct a process that formed a community an acting storytelling community. This was a nuanced process where the stakes in terms of staging local stories were high, and the ability to keep the process on target was challenging. The primary goal of community performance is not to stage advocacy around issues or to entertain. Issues will surface organically but not by design. The integrity with which the play successfully coproduces community storytelling is intended to be primarily meaningful, and secondarily entertaining. It is important to note that the function of these three players Geer, Jinks and Kimbrel, were not isolated roles, but demonstrated an overlapping and mutual partnership. Each had a different position from the other. In general terms Geer held the vision for staging a community forming 
process, while Jinks held the vision for community development, and Kimbrel held the vision for economic development. It is also important to note that these three do not minimalize the roles of a host of other important actors who in any one given year might make an equal contribution alongside of any one of these three. Lastly, this implied synergy of function may illustrate an ideal, but it is not meant to presume that a highly functional synergy was always at play.

Swamp Gravy's mission statement is: "To involve as many people as possible in a theatrical experience that EMPOWERS individuals, that bonds the community and strengthens the local economy while crossing the boundaries of race, social class, age and gender." The nuances regarding CMAC that have been discussed in previous chapters regarding community performance in combination with the mission statement helps to establish Swamp Gravy in the realm of community development. Jinks social work background also helped influence early pre-Swamp Gravy CMAC in a community development direction. In conjunction with Swamp Gravy, CMAC created and launched a number of community serving initiatives. These services are illustrated in the Circle of Services. 


\section{Figure 8: CMAC Circle of Services}

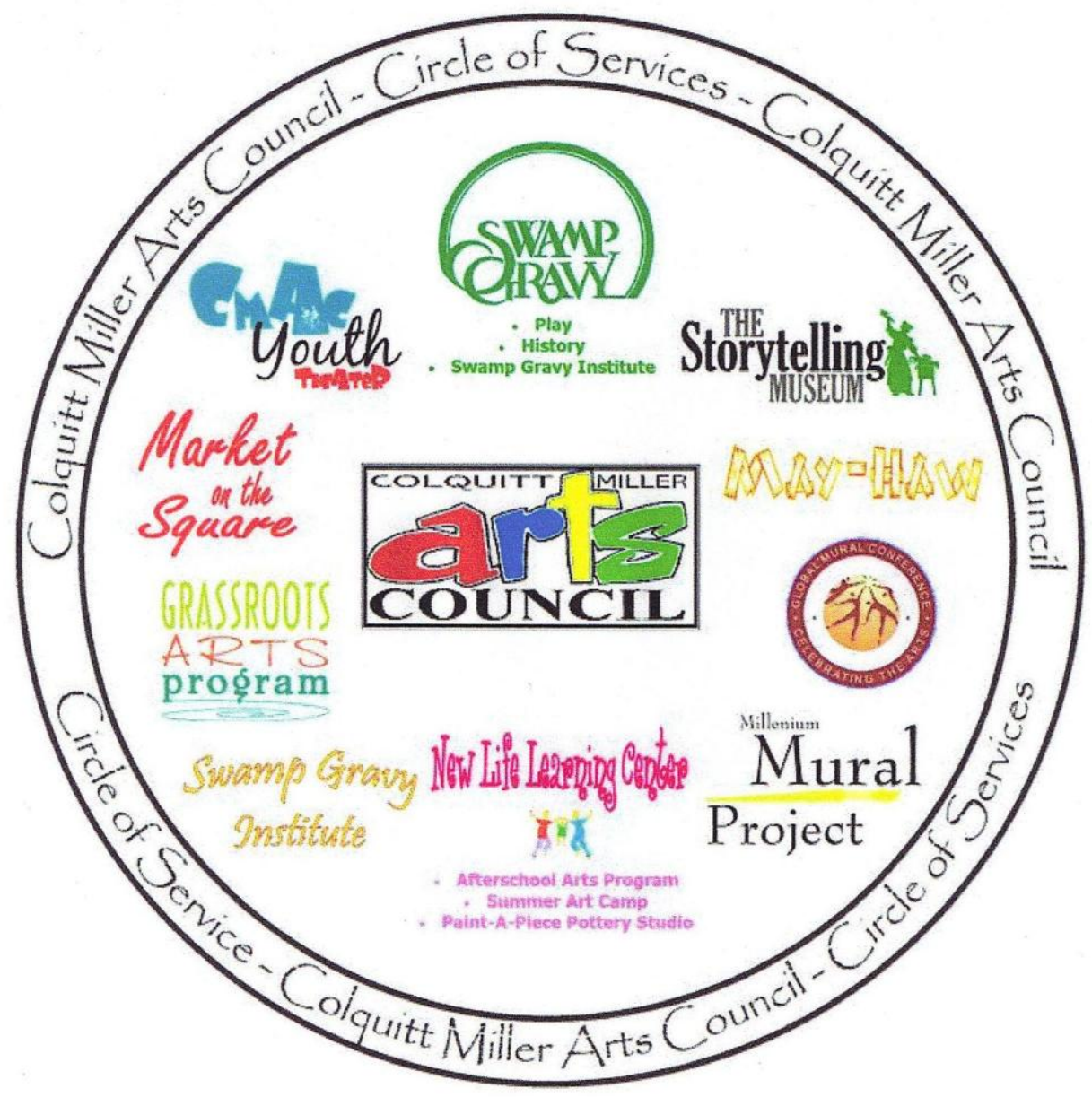

(Kimbrel, 2007)

The New Life Learning Center (NLLC) was initially created in 1999 as a training center where adults and children would learn how to quilt, weave baskets, and make pottery. This was an effort to create a local economy that tapped into the increase of tourists arriving in town to see Swamp Gravy. However, the quality of basket weaving and pottery skill that was required to 
produce a purchasable product was not something that could be learned overnight. When adult participants realized that mastering these crafts with any hope of commercial success would take years, they quickly lost interest (Traywick 2008, interview). As a result, in 2002 CMAC decided to re-focus the program on childhood education and art activities. This was made possible by a $21^{\text {st }}$ Century Leaning Center Grant. A building was eventually purchased at a minimal cost and renovated with funds from the Ruth T. Jinks Foundation and the Robert W. Wood Foundation. Additional grants have been received from The Sapelo Foundation and USDA Rural Development (Kimbrel 1976, 31).

Market on the Square is located on the downtown square. It occasioned the renovation of a corner of the square in 2000 with funds from the Ruth T. Jinks Foundation for the purpose of creating a multi-merchant business space. Since “March 2001 [it] has served as a small-business incubator, a test market for small businesses, and has fostered a cooperative spirit in the community" (Kimbrel 1976, 33). CMAC through grants from the Ruth T. Jinks Foundation has been instrumental in the renovation of six downtown buildings that had become unusable due to decline. In addition to The Tarrer Inn, The New Life Leaning Center and Market on the Square, the other three buildings were: Cotton Hall, 
The Arts and Education Building (1996/1997), and the InterACT Building (1997/1998) (Kimbrel 1976, 35).

The Swamp Gravy Institute (SGI) was created in 1993 for the purpose of “helping communities launch story-based community revitalization projects." SGI was to serve the purpose of spreading the Swamp Gravy possibilities to other cities and towns. Appropriately the mission of SGI as stated in its brochure, is: "Helping people revitalize community through storytelling and the arts". As such, it serves as the consulting arm of Swamp Gravy. SGI has worked with communities in 11 states across the U.S. as well as with communities in Brazil and Kenya. The director of SGI was Bill Grow, formerly from Chicago and a veteran of the Institute for Cultural Affairs. In keeping with the tradition of Swamp Gravy, "veteran cast members help rural towns and urban neighborhoods across American create their own community revitalization projects. The cast's skill in oral history gathering allows them to draw personal stories from diverse mixtures of people and to facilitate life-giving reflection on their significance." The SGI brochure poses the question: "What if neighbors would get to know one another?" The SGI ambassadors from Colquitt taught how this can be achieved through gathering oral histories and conducting story circles and creating community performance plays (SGI Brochure). 
In 1999 CMAC started the Millenium Mural Project which added another layer of beautification to the building renovations of downtown Colquitt. The project start-up was funded by a National Endowment for the Arts - Artists and Communities Millennium Grant that awarded one project from each state. Beyond the obvious beautification benefit, the primary hope was that the mural project "would impact the community the greatest by creating another tourism magnet that would draw visitors" (Kimbrel 1976, 21). At present, a total of 12 murals have been installed in the immediate downtown area of Colquitt. All but one illustrated a direct association with the Swamp Gravy stories. It is unclear to what degree the articulations of Swamp Gravy as Colquitt's brand emerged as a result of the mural project, but it is safe to say that the mural project certainly reinforces the notion of Swamp Gravy as the city's brand.

The murals also serve as a visual form of Swamp Gravy's parallelism that invites reflection and potential application. The downtown area on Saturday mornings was at one time a very populated social and business center of life for residents of Colquitt 
Figure 9: Saturday Morning on the Square Mural

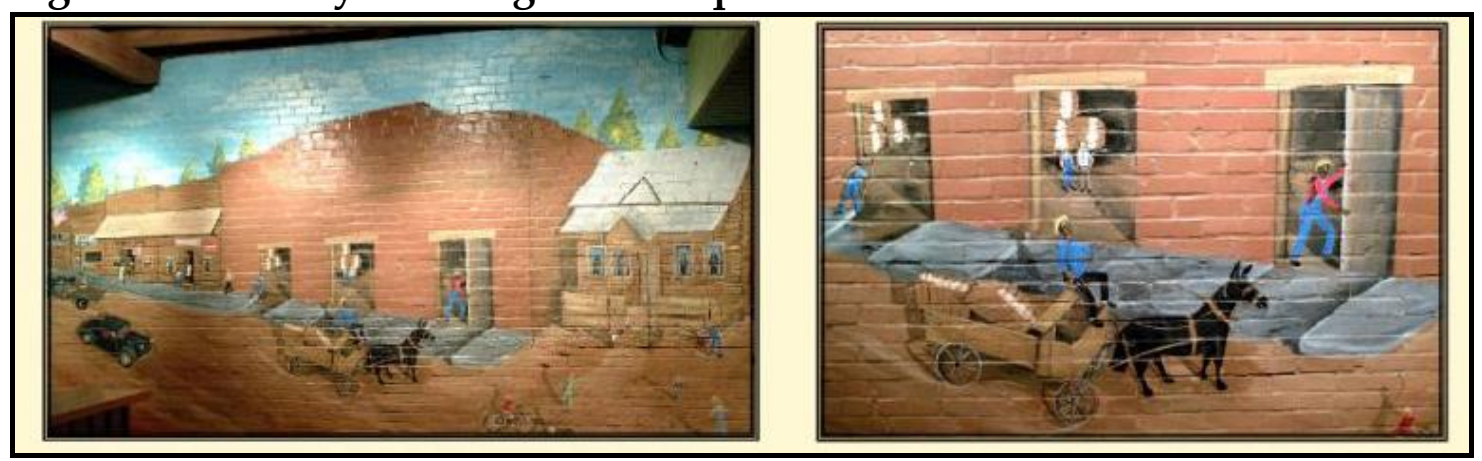

(Colquitt Miller County Arts Council)

(Jinks 2008, interview). This reality is depicted in the Saturday Morning in Colquitt

Mural (see figure 9 above), which was the setting for a number of stories and scenes in the Swamp Gravy plays. In contrast to the mural, (with the exception of special events such as Swamp Gravy plays), today the downtown area is unpopulated and very quiet on Saturday mornings. The mural depicts a picture of a thriving downtown Saturday morning - and can invite the viewer into the possibilities of prophetic imagination in keeping with the Swamp Gravy process of seeing what was that might be. This signifies that for now at least, that the place of community is still predominantly inside the walls of Cotton Hall. It has become in essence the town center which typically generates what downtown life there is on the square today - especially regarding weekends and leisure time presence.

The completion of the $10^{\text {th }}$ mural coincided with CMAC submitting a bid to host the 2010 Global Mural Conference. The Global Mural Arts and Cultural 
Tourism Association was founded in Chemainus, BC Canada, which had become a major tourist attraction as the result of their mural program. Colquitt hoped to replicate the same results as Chemainus. In 1999 Carol Sizemore had written in the CMAC newsletter: "Chemanius has gone from no tourism in 1982 to 400,000 annually; from 40 businesses and five empty stories to more than 300 new businesses. Could this happen in Colquitt? We certainly hope so." (Sizemore 1999, 6). In response to the submission Colquitt was selected to host the 2010 Global Mural Conference. While the conference itself attracted around 100 attendees, the mural features continue to add to the city's overall appeal as a destination of cultural tourism. In addition on March 9, 2009 the Georgia Senate approved legislation that "designated the City of Colquitt as Georgia's first mural city. Senate Bill 484 authored by Senator John Bulloch passed the Senate by a vote of 40 to $3 . .$. The [mural] project is intended to bring the community together, create a tourism magnet, revitalize the local economy and transfer values of the community to the next generation through the creation of public artworks" (Toole 2009, 1).

The Spirit of All Farmers is the $12^{\text {th }}$ and most ambitious mural project to date for CMAC and the city of Colquitt. It potentially reflects back to an image of pre-industrial agriculture in depicting the farmer in the hands-on business of 
inspecting his peanut crop. The value of hard work is a repetitive theme in the Swamp Gravy plays. The song previously referenced, That's All That Matters, is not too far removed from this image. The mural dominates the skyline behind Cotton Hall. Along with the value of hard work, viewers are left to potentially contemplate further - what can one drag forward from this image that might have application for current life in Colquitt?

Figure 10: The Spirit of All Farmers Mural

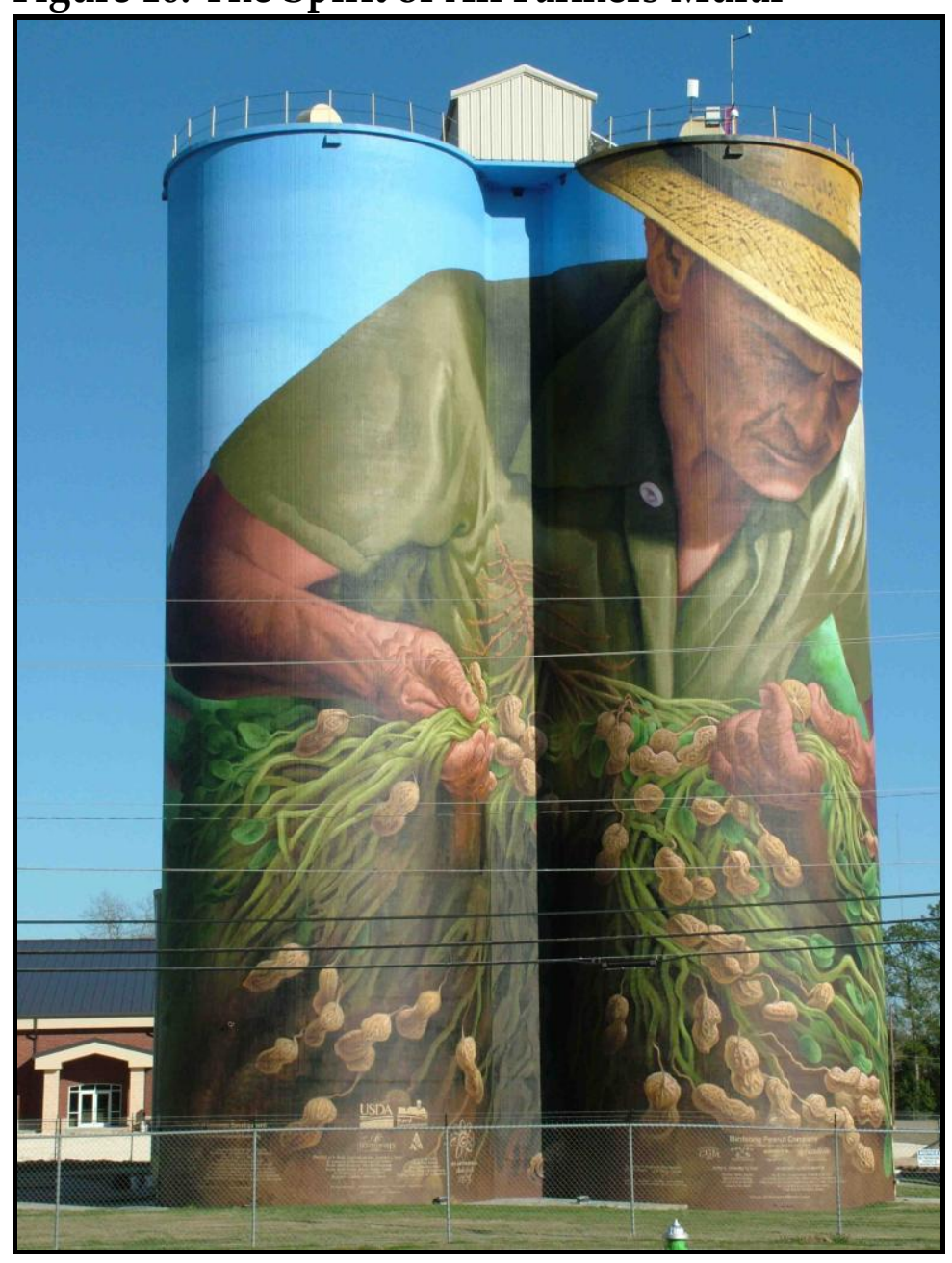

(Colquitt Miller Arts Council) 
Agriculture is not seen as a viable economic path forward for the average citizen in Colquitt, with the exceptions being the wealthy few that are already successfully imbedded in some aspect the machine-driven agricultural industry.

While CMAC has given birth to a number of community serving institutions, there are a couple of community serving initiatives that arose outside of the CMAC circle. One such initiative that was influenced by Swamp Gravy was The Miller County New Vision. As referenced previously, Gayle Grimsley and Veronica Haire joined together through their friendship as members of the Swamp Gravy cast to launch the Miller County New Vision Coalition. Grimsley had become concerned about area young people that didn't have any structured activities once school let out in the afternoon. Grimsley describes how the initiative got started: "I started taking these children to my house and started helping them with their homework, feeding them, everyday, and the numbers grew. Bill Grow [from the Swamp Gravy Institute] heard how I was losing money. He helped me in 1994 get $\$ 300$ grant and we had 70 to 80 children with 15 volunteers from the community. In 1996 we started a non-profit and he got us a grant for 15,000" (Grimsley 2008, interview). Since that beginning New Vision has helped over 1500 children with an emphasis on no pregnancies and no drugs, while developing leadership and improving their school 
performance (Kimbrel 2008, interview). In 2008 the new 23 year old city councilman was a former graduate of the program as was the head of Miller County Head Start (Grimsley 2008, interview). The Miller County New Vision initiative has provided a much needed service to the youth of Colquitt. CMAC helped provide meeting space for the initiative.

Henny Penny was another non-profit that Swamp Gravy played an influential role in helping bring to Colquitt in 2005. Henny Penny was a preexisting non-profit that was started by actor and film director Ralph Wilcox. Jinks and Kimbrel were instrumental in helping Wilcox get the funding to move Henny Penny to Colquitt where he could use his expertise in film in a mentoring and training role with the area's disenfranchised youth. "Without Swamp Gravy, Wilcox (an African American) would never have come to Colquitt. With Jinks'and Kimbrel's aid, Wilcox was successful in raising 1 million dollars which was used to build a 22,000 square foot sound stage (Figure 12). Wilcox had shopped his ideas in other places, but none of them had had given him the time of day (Jinks 2008, interview). 
Figure 11: Sound Stage

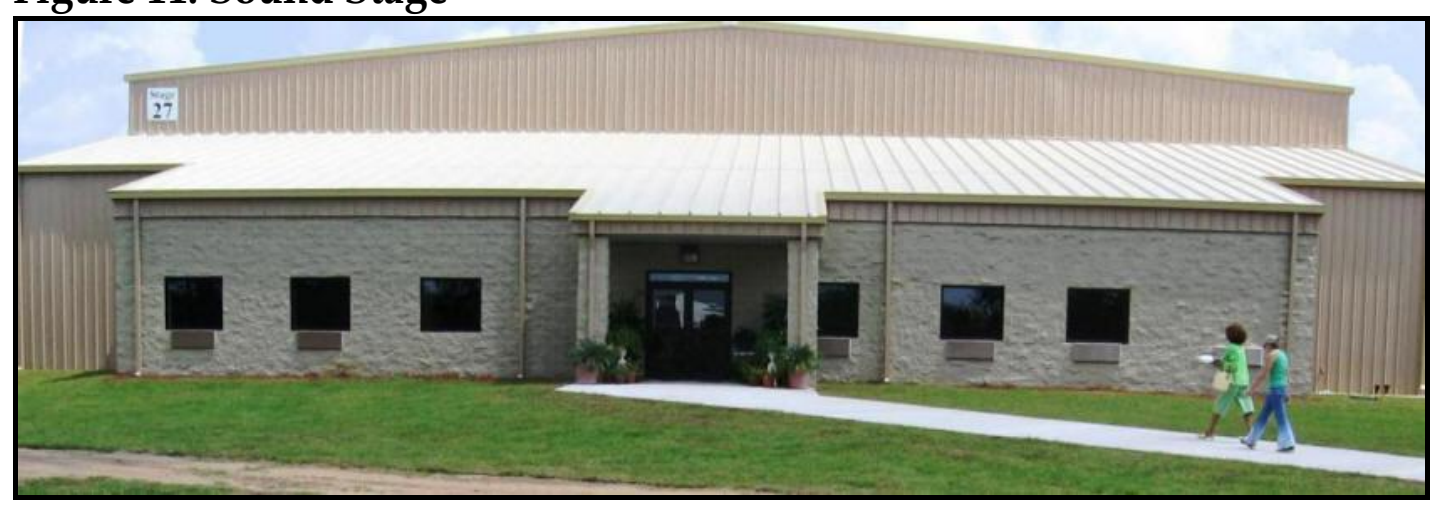

(Kimbrel 2007)

Half of the money ( $\$ 499,000$ dollars) came from the OneGeorgia

Authority, which is the funding arm of the State of Georgia for rural economic development. Congressman Sanford Bishop was instrumental in getting the Federal Government to allocate $\$ 194,000$ for the project. The rest of the money was raised through private contributions. At the January 30, 2005 groundbreaking ceremony, Wilcox stated: "the building of this sound stage is only a precursor of things to come as we continue to use the video/television show business industry as a vehicle to drive economic development". One year later, it was anticipated that the completed sound studio was going to "create jobs, jobs, and more jobs." Acting classes were to start immediately in order to "get the community ready for what is about to come their way" (Toole 2005, 1). Working outside the official umbrella of CMAC, the efforts of Jinks and Kimbrel were instrumental in all aspects of helping Wilcox turn his dream into a reality. 
While Swamp Gravy was instrumental in helping lure Wilcox to Colquitt, it is likely that the successes of Swamp Gravy had helped to open the minds of local officials to the idea that Colquitt's future rested primarily in the entertainment industry (Anonymous city official). Pure entertainment had never been the driving vision behind the Swamp Gravy community performance process. But, it had been successful, which served to further encourage the sound stage idea that Wilcox had brought to Colquitt. To this day, the sound stage has been only minimally used to date, and the high hopes for new jobs that its success might have brought have not materialized. Some of this may have to do with the timing of the project's completion in close proximity to the economic down turn that occurred in 2007 shortly after its completion.

One of features that had helped make Swamp Gravy so successful from an economic point of view was the way that CMAC could combine Swamp Gravy as a dynamic community building project with the physical renovations made possible largely with funds from the Ruth T. Jinks Foundation. Doing such enhanced their ability to acquire additional funds. The pie chart demonstrates a picture of CMAC's 2008/2009 revenue stream broken out into grants, donations and earned income. (see figure 12) Karen Kimbrel's business skills, aided by a degree in business from Troy University, were instrumental in both marketing 
and fundraising for Swamp Gravy and CMAC's community initiatives. Kimbrel and CMAC were able to leverage the local funds that they received from the Jinks Foundation into grant submissions to acquire funding that could be directly applied to moving the processes of Swamp Gravy and other initiatives forward. All of the money received from the Jinks Foundation was applied to building acquisition and renovation. A nominal amount of salary money for the museum director was the only non-property related contribution that the Jinks Foundation made to CMAC and Swamp Gravy.

Figure 12: CMAC Income Pie Chart

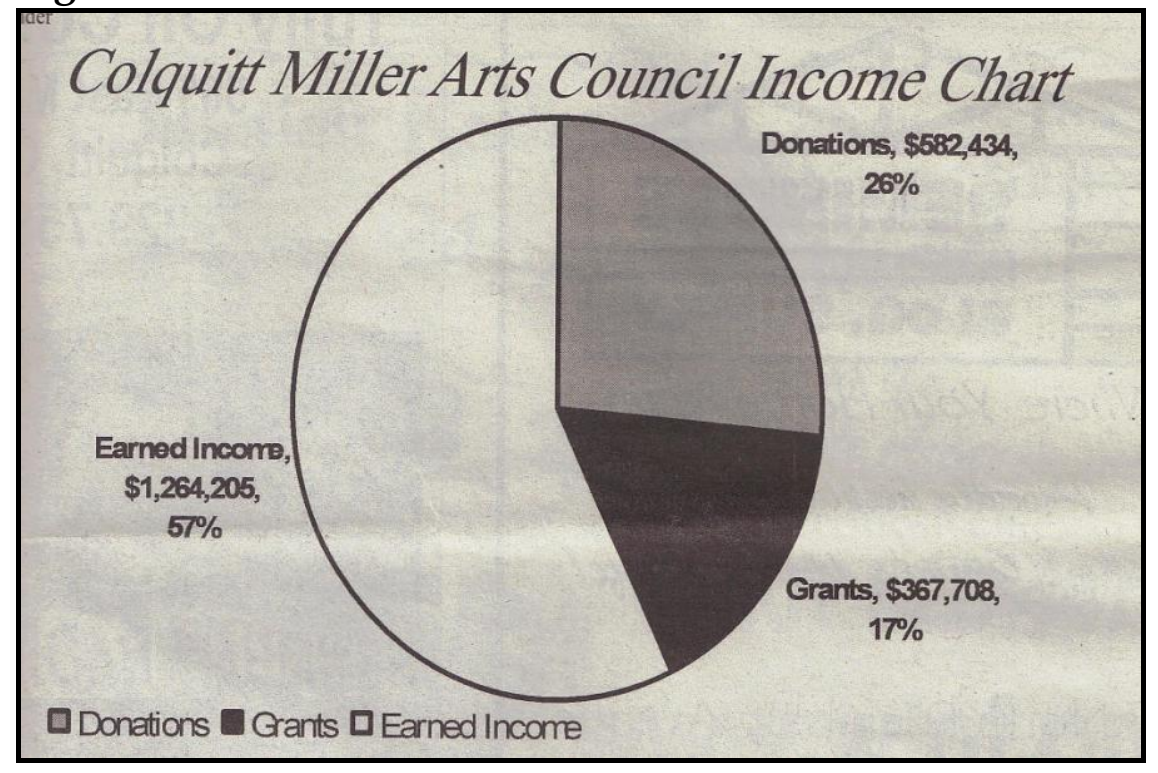

(Cotton Hall Times 2009, 11)

There was a perception that the Jinks Foundation had propped up the illusion of Swamp Gravy success in full. While it was certainly a valuable asset in 
building renovation which helped to secure matching funds through grants, however as mentioned before, virtually no Jinks Foundation funding went into the production of the Swamp Gravy plays. For this reason CMAC created the above pie chart so that people could see that Swamp Gravy itself brought in a substantial amount of earned revenue (57 percent). A list of the economic benefits that flowed from Swamp Gravy through CMAC are described below:

Approximately 50,000 visitors each year Approximately 10,000 attend a Swamp Gravy play each year (75 percent from out-of-town)

Annual Budget of $\$ 2.2$ million

Assets have grown from 0 to $\$ 4.5$ million

Employs 20 full time and 40 part time employees (2006)

Renovated 5 historic buildings (Cotton Hall, Arts \& Education Building, InterAct Building, Market on the Square and New Life Learning Center) Fifth largest employer in Miller County Averaged $\$ 14$ million in actual cash over 14 years

Produced 140,000 volunteer hours - averaging 10,000 hours per year

The above appeared in an illustrated book titled, Colquitt-Miller County, Georgia: Benchmarks of Progress 1976 - 2006. It was written by Karen Kimbrel and funded by the Ruth T. Jinks Foundation. Kimbrel's role at CMAC was to raise money and market Swamp Gravy and other arts council initiatives. Having played such a critical role as an actor, singer and composer gave her an insider's perspective about the Swamp Gravy performances. She believed deeply in what she was promoting. At the same time she aggressively promoted the City of 
Colquitt. There doesn't appear to be any separation for Kimbrel between promoting Colquitt-Miller County the place by promoting the Swamp Gravy performances.

A cascade of articles have appeared over the years in regional newspapers and magazines that included variations of the above statistics as part of stories about how Swamp Gravy had saved Colquitt, Georgia. The common theme in these stories was that Swamp Gravy had been an economic boom to the struggling city of Colquitt through its unique blend of cultural tourism. These titles included:

Cultural Event is Big Business for Colquitt (The Cairo Messenger, December 1, 1999)

On the Gravy Train: Colquitt Cashing in On Musical Production (Georgia's Cities. Vol. 10, No. 11, Nov. 12, 1999)

Towns Turn to the Arts and Revive Main Streets (The Atlanta JournalConstitution. Jan. 1, 2007)

Town's Tales of Rural Life Keeps it Going: Colquitt Turned its stories into plays that have attracted audiences and revenue (The Times-Union. September 17, 2006)

Swamp Gravy Turns Around Colquitt's Economy (The Valdosta Daily Times. September 17, 2006)

Swamp Gravy piled up economic articles and continued to add to its growing list of accomplishments. In 2005 Colquitt was named Georgia's ninth entrepreneur 
friendly community (and the first from Region 10) by the Georgia Department of Economic Development (Toole 2005, 1). Perceptions from those inside Colquitt were in sync with the press that continued to pour in from around the southeast. The rallying slogan from Jinks and Kimbrel that was repeated often was how through Swamp Gravy, CMAC and the citizens of Colquitt had discovered that the arts can be an economic engine.

The Center for Creative Community Development, affiliated with the Massachusetts Museum of Contemporary Art conducted an itemized economic impact study of Swamp Gravy in Miller County. The results are summarized below in Table 2 .

Table 2: Estimated Economic Impact of Swamp Gravy

\begin{tabular}{|c|c|c|c|c|}
\hline & Direct & Indirect & Induced & Total \\
\hline $\begin{array}{c}\text { Swamp Gravy } \\
\text { Operations }\end{array}$ & $\$ 1,390,621$ & $\$ 101,090$ & $\$ 141,224$ & $\$ 1,632,935$ \\
\hline Non-local Visitors & $\$ 370,168$ & $\$ 38,360$ & $\$ 64,648$ & $\$ 473,176$ \\
\hline Total & $\$ 1,760,790$ & $\$ 139,449$ & $\$ 205,872$ & $\$ 2,106,111$ \\
\hline
\end{tabular}

(The Center for Creative Community Development, 2007)

According to the above table Swamp Gravy had a significant impact on the local economy of Colquitt. The itemized study assigned impact values to itemized categories that could be tied to the Swamp Gravy plays. These 
discovered impacts had yet to be taken into full consideration by many in the community. The study served to add validity to what many already knew, that the benefits of Swamp Gravy were not isolated to just CMAC and its interests, but were widespread. Some businesses sprang up in response to the obvious increase in tourism. Bleu's Coffee was opened up on the downtown square by a Swamp Gravy cast member. All of the downtown merchants reported that they were acutely aware of what Swamp Gravy meant to businesses on the square. Most adjusted their hours of operation to coincide with the Swamp Gravy performance schedule. Before Swamp Gravy the downtown square was mostly boarded up. After Swamp Gravy picked up momentum buildings started being renovated and businesses began to fill in. Ten mostly new business establishments opened on the square. A handful of other businesses started up in close proximity to downtown, including a 24 hour restaurant.

A striking consistency among the business startups was that all but a few were service industry operations whose anticipated success was geared towards serving the growing flows of tourists. The tourism momentum in 2006 ramped up several degrees with the completion of the sound stage in the industrial park on the outskirts of town. The sound stage had gotten city officials fully on board. Officials increasingly spoke of Colquitt's future being directed towards the 
"entertainment industry" (City official 2008, interview). Swamp Gravy

professional staff and the cast of volunteers never referred to Swamp Gravy as "entertainment," but always described it as something much more meaningful, such as "knowing who we are" (Stage manager 2008, interview). In contrast, community business leaders described Swamp Gravy as being essentially the community's baptism into the "entertainment industry" - something that they wanted to see expand.

Different perceptions about Swamp Gravy do exist. For some Swamp Gravy is a deeply meaningful, and in some ways even a spiritual experience of doing church, not just hearing about what it is in persuasive and normative terms on Sunday (Actor 2008, interview). Similar to the issues in planning, church too can adapt a therapeutic role to intervene upon a problem and thus ensure a desired end - or, it can occasion an opening out into discovery of self and other through engaging the multiple points of view of multiple stories. Doing Swamp Gravy has begun to deepen the enthusiast's own understanding of what the application of their faith involves doing Monday through Saturday. Other comments about what Swamp Gravy means to Colquitt include:

That is more than just a play it is peoples lives, true stories, how healing that is, or having their story told (Traywick -- CMAC official, 2008, interview). 
The stories are real and true, and that it's the story of the community, not just to entertain, but a statement this is who we are - real stories by real people (Stage manager 2008, interview).

You sharing real and true stories, and if you love it, it shows (Grimsley 2008, interview).

For some, Swamp Gravy is primarily about being entertained by some surprisingly talented members of the community (Business source 2008, interview). While for other Swamp Gravy process enthusiasts (both volunteers and attendees), it is about the experience of being in community with others. The first reduces Swamp Gravy to being a market that serves up something to be consumed. On the surface, the economics of Swamp Gravy are demonstrated by all the familiar signs - tour buses, tourists, outside flows of revenue - but the question is -- are they coming to be entertained? - or, are they coming to experience, even if for only a brief time, a "sense of community with others?" While Swamp Gravy can be first an experience of community that is also entertaining, one has to ask, can it be first entertaining and still facilitate an inviting experience of genuine community? Or, will the desired end of entertainment become the plan that redesigns the stories of a community to attract consumers of nostalgic notions of small town community. Which direction will Swamp Gravy and CMAC go from here? Being aware of what story 
one is in can enable persons to become viable actors in their community.

Ignoring the real story, on the other hand rarely works out well in the end. 


\section{Chapter 7: Conclusion}

At current, twenty years of Swamp Gravy plays have been performed in Cotton Hall as well as at more distant places such as Washington DC and Brazil. As a result, a wide range of effects have taken place in the community. The purpose of this study has been to focus on what Swamp Gravy has meant to the people of Colquitt. Discovering the answer to that question has required a mix of interviews and event observations along with documentation review - all for the purpose of discovering what the people of Colquitt/Miller County have to say about Swamp Gravy. One question pertains to the formation of new community relationships including those that involve a racial mix of Blacks and Whites, while other questions focus on what local residents say about the play's effects on personal empowerment, the community's identity, and institutional and economic development. This last chapter will present the prominent findings that this study has arrived at, along with discussing corresponding theoretical implications and concepts, and conclude with suggestions for potential further research that are prompted by this study about Swamp Gravy and Colquitt, Georgia.

These findings do not occur and progress cumulatively along a linear timeline or emerge from the cumulative momentum of the Swamp Gravy 
performances. Similar to the formation of a community, that "happens where it happens" (Bender), the effects of Swamp Gravy happen when they happen. There was a general pattern of momentous growth for the performances during the first 8 years, followed by the ebb and flow of popularity over the last 12 years. By 1999 the performances had become so popular that tickets had to be purchased a year in advance. From 2000 to 2005 Geer and CPI were replaced by a series of more local writers and directors, during which Karen Kimbrel made her directorial debut. While some of the performances during CPI's absence were very popular, in 2005, Geer and CPI were brought back in hopes of reinvigorating the early performance energies. While some of the original enthusiasm was regained, tourist attendance began to drop following the economic downturn in 2007. In 2010 Geer and CPI once again left Swamp Gravy, which resulted in the staging of previous Swamp Gravy productions for 2010 and 2011. Swamp Gravy has yet to fully recover from the economic downturn. In the last year CMAC has hired a full time director to lead Swamp Gravy and the other more recently developing Cotton Hall events -- May Haw and the annual youth production, such as Seussical.

In parsing through the findings sections there are three general categories of respondents that inform the findings. Enthusiasts are those local participants 
that are most aligned with the directorial vision of Geer and CPI, as is reflected in their perceptions of the primary benefits of Swamp Gravy as bringing persons out into the experience of community with each other. Enthusiasts are made up of both various kinds of volunteers (actors and event support) as well as local attendees or audience members. All others fall into one of two general categories: those local attendees that see the primary benefit of Swamp Gravy as promotional, meaning that the performances were instrumental in attracting outside recognition and/or tourists; and local others that were indifferent to the performance and the process, but generally glad to see outside recognition and tourists.

Finding 1: Experiencing Community - Swamp Gravy invited persons to venture out of their small-town clan (gemeinschaft) to experience community with diverse others through inclusive storytelling.

Swamp Gravy is an invitation to Wade in the Water - what one Black Colquitt resident described as, Colquitt's "coming out" (Anonymous Black storyteller). This coincides with what another resident of Colquitt and a Swamp Gravy cast member described when he said that, "Colquitt like most small towns was clannish" (Anonymous White actor). Both of these residents along with most of the volunteers and other enthusiast of the performances affirmed that Swamp Gravy was the place where they experienced community in their small town. 
Describing what those residents of Colquitt mean by the experience of community mirrors Bender's study regarding the many features of community "face to face, an experience, mutual, sentiment, I/thou [communication]," and not featuring the "self interest" of competition (Bender 1978, 6-8).

Colquitt's size and scale fit the very ideal of a small town where the popular notion that territorial proximity and simplicity presume the nostalgic association of a way of being that is community - especially in contrast to more populated and impersonal urban environments which are associated with competition and society. Tonnies small town sociological type - gemeinschaft "an intimate, private and exclusive living together," differs from the city as society, or gesellschaft, which "is an artificial construction of an aggregate of human beings, characterized by competition" (Bender 1978, 17). It has been popular for many to fall back on the nostalgic ideal of a geographically bounded small town as the ideal of community in the city - seeing the neighborhood as the equivalent of the small town where community is found (35). In lieu of Tonnies's two sociological types, Bender has provided a historical analysis of community that is defined by a certain quality of personal interaction that dislocates it from territorial determinism or exclusion - meaning that the experience of community is "where it happens," regardless of the sociological 
types - in a setting of gemeinschaft or gesellschaft (6). Descriptions of the experiences of community by Swamp Gravy participants support Bender's historical view of community - that it is not inherent within a sociological type as small town (gemeinschaft), or excluded by the territorial arrangement of an urban city.

The formation of community in a small town is not complicit with or the same as the sociological organization of gemeinschaft, which is "characterized by intimate, private, and exclusive living together" (Bender 1978, 17). These characteristics are more consistent with a communitarian clan than the general conditions of community that have been previously discussed. As such, the formation of community in small towns require individuals to come out, or open out into a quality of being together where community can be experienced. What Swamp Gravy contributes to the discussion of community is that it illustrates a particular activity - inclusive storytelling, where the possibility for coming out of a clan (gemeinshcaft) to experience community is facilitated.

As we have seen, one new resident that relocated to Colquitt from the Pacific Northwest got involved in Swamp Gravy during his first year in Colquitt where he was cast in a very visible role. The sense of community that he experienced within the Swamp Gravy cast was profound, while his recognition in 
the larger Colquitt as town came from his visible stage presence. He contrasted this new experience of community with having previously lived in both "impersonal and competitive urban and suburban Seattle," which confirmed to him that the place where a person experiences community is in fact, a small town (Anonymous White actor). However, his experience conflicts with another outsider from Sarasota, Florida who moved to Colquitt to work as the manager of Cotton Hall. She describes the same profound community experience that came from working with the cast of Swamp Gravy volunteers. But, at the same time she had never felt any connection to area residents outside of the cast of volunteers. Unlike his visible role on stage, her role was not visible to the public, and was instead completely behind the scenes. Her experience of not being connected to anyone outside the cast of volunteers is similar to other new residents who never had the stage visibility that afforded them recognition in the surrounding town. It is possible to see how his perceptions of community as gemeinschaft / small town, where everyone experiences community was colored by his experiences within the cast, which converged somewhat seamlessly in his mind with his stage recognition and thus sense of community in the town (White actor interview) (stage manager interview). 
Being a person in community with others requires coming out of the gemeinshchaft sociological patterns of existence in small towns, and into liberalizing interaction with others. Through Swamp Gravy individuals are coming out to engage with local stories that are rooted in the traditional community. The liberalizing is not accomplished at a competitive intersection between small town gemeinschaft and urban gesellschaft actors, but instead where "two [or more] social and psychological worlds" (Black and White, or rich and poor) overlap, to provide the "creative disorderliness" where pause for responsive interpretation of personal stories is invited (Bender 1978, 146). The two or more social psychological worlds in the case of Swamp Gravy are provided by storytellers whose daily life experiences were different enough from each other that they provide informing points of view for each other. These points of view can emerge from a variety of features including: race; socio-economic status; age; levels of education, gender; religion; and politics. As such, the ingredients for a spicy gravy were already present in Colquitt, as is probably the case in most small towns as well as cities. All that was needed was to gather the stories as much as possible from across various social-psychological boundaries, and then stage them for reflective viewing where they appeared as a rich feast of personal stories that could be enjoyed by all. 
Worth mentioning as a possibility for further research is the perception about Swamp Gravy from former residents of Colquitt who came back to see Swamp Gravy yet live in distinctively urban cities (gesellschaft). One attendee that fit this description expressed that she felt that Swamp Gravy had provided a place where the community could address issues like race, more so than it was a place where community and a new community heritage were being formed. She saw Colquitt as a place where she had experienced community previous to the advent of Swamp Gravy. A question worth pursuing is whether her memory of community was more a case of nostalgia that results from her now living in the context of the much different sociological setting of urban gesellschaft. As such, further research comparing the perceptions about Swamp Gravy gathered from former residents that now live in large urban cities could be very telling especially regarding nostalgic perceptions of community that may overshadow a more clannish historical reality. Or, do such urbanites see Swamp Gravy as venturing into the more urban territory of competing points of view? - and, therefore fail to recognize the process as mediating multiple points of view for the purposes of experiencing community and the learning that is being in community occasions. 
Finding 2 - An open learning community was activated to stage local stories for the purpose of coproducing an inclusive community heritage.

After a couple of years of Swamp Gravy, Pedro Sandor, a visiting Chilean community organizer and film producer remarked about Colquitt and the Swamp Gravy play - "the Gravy Soup [Swamp Gravy] is a dirty trick - you lure people in to what appears to be a conservative event - the celebration of heritage, which is in fact a liberalizing process, which exposes people to one another - and to themselves" (Jones 1994, 147). At the heart of Swamp Gravy is the public staging of an inclusive storytelling process that coproduces an emerging heritage of Colquitt. Placing multiple stages in Cotton Hall theater where multiple local stories were staged created a more representative interpretation of the town's heritage. The various subgroups that self-select memories as artifacts to use in constructing their heritage were brought into fuller public view where those things that a group is proud about (typically highlighted in their heritage) can be seen from both a different point of view, as well as alongside of those things that a group or clan chooses to hide or repress. The Swamp Gravy plays resulted in the fuller exposure of culture through stories, which can occasion the potential revision of a heritage that is potentially less glorifying, yet at the same time can be more realistic. As such, the Swamp Gravy process brings to light unselected or repressed details that can lead to deeper knowledge of self and other, while also 
affording the occasion for exposing a more representative and thus fuller heritage.

Redeeming those details and making such exposure a desirable thing to do required the mediation of a learning community and the skill of a trusted facilitator. As one participant put it, as a volunteer cast member "you have to be a big person" (Anonymous Black actor). The circle of prayer ritual for Swamp Gravy was the equivalent of the collective locker room speech where cast members expressed their love and solidarity for each other in leading a community into the acts of exploration, discovery, reflection, and response. The trusted director/facilitator had more often than not, succeeded at enabling the cast to see the value of what they were doing through the long hours of rehearsals. The director and the cast utilized a sense of timing in interspersing the serious with the humorous while ensuring that it was all meaningful, and thereby nudging new lessons to be potentially learned. Ending with the singing of the familiar Amazing Grace song symbolized that it was all redeemed - those things to hide and those things to be proud about. And the departing Storytelling Song invites not an ending, but a beginning to a new way of being together - as storytellers in a learning community. 
Some of those things learned pertained to lessons about others across boundaries of race. Critical race theorist Derrick Bell's book Faces at the Bottom of the Well, suggests that Whites' full investment in the race to the top of the economic ladder results in habitual pursuit of competitive advantage. Even attempts to aid Blacks are usually full of "self-interest" (Bell 1992, 54). While this race has tragic ontological implications for Whites, it continues to have material implications for Blacks. What Bell describes has all the features of a competitive game of race. It is in Whites' material self-interest to win the race to the top, which motivates Whites to use all their skills to subvert any and all structural attempts at leveling the playing field. Even acts of benevolence are ways to re-affirm superiority and gain further distance. In a more previous book, And We Are Not Saved, Bell described the variety of ways that Whites creatively outmaneuvered Brown vs. Board of Education to increase their competitive advantage.

It stands to reason that if Bell's conclusions point to a perpetual game of race wherein Whites strive for competitive advantage, then perhaps it is during those rare occasions when White Americans temporarily suspend the pursuit of self interest that stories from Blacks have the most opportunity to be entered into and thus understood. This is why Bell's books on race are typically framed as stories. Like Swamp Gravy, Bell uses stories to inform broadly, especially in 
exposing the plotted outcomes that the competition ideology seeks. It is here where Swamp Gravy is at its subversive best, luring attendees into an inclusive storytelling - that place where, to the extent that a person fully enters in attentively, can facilitate the suspension of agendas of competition just long enough to see real persons face to face rather than through a convenient and deterministic lens. Through attending to stories Whites are thus enabled to see persons in a community context instead of opponents to beat, or "objects of talent" to be exploited (Bell 1992, 66).

In Swamp Gravy when many Whites got to know Blacks as persons in their community, relationships of genuine affection and mutual respect were able to be entered into equally. A relationship requires reciprocity - otherwise it is one sided and therefore unequal. The story of Craig Tully and Shadow (Emanuel Haire) certainly demonstrated this reciprocal I/thou relationship where each learned from the other and deep affection resulted. For others so totalized by economic agendas and the game of race, Blacks were seen as surprising talents, and very little more - which signifies a reductive conclusion that only recognizes instrumental value. Those that saw Swamp Gravy as merely entertainment described the primary benefit of the play as being the discovery talents (whether Black or White). In contrast, those participants and attendees who expressed that 
Swamp Gravy had been an experience of community saw the play's value in the celebration of a coproduced diverse community heritage. For these Swamp Gravy enthusiasts, seeing others in stories revealed that, "people are people," albeit with particular differences, but also with an abundance of situational commonalities (Anonymous volunteer and attendee sources). To them the meaning of Swamp Gravy was personal and very important to both informing and sustaining the future of their city.

Finding 3: Personal Empowerment - Swamp Gravy invited persons to experience a collaborative power with others, which can enlist persons to take on bigger community-serving roles, build their confidence, and enhance their social connections.

As one Swamp Gravy cast member put it, "you have to be a big person to participate in this process" (Anonymous Black actor). Being a storyteller is an active exercise in responding to a situation/context in such a way that interprets that situation into a complete story that includes: character; plot; situation or context; antagonist; and climax. This may sound easier than it really is. It takes a big person to maintain a (non-reactive) responsive posture that being a storyteller requires. Secondly, most people are able to describe what happens to them, but may never construct the occurrence inside the interpretive framework of a story. On one hand, such passivity leaves people vulnerable to the interpretations of outside sources. Or, a general passivity to fully interpret the 
meaning of a situation can also lead to the selection of a convenient framework that best complies with a desired end. However, Swamp Gravy storytellers understand fully that the stories that they are telling are intended to be true. And, the responses of audience and cast members alike also reflect that the Swamp Gravy stories are intended to be true, with the understanding that some details are intentionally changed so that some stories are not overtly identifying and thus problematic. Regardless of the change, the central plot and the meanings of the stories are not altered. As a result, having their stories performed in Swamp Gravy makes many of the storytellers feel like they have become a bigger part of the Colquitt community and its emerging heritage. While some Swamp Gravy volunteers benefited from new-found confidence and increased social connections, the common response by performers and many audience member enthusiasts was that Swamp Gravy enabled them to see themselves in a bigger role of serving the community of Colquitt. These expansions were not reactions to feelings of ought, or guilt, but generous responses that welcomed new possibilities for serving the common good. Swamp Gravy volunteers were commonly known to volunteer in the community outside their roles in Swamp Gravy (Multiple anonymous sources). Within the process, the cast member's enlarged roles included co-producing the 
plays by being mediators of the stories. This required frequent collaboration in order to make changes that could improve the performances - all under the encouraging direction of Geer and other members of the Community Performance professional team. As has been seen, these enlarged roles didn't stop at the exit door to Cotton Hall - but trickled out into new responsibilities in the town of Colquitt.

What is being suggested is that the kind of communicative agency that Swamp Gravy activates can be described as functioning as a genuine storyteller a communicative process that has the potential to fulfill the qualities of Habermas's ideal speech act. This combination suggests that a person is genuinely a storyteller when they intend to communicate clearly meaning or meanings of a given context, and do so honestly, sincerely, and for the intended purpose of being understood by others. Where two or more of these storytellers / responsive communicative agents practice storytelling together, self interest takes a subordinate role to the active work of coproducing meaning, and by doing such, a collaborative learning community emerges. This is optimistic, and certainly represents a higher expectation of planning's stakeholder-participants than the planner as skilled mediator may typically experience. As Bell has described, "self- interest" $(1992,54)$ is a dominant feature of being an American, 
and as such it is realistic to expect that at the intersection of stakeholders and planners something more akin to a competitive game of language is more likely to be found than the generative storytelling ideal of responsive communicative agents. If planners cast bigger roles for the stakeholders it potentially changes the planning dynamics from mediating conflict to facilitating responsive re-narration in a learning community - which means that the stakeholders are invited to step up into mediation roles with each other and each other's stories.

One of the biggest obstacles to narrative processes in urban planning is that this ideal of communicative agency is in all probability uncommon. Therefore, the weakest link has been the praxis question and not the theory. Where does one find genuine storytellers that are desirous and/or capable of making the process work? Without stakeholders as genuine storytellers the planner's role stays significantly large, which corresponds to the smaller role of stakeholders as agenda driven contestants. Mediation as a communicative process in a postmodern and conflicted world is more realistic, but increases the responsibility of the planner in the process. Craig Tully's experience of Swamp Gravy led him to the conviction that: "being open to change was a good thing, and that local stories can teach us that if we truly listen. I saw where it blossomed into things - making people in the stories better, made them more appreciative of 
the town and the people. The older day stories makes me appreciate what my ancestors went through to get us where we are today. And, it is very important for a town to tell as many stories about what went on as they can. Made us aware. It's sort of like a chronological deal of - here is where we were, and here is where we are at now, and we are going to build on that and here is where we are going - is how I look at it" (Tully interview). Such a response should cause us to wonder, what if, and perhaps more important, how? What if the prospects for a planner to host and facilitate a planning table that was populated by this ideal of responsive communicative agents was reachable? Such communicative agentstakeholders would have learning expectations and the desire to collaboratively mediate together a plan that re-shapes individual agendas to serve a vision that is potentially good (sustainable) in all respects. While this may seem like a dream, looking back at Swamp Gravy suggests that such a reality might be within reach. If it is possible, then how might it be achieved?

As mentioned before, much of the conversation about narrative processes in urban planning has focused on narrative as a defamiliarizing and potentially "transformational" process, that cast the planners as storytellers and enlisters of stories (Eckstein 2003b, 35,21). But there has been very little focus on the narrative capacities of stakeholders, or more importantly, the possible lack 
thereof. The current culture is polarized by neo liberal economic actors that are fully invested in a competitive game of economics on one side, and postmodern actors with their philosophical suspicion that all language (including story) is a slanted agenda-game for those that only desire to increase their individual power and wealth. These two polarizing extremes are real, and perhaps similar to each other, if not altogether overlapping in communicative tendencies. Within such framing, the resulting game is a game of power struggle. However, this polarization is not entirely dissimilar to the distrust that existed in a polarized and clannish Colquitt, where some waded out into the Swamp Gravy process, while others stayed away. Therefore, these difficult cultural realities do not necessarily preclude planners from trying the narrative route - especially one that states the rules and expectations of the process up front where a truly coproductive table can be introduced, discussed and set in place from the outset.

It is reasonable to think that normally functioning individuals would have the capacity for entering into a process of being or becoming a genuine storyteller with others. Given the proper instruction, it is possible for persons to rise to the occasion. The role of the planner would involve first education about the process and what is expected, and then invitation to, and facilitation of the process. Mediation, like it was in Colquitt, would become the work of the 
stakeholder-group. Mediation would involve: attending as a storyteller to multiple stories and points of view; converging the lessons learned about what is good from those stories into a consensus story; and then submitting the consensus story to be converted into a plan that includes all the technical means that would be involved in the implementation of the plan. Here again, as was the case in Colquitt, the technical end can accommodate a more co-productive arrangement as well, where materials and design, etc., can also become in collaboration with technical experts, the work of all the people. This is not unlike what was attempted in Swamp Gravy by a cast of volunteer mediators (the community stakeholders) under the direction of a facilitating guide (Geer interview) and a staff of technical experts. What this process intends is for a mediated and collaborative vision to emerge that moves beyond the compromises of negotiated agendas that may be less good in the end, as well as less a result of coproduction. Coproduction, as it did in Swamp Gravy can ensure a high degree of project ownership, which helps to energize stakeholders to follow through and sustain the emergent end result.

Perhaps most encouraging about the prospects of setting up a generative planning table with willing, albeit potentially inexperienced communicative storytelling agents, is the prospect of at least distinguishing up front what stories 
mean versus the various desired end results that are the rationalizations of agenda driven stakeholders. When stakeholders agree and are willing to start the planning process by dividing the stories of meaning that pertain to the subjectplace at hand from the rationalized agenda-ends, then the planning table has been cleared for stories of meaning to be told, heard, responded to, and even renarrated. Rationalizations could thus be placed in a subordinate role to what can be learned and converged from multiple stories. This does not subdue a development or advocacy actor that may not have a meaningful story that takes place in the subject place at hand. Such an actor still has an important role in listening and responding, or telling a parallel story, and participating in renarrating. As one might imagine, starting this off well is not only vital, it is challenging. It requires planners to be very clear and understood in presenting the process while demonstrating an attentiveness that can be trusted.

Another what if to ponder is what might change in a city or town where a process like Swamp Gravy becomes an established venue or story infrastructure? Creating a public venue that intends to nurture genuine storytellers could eventually have a direct impact at the planning table where communicative agents arrive with some experience. Such a venue could also set the tone for a more engaged and responsive community populace. Having such an influential 
venue could be valuable to a city or town - not to mention the various ripple effects that the community performance process might activate. The logistics, scale of the production, and the costs might seem prohibitive to town and city leaders that are more accustomed to straight-line approaches to addressing a problem directly with a specific intervention. This type of thinking represents another challenge, more so than scale, logistics or cost which can all be significantly sized to a variety of situations.

Straight-line thinking also threatens genuine storytelling as a communicative process for multiple stakeholders. When storytelling is reduced to being a one-sided instrument of intervention to bring about a desired end on behalf of some, then the game of story is on. Such a reduction of storytelling or narrative processes potentially undermines the communicative trajectory that is inherent to being what has been described as a responsive storyteller. With Swamp Gravy, once a significant number of the cast members began to believe that the community performance team (Geer/Corriere interview) was using storytelling to intervene on behalf of a marginalized group, the group's cohesiveness began to erode. Regardless of whether these perceptions were accurate, the situation illustrates the obvious, that narrative as an instrument of intervention on the behalf of a marginalized group is a significantly different 
process than what has been described in this study as the intended communicative narrative processes of storytelling - intending inclusivity, truthfulness and sincerity. In what has been described as communicative storytelling, there are no marginalized - all storytellers and stories are centerstage - and all end agendas and rationalizations are marginalized as a result of the process design. Clearly this overturns the planning table as the space for contesting rationalizations. As such, this suggests that narrative processes aren't tools of intervention, but the communicative process from which planning begins.

A good example of a planning event that demonstrates the potential viability of inclusive storytelling as a communicative process for producing more democratic outcomes is that of urban renewal. As is described by Fincher and Iveson, urban renewal is an intended action plan for "redistribution" in hopes of arriving at a more "just diversity" in cities $(2008,51,23)$. Yet, as is commonly demonstrated, urban renewal has become associated with failures much more often than successes. "Redistribution is rarely possible without effective recognition and encounter (14)". Without a contextual understanding of the fluid meanings of a place and its residents (recognition), or the formation of a face to face mutual partnership / working relationship (encounter), outcomes of urban 
renewal are swept up in the flow of market actors that seek to maximize profits. This typically results in the displacement of the very residents that urban renewal projects are intended to benefit in the first place. Narrative processes like community performance can facilitate the discovery of both recognition as well as occasion encounter through responsive collaboration.

A narrative process such as community performance has the potential to "disentangle the different kinds of diversity which characterize city life" (3), and thus move the conversation to "cross group dialogue" that through multiple points of view are able to discover new identities, commonalities and uniqueness. As such narrative processes move beyond "fixed concepts of identity" that typically lead to combative postures. Community performance gathers inclusive and mundane stories that take place in the subject space, which enhances the prospects for re-narration and new discovery amongst a "range of groups" (99), rather than become bogged down by the competing rationalizations that seek to advance an agenda.

Due to the time restraints of urban planning, methods of inviting this meaningful dialogue that a narrative process like community performance affords may need to incorporate consultants in a pre-planning table narrative production. The prior production of stories by competent consultants that are 
trained in community storytelling concepts can initiate the planning table in a narrative trajectory from the outset, while not imposing burdensome delays on the planning process. Leonie Sandercock has begun to activate a pre-planning dialogue process through the filming of stakeholders that are involved in collaborative storytelling. Setting the planning table with a pre-produced narrative(s) makes what Fincher and Iveson describe as the three logics of planning a just diversity in the city - recognition, encounter (collaboration), and thus redistribution, more achievable, which has implications for moving planning into a more transformational trajectory. As such, narrative processes like community performance and documentary film may become less of an intervention, and more of a reframing of an occasion for reframing planning processes as communicative action. Pre-empting the starting point and thereby disrupting the normal flow of planning as mediating conflicted agendas with a narrative presentation or even performance has the potential to set the trajectory for what follows to enlist the meaningful dialogue of communicative agents that build on the storytelling discoveries, which can further enhance recognition and encounter. 
Finding 4: Community Identity, Brand and Development - The success of Swamp Gravy to attract outside audiences occasioned the renovation of the downtown city square, birthed a unique brand of cultural tourism and enhanced community recognition.

What community performance brought to Colquitt through Swamp Gravy was a process of discovery of self and others, which manifested some partnerships that are hard to imagine having ever taken place otherwise. The volunteer fire department and CMAC was one such odd partnership. Another odd partnership was Geer, Jinks and Kimbrel. Without Jinks, Geer's prospects of hearing about Colquitt, much less getting traction with anyone from the town about a community performance would be difficult to imagine. Her framing of the event as a celebration of heritage, while subversive in respects to the inclusivity of the storytelling process, was none-the-less critical to getting the early buy-in that was necessary to pull in the necessary volunteers. And, without Kimbrel's business savvy, grant-writing and music abilities, it is difficult to see how the rise of Swamp Gravy could have achieved the level of success that it did. Jink's access to the Jinks foundation was another critical link to establishing downtown revitalization, which enhanced the momentum and recognition. This trio was able to launch the revitalization of a community through hundreds of volunteers, thousands of volunteer hours, and millions of dollars from both 
inside and outside of Colquitt. While there were others that played critical roles as well, this trio played the key roles in the story of Swamp Gravy.

While the downtown area has been significantly renovated, the revitalization of the community took place inside Cotton Hall as the public commons. Renovation of the downtown square was less a result of community experiences inside Cotton Hall spilling out onto the square, and more of a strategy to attract, serve and accommodate tourists. The Murals were another strategy to attract tour buses to come and visit Colquitt. Many of the circle of services also go hand in hand with the strategy of further attracting, serving, and/or accommodating outside visitors. The external focus of these attractional strategies reached their peak at the intersection of three developments: Colquitt's submission to host the 2010 International Mural Conference; the economic impact study by The Center for Creative Community Development, 2007 Williams College; and the building of the sound stage - all taking place between 2005/2007. “The arts as an economic engine” (Jinks/Kimbrel) became the new mantra for CMAC during this time. Many in the business community spoke of the primary value of Swamp Gravy as having led to outside recognition and the presence of tour buses, which had fueled optimism that Colquitt's future was primarily going to be as an emerging entertainment industry destination. This 
dichotomy between what happens on the downtown square is most observable when contrasting the life on the square on performance days during Swamp Gravy related events to the absence of a significant local presence on the square especially on weekends when Swamp Gravy performances are not in season. While the downtown square may be renovated, and periodically bustling with outsiders, it has yet to demonstrate that it has become revitalized through a resurgence of local importance.

Geer's conviction was that Colquitt had what it needed within reach to build a community of actors - which were the experiences inside the community's stories. Jinks and Kimbrel thought that they had something that the rest of the world needed. And they set about to do everything within their power to attract outside recognition and potential economic interests. There was a tension between these intentions - a process for the formation of a community of actors on the community performance side, contrasting the intent to make Swamp Gravy an arts attraction that drew in tourist. This tension existed from the beginning. The celebration of heritage conjures up nostalgic images that are the primary appeal in many cultural tourism venues in the South and beyond. The inclusion of multiple, even conflicting points of view however, combined with those things told that might otherwise remain hidden or repressed, juxtaposes 
Swamp Gravy on a different plane of community experience from what nostalgic tourism typically trades on. For those most enthusiastic about Swamp Gravy as a process, it was the sense or experience of community that was most important and informing of its emerging identity as a town that valued diversity. For those in the business community that were more focused on what Swamp Gravy had afforded - recognition, tourists and tourism dollars, Swamp Gravy had become the town's brand of entertainment.

As far as entertainment goes, Swamp Gravy is not on par on an individual basis with the talent level of professional entertainment. Geer asserts that the two are just not the same thing. What attracted people to Swamp Gravy from afar was its uniqueness - a mix of local stories in a ritual celebration that becomes a feast of community meaningfulness. Regardless of where someone is from, they can usually find something to relate to Swamp Gravy in some meaningful way. The internal focus of Geer on staging inclusive storytelling matched the external focus of Jinks and Kimbrel, who believed that what Geer was exposing was special. Many attendees from outside of Colquitt who were familiar with professional theater report that what they witnessed in Swamp Gravy was more powerful than their previous experiences with professional theatre. 
Jinks and Kimbrel have been instrumental in establishing Swamp Gravy as the brand for their city, which has extended at times across the nation and beyond. But, what is behind the brand is a communicative process for catalyzing community itself that in turn activates community actors, and brings to life a heritage that potentially everyone can celebrate. As such, it is important to see how valuable each of these individuals were to keeping the Swamp Gravy community performance project moving forward. Odd partnerships seem to work that way, where one individual's emphasis counter-balances with others in such a way that produces an end that was otherwise unimaginable.

Tully, the chief of the volunteer fire department learned this lesson when he joined together with very diverse others in a partnership that on the surface didn't seem to make any sense. Swamp Gravy had taught him this lesson, and he had acted on it by partnering with CMAC. In fact, the benefits of forming odd or diverse partnerships became a new type of guiding common sense Gramscii) for Tully. He had become aware that the way he had previously thought things worked might be wrong. He had learned that in diversity there could be hidden benefits that you might not be able to see on the surface, but if you anticipate them, and act on that anticipation, then you might find yourself better off in the long run in ways that you could never have imagined. Swamp Gravy as a 
dynamic way of coproducing cultural heritage tended to expose that the common sense that comes from clans is controlling rather than generative. Once he became aware that he had a choice, Tully decided to go with the common sense that he had learned from Swamp Gravy - an emerging, living, breathing cultural heritage that celebrated and valued multiple points of view, diversity, as well as "change (Tully interview)." His choice for him demonstrated that the common good of a community is found in the experiences of community with diverse others.

With the departure of Geer in 2010, we are left with a question: Will a desired end such as building the individual self confidence of youth begin to design and determine the performances, or will Swamp Gravy live on as an inclusive storytelling process whose primary benefit is the fresh discovery and understanding of self and other that forms a community of just diversity? Promoting individual self confidence stands in counter-distinction to entering into a process that teaches a person that they could be wrong about not just others, but themselves as well. In 1865 a feast beyond the imagination was held for several hundred people that was made possible by an abundance of local and diverse foods - all grown without the benefit of machines or modern chemistry. That evening drew to a close with a speech by the host that encouraged the men 
in the crowd to move beyond pursuits of the "self" towards marriage and a commitment to being in a family (Davis 1980, 59). In 1992, a different kind of feast started up in Swamp Gravy - one that for some was also a departure from the ways of self interest into the ways of being in a community - a quality of I/thou that brings people out of the static confines of a clan. Perhaps there are lessons to be interpreted, discussed, and played forward from both feasts.

Potential further research: Further research could be undertaken to study the viability of planners facilitating the planning table as a stage for stakeholders to self-mediate a collaborative storytelling experience. Questions that this might pose for research are:

1. How might the framing of the planning table as a learning community, enlist stakeholders to open out and step up into more responsive and collaborative roles for determining what is good in a given planning matter?

2. What instruction on the front end of a planning situation best sets the stage for this attempt at a facilitating a more generative storytelling dialogue between stakeholders?

3. Could the problem of the rationalizations of economic actors that sometimes dominate planning outcomes be solved by starting the planning process by listening to, telling and responding to a community 
performance of stories? Might this starting point establish a narrative depth of "recognition" and "encounter" that can lead to the construction a collaborative plan that seeks a "just diversity" in the city? (Fincher, Iveson 2008) 


\section{References}

American Profile. 2000. Swamp Gravy: The Play That Renewed a Town. http://www.americanprofile.com/articles/swamp-gravy-play/

Altshuler, Alan. 1965. The City Planning Process. Cornell University Press.

Ary, Ted. 1996. "Swamp Gravy Performs for Full House in Washington D.C." The Miller County Liberal. November 26: 1.

Bacon, Stephen. 1983. The Creative Use of Metaphor in Outward Bound. Denver, CO:Colorado Outward Bound School.

Bales, Susan Nall. 2007. Reframing Community Messages through Myths and Metaphors. Center for Communications and Community: UCLA. http://www.c3.ucla.edu/toolbox/terms-concepts/strategic-frameanalysis/reframing-community-messages-through-myths-and-metaphors

Beauregard, Robert A. 2003. "Democracy, Storytelling, and the Sustainable City." In Story Sustainability: Planning, Practice, and Possibility for American Cities, edited by Barbara J. Eckstein, James A. Throgmorton, 65-77. Cambridge, MA: MIT Press.

Bell, Derrick. 1992. Faces at the Bottom of the Well. New York: Basic Books.

Bell, Derrick. 1992. And We Are Not Saved. New York: Basic Books.

Bender, Thomas. 1978. Community and Social Change in America. Baltimore, MD: The Johns Hopkins University Press.

Bollens, Scott A. 2002. “Urban Planning And Inter-Group Conflict: Confronting A Fractured Public Interest." Journal of the American Planning Association 68(Winter): 22-42.

Borrup, Tom. 2003. Urban Alchemy: In Search of a Formula for the City of Tomorrow,http://wayback.archiveit.org/2077/20100903220200/http://www.communityarts.net/readingroom/ archivefiles/2003/12/urban_alchemy_a.php 
Brehm, Joan M., Eisenhauer, Brian, and Richard S. Krannich. 2004.

"Dimensions of Community Attachment and Their Relationship to Well-Being in the Amenity-Rich West." Rural Sociology 69:405-429.

Burnham, Linda Frye. 2003. "A More Perfect Union."

http://wayback.archive-

it.org/2077/20100906202354/http://www.communityarts.net/readingroom/ archive files/2003/02/a_more_perfect.php

Burnham, Linda Frye. 1994. "Swappin Lies in Miller County." Art Paper: Community Arts. (September/October): 38-41.

Butterwick, Shauna and Selman, Jan. 2003. “Deep Listening in a Feminist Popular Theatre Project: Upsetting the Position of Audience in Participatory Education." Adult Education Quarterly (November).

Cohen, Adir. 1983. The Educational Philosophy of Martin Buber. Rutherford, NJ: Farleigh Dickinson University Press.

Cotton Hall Times 2009, 16 (Spring): 11.

Colquitt-Miller Arts Council. 2008. Cotton Hall Times, 1.

Cordova, Teresa. 1994. Refusing to Appropriate: The Emerging Discourse On Planning and Race. Journal of the American Planning Association 60 (Spring).

Davis, Nellie. 1980. The History of Miller County, Georgia. Colquitt, GA: Citizen's Bank

Denzin, Norman.K. and Yvonna S. Lincoln. 2003. "The Seventh Moment: Out of the Past, edited by Denzin, Norman.K. and Yvonna S. Lincoln, 611-640. In The Landscape of Qualitative Research: Theories and Issues. London: Sage Publications.

Carson, Jo. 2008. "Presentation: Oral Histories and Swamp Gravy." Building Creative Communities Conference. Colquitt, GA. 
Davidoff, Paul. 1965. "Advocacy and Pluralism in Planning." Journal of the American Institute of Planners.

Eckstein, Barbara and Throgmorton, James. 2003b. Story and Sustainability. Making Space: Stories in the Practice of Planning, 11-36. Cambridge, MA: MIT Press.

Elkins, James R. 1985. “On the Emergence of Narrative Jurisprudence: The Humanistic Perspective Finds a New Path." Legal Studies Forum, 9:123-155.

Fincher, Ruth and Iveson, Kurt. 2008. Planning and Diversity in the City. NY: Palgrave Macmillan.

Flyvbjerg, Bent. 2004. "Misrepresentation Drives Projects." Engineering NewsRecord, 252 (January): 87.

Flyvbjerg, Bent. 1998. Rationality \& Power: Democracy in Practice. Chicago: University of Chicago Press.

Forester, John. 2001. The Deliberative Practitioner. Cambridge, MA: MIT Press.

Forester, John. 1999. "Reflections on the Future Understanding of Planning Practice." International Planning Studies, 24(June): 175-194.

Frank, Arthur W. 2002. "Why Study People's Stories? The Dialogical Ethics of Narrative Analysis." International Journal of Qualitative Methods, 1(Winter):1-20.

Geer, Richard. 2011. Unpublished Manuscript: Story-Bridge.

Geer, Richard. 1993. "Of the People, By the People and For the People: The Field of Community Performance." High Performance, (Winter):28-35.

Griffin, Emily. 1994. A First Look At Communication Theory. New York: McGraw-Hill.

Grow, Nancy. 1994. Cotton Hall Times. Issue 3 (May). 
Harris, Britton. 1967. "The Limits of Science and Humanism in Planning." Journal of the American Institute of Planners. (33):324-335.

Healy, Patsy. 1992. "A Planners Day." Journal of the American Planning Association.58(Winter): 9-21.

Innes, Judith. 1999. "Consensus Building and Complex Adaptive Systems: A Framework for Evaluating Collaborative Planning. Journal of the American Planning Association, 65(Autumn):412-424.

Jones, Debra. 1994. Swamp Gravy: Folk Tales From Southern Georgia. Colquitt, GA:Sobek Press.

Kimbrel, Karen. 2007. Colquitt-Miller County, Georgia: Benchmarks of Progress 1976-2006. The Ruth T. Jinks Foundation.

Kimbrel, Karen Smith. 1994. That's All That Matters (song lyrics).

Kimbrel, Karen Smith. 1993. The Story Song (song lyrics).

Kravitz, Alan. 1970. "Planners as the Handmaidens of Politics." Planning and Politics:Uneasy Relationship. ed. Thad L. Beyle and George T. Lathrop. Odessey Press.

Lane, Brett. and Dorfman, Diane. 1997. Strengthening Community Networks: The Basis for Sustainable Community Renewal. (Program Report). Northwest Regional Educational Laboratory: Office of Educational Research and Improvement. Washington, D.C.

Levinson, Natasha. 1997. "Teaching in the Midst of Belatedness: The Paradox of Natality in Hannah Arendt's Educational Thought." Educational Theory, 47:435-451.

Maines, David R. 1993. “Narrative's Moment and Sociology's Phenomena Toward a Narrative Sociology". Sociological Quarterly, 34:17-37. 
Mandelbaum, Seymour. 2003. "Narrative and other Tools". Story Sustainability: Planning, Practice, and Possibility for American Cities, edited by Barbara J. Eckstein, James A. Throgmorton, 185-192. Cambridge. MA: MIT Press.

Mankowski, Eric. and Rappaport, Julian. 1995. "Stories, Identity, and the Psychological Sense of Community." Knowledge and Memory: The Real Story (Advances in Social Cognition, No. 8), edited by R.S. Wyer Jr., Hillsdale, NJ:Lawrence Erlbaum Associates.

Margerum, Richard. 2002. “Evaluating Collaborative Planning: Implications from an Empirical Analysis of Growth Management. Journal of the American Planning Association, 68 (Spring):179-193.

Monk, Gerald. and Winslade, John. 2000. Narrative Mediation: A New Approach to Conflict Resolution. Jossey-Bass: San Francisco.

Mooney, Patrick. 2004. “Democratizing Rural Economy: Institutional Friction, Sustainable Struggle and the Cooperative Movement. Rural Sociology, 69 March):76.

McFadyen, Alistair. 1990. The Call to Personhood: A Christian Theory of the Individual in Social Relations. Cambridge, England:Cambridge University Press.

Murdoch, Iris. 2001 The Sovereignty of Good. London: Routledge Classics.

Nietzsche, Frederick. 1968. Twilight of the Idols. (R. J. Hollingdale, Trans). Middlesex, England:Penguin

Nussbaum, Martha. 2001. Upheavals of Thought: The Intelligence of Emotions. Cambridge UK: Cambridge University Press

Osinski, Bill. 1999. "Swamp Gravy: Telling Their Own Story." The Atlanta Constitution. October 3. E1.

Parry, Alan. 1994. Story Re-Visions: Narrative Therapy in the Postmodern World. New York:Guilford. 
Percy, Walker. 1991. Signposts in a Strange Land. New York: Farrar, Straus and Giroux.

Polkinghorne, Donald. 1988. Narrative Knowing and the Human Sciences. Albany, NY:SUNY Press.

Rossing, Boyd. and Glowacki-Dudka, Michelle. 2001. “Inclusive Community in a Diverse World: Pursuing an Elusive Goal Through Narrative-based Dialogue." Journal of Community Psychology, 29(6):729-743.

Sandercock, Leonie. 2011. "Finding our Way: Film as Planning Intervention." William Gray Endowed Forum. http://pdx.edu/usp/william-gray-endowed -forum

Sandercock, Leonie. 2003a. Cosmopolis II: Mongrel Cities in the 21 $1^{\text {st }}$ Century. London,England:Continuum.

2003b. "Out of the Closet: The Importance of Stories and Storytelling in Planning Practice." Planning Theory, 4(1):11-28.

Sandercock, Leonie. 2000. “When Strangers Become Neighbors: Managing Cities of Difference." Planning Theory and Practice, 1(1):13-30.

Sennett, Richard. 1977. The Fall of Public Man, 255. New York: Knopf.

Sizemore, Carol. 1999. "News From CMAC." Colquitt Miller County Arts Council Newsletter. (November 25):6.

Sojourn Theater and visionPDX. "One Day". November 8, 2006. http://www.sojourntheatre.org/history_2006.asp

Sojourn Theatre. "Good". June 13, 2007. http://www.sojourntheatre.org/history_2007.asp

Sonn, Christopher., Bishop, Brian and Drew, Neil. 1999. "Sense of Community: Issues and Considerations." Community, Work \& Family, 2(2):205-218. 
Southern Growth Policies Board. 2003. Charting Southern Prosperity with Innovative Ideas and Collaborative Actions.

http://www.southerngrowth.com/pubs/pubs_pdfs/rfs2003.pdf

Southwest Georgia Regional Development Center.

http://www.dca.state.ga.us/development/planningqualitygrowth/ programs/downloads/plans/MillerAssessment.PDF

Staff. 1994a. "Swamp Gravy Garners Olympiad Award." South Georgia Business Journal. (March/April): 15.

1994b. "Historic Tarrer Hotel in Colquitt/Miller County to Open to Guests in Mid-summer 1994." South Georgia Business Journal. (April/March): 15.

Taylor, Nigel. 1998. Urban Planning Theory since 1945. London:Sage Publishers.

The Center for Creative Community Development. 2007. “Estimated Economic Impact of Swamp Gravy." Williamstown, Mass: Williams College.

Throgmorton, James. 2003a. "Planning as Persuasive Storytelling in a GlobalScale Web of Relationships." Planning Theory, 2(2):125-151.

and Eckstein, Barbara. 2003b. "Imagining Sustainable Places." Story Sustainability:Planning, Practice, and Possibility for American Cities, edited by Barbara J. Eckstein,James A. Throgmorton, 37-61. Cambridge. MA: MIT Press.

Toole, Terry. 2009. “Colquitt, Georgia's First Mural City, passes senate.” Miller County Liberal.( March 8): 1.

Toole, Terry. 2005. "Official Ground Breaking Ceremony Set for Sound Stage." Miller County Liberal. (Feburary 2): 1.

Toole, Terry. 2005. "Hee Haw Comes to Cotton Hall." Miller County Liberal. (July 13):1. 
Toole, Terry. 2005. “Colquitt named Georgia's ninth entrepreneurial friendly city." Miller County Liberal. (July 20): 1.

Toole, Terry. 1997. “A Bit of History Will Come Down Soon.” Miller County Liberal. (March 13): 10.

Toole, Terry. 1994. "Swamp Gravy Named Georgia's Official Folk Life Play." Miller County Liberal. (March 1): 1.

United States Census Bureau. 2010 Census Interactive Population Search. http://2010.census.gov/2010census/popmap/ipmtext.php?fl=13

United States Census Bureau. Census of Population and Housing. http://www.census.gov/prod/www/abs/decennial/

Urban Institute. 2003. "Arts Participation: Steps to Stronger Cultural and Community Life." The Wallace Foundation: Community Partnerships for Cultural Participation Initiative, 7(403):20.

USA Today. 1996. "Kennedy Center Partners with NAPE to Present Swamp Gravy." November 1: D1.

Vargas, Joe. 2011. Unpublished Manuscript: The Story Bridge.

Weber, Max. 1958. From Max Weber: Essays in Sociology, edited by H.H. Gerth and C. Wright Mills. New York: Oxford University Press.

Weinstein, Joshua. 1975. Buber and Humanistic Education. New York: Philosophical Library, Inc. 